\title{
Thin-Film and Marginal Lubrication of PolyEtherKetone-Steel Sliding Contacts at High Temperature and High Speed
}

\author{
Christopher J Dyson ${ }^{1 *}$, Martin Priest ${ }^{2}$, Malcolm F Fox ${ }^{2,3}$ and William A Hopkins ${ }^{1}$, \\ ${ }^{1}$ ROCOL Lubricants, Leeds, UK, ${ }^{2}$ School of Engineering, Faculty of Engineering and Informatics, University of \\ Bradford, UK. ${ }^{3}$ Nylacast Ltd Leicester, UK *chris.dyson@rocol.com
}

\begin{abstract}
PolyEtherKetone (PEK) is a suitable material for tribological systems which specifically require the properties of high chemical resistance, low component weight, seizure resistance under starved lubrication conditions and operation at higher temperatures than many other engineering polymers can survive. PEK is used with a liquid lubricant at high temperatures and velocities to reduce friction and also to control unstable friction and wear, particularly in the region of the material's glass transition temperature, $\mathrm{T}_{\mathrm{g}}$.

Intermittent and marginal lubrication using representative high temperature synthetic lubricants was applied to high speed, high temperature PEK/steel sliding contacts to determine the effectiveness of lubrication under these conditions. Variations in the stability of the thin lubricant films were observed, particularly under different load conditions. Under low load conditions, the lubricant polarity and the related ability to form a film in the contact was important. Under high load conditions, the thermal stability of the lubricant became more important in retaining stability in the friction and wear mechanisms. Whilst not ideal practice, marginal lubrication of PEK-steel sliding contacts can be achieved by selection of an appropriate lubricant, even in the glass transition region of PEK.
\end{abstract}




\section{Introduction}

\subsection{The PAEK Family of Polymers}

PolyEtherKetone (PEK) is a semi-crystalline member of the PolyArylEtherKetone (PAEK) thermopolymer family, synthesised by polymerising phenolic and benzaldehyde aromatic molecules. Different input proportions of the monomers give a range of materials whose structural units consist of aromatic rings connected by ether and ketone linkages in varying proportions, Figure 1. The PAEK polymer 'family' is relatively unique in that their basic structural units can be varied by fundamental molecular design of each repeat unit, reflected in their respective physical properties, Table 1.

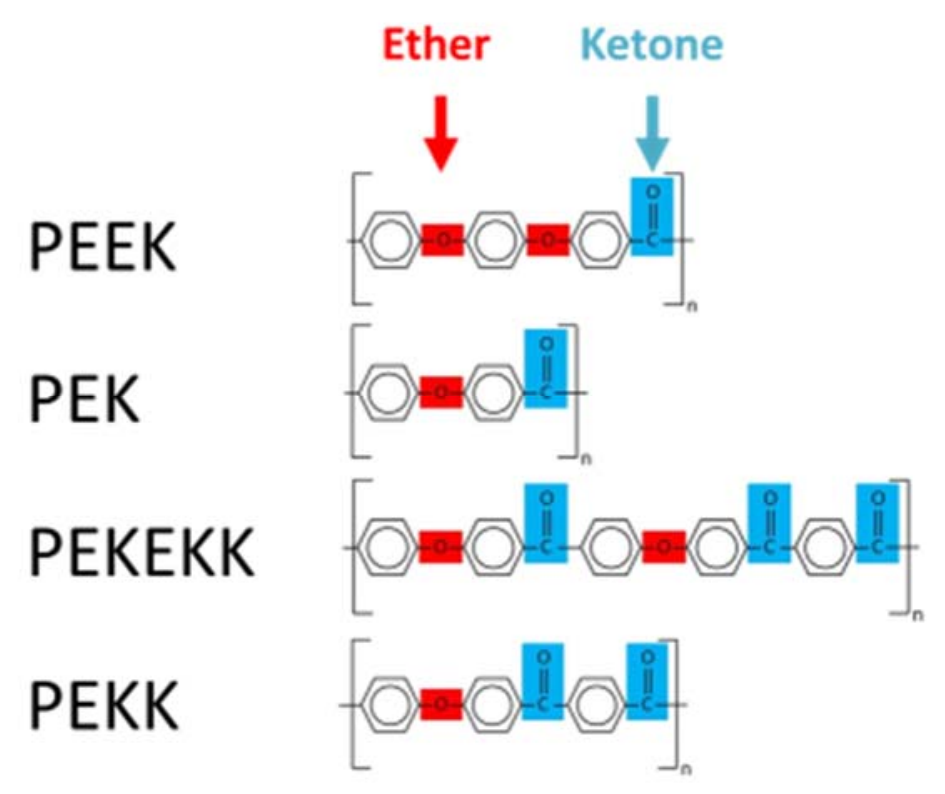

Figure 1: Fundamental Units for the PolyArylEtherKetone (PAEK) Family

The PAEK polymer family have relatively high strengths, high dimensional stabilities and a high level of chemical resistance. They can be used continuously at temperatures up to $230^{\circ} \mathrm{C}$ [1], compared to other thermopolymers such as nylon which is limited to $110^{\circ} \mathrm{C}$ for continuous use. Because of these properties, together with their potential weight saving over metals, PAEKs are increasingly used in an increasing variety of engineering systems. PEEK is the most commonly used member of the PAEK family; PEK, because of its higher ratio of ether to ketone linkages, is often used at higher temperatures than PEEK due to its higher glass transition temperature, $T_{g}$, and higher melting point $T_{m}$, Table 1 . 
Table 1: Glass Transition and Melting Point for Various PAEK Polymers, where $T_{m}$ is the Melting Point and $T_{g}$ is the Glass Transition Temperature of each Polymer

\begin{tabular}{|c|c|c|c|}
\hline PAEK & Ether/Ketone Ratio & $\mathbf{T}_{\mathrm{g}}\left({ }^{\circ} \mathrm{C}\right)$ & $\mathbf{T}_{\mathrm{m}}\left({ }^{\circ} \mathrm{C}\right)$ \\
\hline PEEK [1] & 2 & 143 & 343 \\
\hline PEK [1] & 1 & 157 & 374 \\
\hline PEKEKK [1] & 0.67 & 162 & 387 \\
\hline PEKK [2] & 0.5 & 165 & 357 \\
\hline
\end{tabular}

A fundamental property of thermopolymers is the 'glass transition' of their amorphous regions. Thermopolymer glass transitions can take place over a range of up to $50^{\circ} \mathrm{C}$, the midpoint of which is termed 'the glass transition temperature, $\mathrm{Tg}_{\mathrm{g}}$. The polymer is harder and more brittle below the glass transition; above it, the amorphous regions soften and the polymer's physical properties become more rubbery and viscoelastic, manifested as a change in many mechanical properties, such as the:

- Storage modulus (elastic modulus under shear as measured in e.g. Dynamic Mechanical Analysis, DMA) [3, 4],

- Young's modulus (elastic modulus under extension) [5],

- Yield stress [1], and,

- Thermal expansion coefficient [1].

Whilst the transition in the properties described is gradual, a more precise measure is given by the polymer's viscoelastic response where $\mathrm{T}_{\mathrm{g}}$ is marked by a clear peak in the Mechanical Loss Factor, $\tan \delta$, [3, 4]. For PEK, $\mathrm{T}_{\mathrm{g}}$ is $157^{\circ} \mathrm{C}, \mathrm{T}_{\mathrm{m}}$ is $374^{\circ} \mathrm{C}$, Table 1 , [1].

\subsection{The Tribology of Fibre Reinforced and Additivised PAEK Polymers}

In many tribological systems, PAEK polymers are reinforced with either carbon or glass fibres $[6,7]$. Reinforcement significantly reduces friction and wear in dry sliding; Glaesser found that $30 \%$ wt fill of carbon fibres is optimal [8]. Carbon fibres have a greater effect on reducing friction [9] and wear [9-11] than glass fibres under some conditions. Many tribological systems using PAEKs are not liquid lubricated but rely on low shear strength layers of polymer being transferred on to the counterface: This mechanism effectively reduces to a polymer-polymer 
contact of extremely low friction coefficient $[6,12]$. To enhance this effect, solid lubricants such as graphite [10,13-18], $\mathrm{MoS}_{2}[17,19]$, PTFE $[10,13-15,17,18,20-23]$ or a combination of these $[10,13,18]$ were included in the polymer matrix. Some systems, however, are lubricated by liquids [24-26]; for these systems, solid lubricant additives in the polymer are rare.

Tribological systems using PAEKs are usually low speed, $0.1-1 \mathrm{~ms}^{-1}$, with low contact pressures, 0.25-2 MPa [1, 27]. However, some systems such as for thin polymer film production use PAEKs under much more demanding tribological conditions at high sliding speeds, up to $10 \mathrm{~ms}^{-1}$, and high temperatures, up to $170^{\circ} \mathrm{C}$; liquid lubricants are often required under these more demanding conditions.

Previous work found that PAEK's used in sliding interfaces have very different behaviour above and below their $T_{g}$, Table 2 and [28]. The effect on friction and wear depends on the contact geometry, reinforcement of the polymer and solid lubricant additives. In all reported cases wear rates were significantly higher above $\mathrm{T}_{\mathrm{g}, \text {; }}$ in most cases, friction coefficients were lower above $\mathrm{T}_{\mathrm{g}}$. Below $\mathrm{T}_{\mathrm{g}}$, friction and wear were defined by mild abrasive wear. Above $\mathrm{T}_{\mathrm{g}}$, increased surface melting, plastic flow and adhesion was observed, attributed to softening of the amorphous regions in the PAEK. Briscoe [5] used an indenter sliding on a surface to show that the interfacial shear strength decreases above $\mathrm{T}_{\mathrm{g}}$, explaining the reduced friction coefficients under most conditions. Increased friction coefficients were observed above $\mathrm{T}_{\mathrm{g}}$ with unreinforced PEEK, [29-31], attributed to the non-conformal ball-on-disc geometry used and, due to the reduced yield stress above $\mathrm{T}_{\mathrm{g}}[1]$, 'ploughing' occurred where plastic flow dominated friction, causing increased energy dissipation. The same PEEK reinforced with carbon fibres gave the opposite trend because the reinforcement reduced plastic deformation and prevented a resultant large increase in contact area [30]. 
Table 2: Previous Friction and Wear Studies of PEEK around $T_{g}$

\begin{tabular}{|c|c|c|c|c|c|}
\hline \multirow{2}{*}{ Reinforcement } & \multirow{2}{*}{ Material } & \multirow{2}{*}{$\begin{array}{l}\text { Contact Ge- } \\
\text { ometry }\end{array}$} & \multicolumn{2}{|c|}{$\begin{array}{c}\text { Performance Above } T_{g} \\
\text { versus Below }\end{array}$} & \multirow{2}{*}{ Source } \\
\hline & & & $\begin{array}{c}\text { Friction } \\
\text { Coefficient }\end{array}$ & Wear Rate & \\
\hline Carbon Fibres & $\begin{array}{l}\text { PEEK and PEK with } \\
\text { PTFE, Graphite }\end{array}$ & $\begin{array}{l}\text { PAEK Block } \\
\text { on Steel Disc }\end{array}$ & Lower & Higher & Friedrich et al [10] \\
\hline Carbon Fibres & PEEK & $\begin{array}{l}\text { Steel Ball on } \\
\text { PEEK Disc }\end{array}$ & Lower & Higher & Hanchi and Eiss [30] \\
\hline Unreinforced & $\begin{array}{c}\text { PEEK with PTFE and } \\
\text { Graphite }\end{array}$ & $\begin{array}{l}\text { PEEK Block } \\
\text { on Steel Disc }\end{array}$ & Lower & Higher & Friedrich et al [10] \\
\hline Unreinforced & PEEK & $\begin{array}{l}\text { Steel Ball on } \\
\text { PEEK, PEEK } \\
\text { coated Disc }\end{array}$ & Higher & Higher & $\begin{array}{c}\text { Hanchi and Eiss [29] [30], } \\
\text { Zhang et al [31] }\end{array}$ \\
\hline
\end{tabular}

In unlubricated contacts, adhesion of PAEK wear particles to (typically) steel counterfaces forms a PAEK transfer film [14, 32-34]. If this film is stable to shear and temperature, the tribological system effectively reduces to a PAEK-PAEK contact where a thin layer of molten or softened polymer provides the shear interface between the surfaces [6]. Such conditions produce low friction coefficients and low net wear rates [35]. High contact temperatures, especially under high loads, cause instability when significant parts of the transfer film melt or soften: Relative motion occurs at the interface between the transfer film and the surface on which it has been formed [36]. Previously published work has shown that for a combination of high speed $\left(9 \mathrm{~ms}^{-1}\right)$, low contact pressure (0.5-1.0 MPa) and linear sliding PAEK-steel systems the instability is related to thermal transitions of the polymer, especially $T_{g}$, in the near-contact region of the PAEK [28]. An increased friction coefficient was observed through the glass transition of critical contact regions and above this region, where polymer softening, plastic deformation and, ultimately, abrasion by the steel counterface occurs.

\subsection{Lubricated PAEK/Steel Systems}

For the same system under the same conditions, a synthetic ester lubricant reduced the variation of friction coefficient with system temperature above, below and through the $\mathrm{T}_{\mathrm{g}}$ of the PAEK [28]. Use of the lubricant gave mixed lubrication with a friction coefficient greater than the dry contact below $\mathrm{T}_{\mathrm{g}}$, where the dry contact formed a stable transfer film, but lower than the friction coefficient above $\mathrm{Tg}$. To summarise, the benefits of the stable transfer film were lost when a suitable liquid lubricant was used because a transfer film could not be formed; however, the loss of potentially unstable sensitivity to temperature was a greater benefit. 
The latter effect is one of the reasons why a liquid lubricant is used in some industrial systems, especially at high sliding speeds operating around the $\mathrm{T}_{\mathrm{g}}$ region of the PAEK, to give more stable friction and wear when variations in system temperature occur [28]. However, it is noted that liquid lubricants do not always have a positive effect on PAEK-steel systems. Because a liquid lubricant entrains wear particles, they are typically removed from the contact area and, therefore, cannot form a transfer film $[25,35]$. Furthermore, a polar or a surface-active lubricant can form a physically or chemically adhered film on the non-polymer face which may prevent any wear particles adhering to the surface should they reach it. The lack of transfer film formation is not a problem when the liquid lubricant performs well as the film is not required $[24,28]$. However, several studies report that, when liquid lubricants operate under conditions that cannot support stable lubrication, catastrophically high wear rates can occur because a transfer film cannot be formed $[22,26]$. In some systems, PAEK-steel systems are used because they offer protection to full film contacts (liquid, air, magnetic) on start-up, shut down or sudden transient load, when surfaces contact [37]. In a metal-metal contact, adhesive wear may cause serious damage. Clearly though, this not intended as anything other than a temporary lubrication mechanism.

For industrial systems using PAEK-steel systems that operate around the PAEK glass transition, the intrinsic instability in dry sliding can be avoided with a liquid lubricant [28]. However, if the liquid lubricant film formation is marginal, unstable or at its performance limit, the behaviour of the system as a whole is not well understood. In some industrial systems, lubricant is applied periodically rather than continuously. In such systems, the lubricant stability is put under further strain as sudden, plentiful, lubricant drains away and diminishes over time into a thin, often marginal, film on the lubricated surfaces.

This study investigated the effects on friction and wear mechanisms of marginal lubrication of PEK-steel contacts under high speed, low load sliding at operating temperatures above, below and in the region of the $\mathrm{T}_{\mathrm{g}}$ of PEK. 


\section{Apparatus and Test Programme}

\subsection{The Test Apparatus}

PEK-steel sliding contacts were tested in a pin-on-disc tribometer designed to reproduce conditions representative of industrial high speed, high temperature PEK-steel systems, Figure 2. A $10 \mathrm{~mm}$ diameter, flat-faced PEK pin was loaded against a rotating steel disc by a hinged arm, Figure 3. The prescribed load was applied by weights hung from the arm. The PEK pins were machined and faced such that when carbon fibre reinforcement was used, the fibres at the running surface were randomly aligned in the surface plane. This negated the effect of pre-existing fibre and matrix alignment, known to have a significant effect on friction and wear [10]. The steel discs were AISI 4140 steel with a surface finish value, $\mathrm{R}_{\mathrm{A}}$, of $0.6 \mu \mathrm{m}$, typical of the initial finish of some industrial surfaces for lubricated PEK-steel contacts.

The pin-on-disc mechanism was surrounded by an insulated enclosure; the air within the enclosure was electrically heated and thermostatted to the set test temperature.

To replicate the intermittent lubrication systems used in industry, the tribological interface was not flooded but lubricant was applied using an external gravity-fed lubricator. A timeractivated solenoid valve regulated lubricant flow from the bottom of a reservoir through a PTFE tube onto the leading edge of the PEK pin. Because the lubricant feed tube ran through the heated enclosure and lubricant doses were small, the lubricant was considered to be applied at the enclosure temperature.

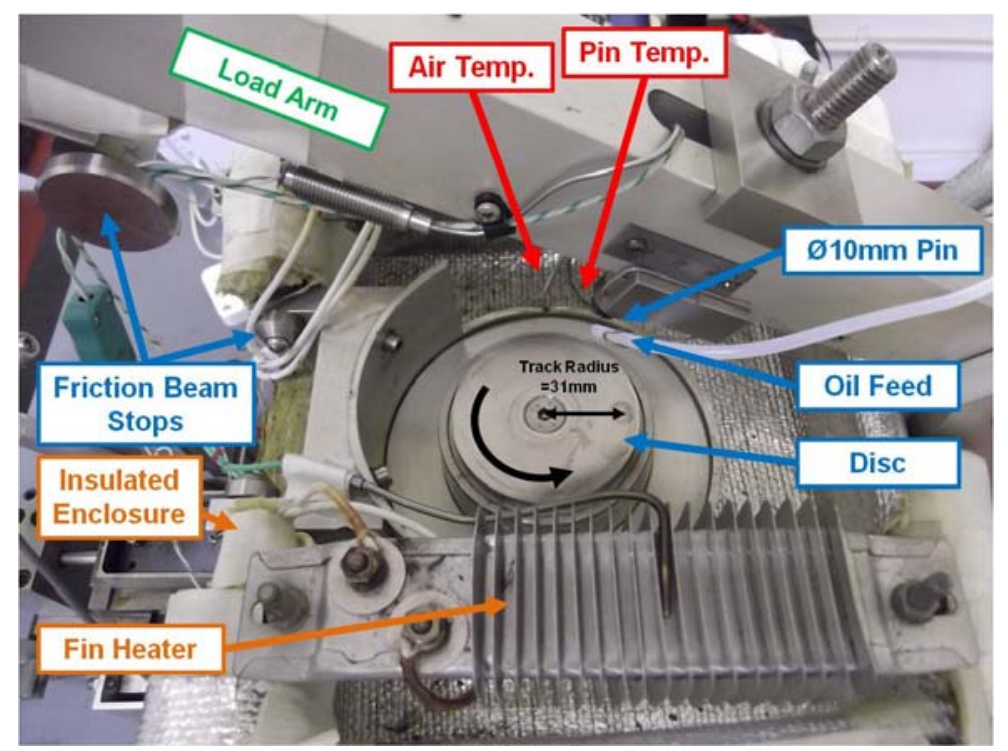

Figure 2: The Pin-on-Disc Tribometer 


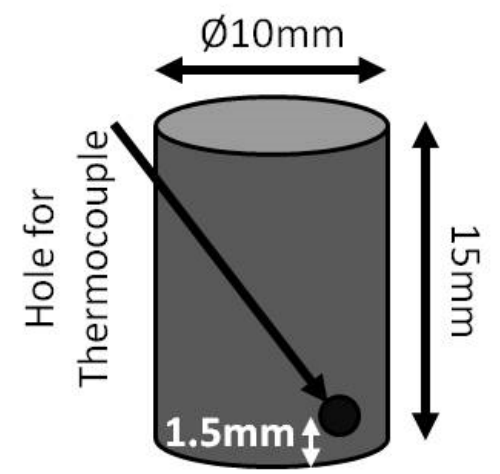

Figure 3: PEK Test Pin Geometry

\subsection{The Test Program}

A typical test procedure is shown in Figure 4 and contained the following steps:

1. Warm-Up - The heaters were turned on for the enclosure to begin heating. The disc was not rotated. Due to the highly stratified nature of air temperature in a heated enclosure, heating to the test temperature was not usually complete until part way through the test stages.

2. Run-In - Extensive testing with these materials indicated that mild running-in conditions were both necessary from a performance point of view and representative of good industry practice. The samples were run in for one hour at low contact pressure $(0.25 \mathrm{MPa})$, low average sliding speed $\left(3 \mathrm{~ms}^{-1}\right)$ and at the desired test temperature. $0.5 \mathrm{ml}$ of the test lubricant was applied at the start of running-in, except for unlubricated tests. Steady-state friction was reached after around $30 \mathrm{mins}$, which indicated that running-in was complete. The stratification of enclosure air temperature also meant that, under some conditions, the near contact pin temperature was lower than the measured ambient temperature.

3. Test - After the running-in procedure, a further $0.1 \mathrm{ml}$ dose of lubricant was applied to the pin, the test load was applied and the speed increased to the test value. The test phase lasted 3 hours and a $0.1 \mathrm{ml}$ dose of lubricant was applied at the start of each hour of the test. Typically, a steady-state friction was reached after the first hour at test conditions. Therefore, the second and third hours of the test phase were typically under steady conditions after the lubricant had been distributed around the system. After the lubricant was added, friction was substantially reduced initially and then stabilised after $\sim 5$ minutes. 


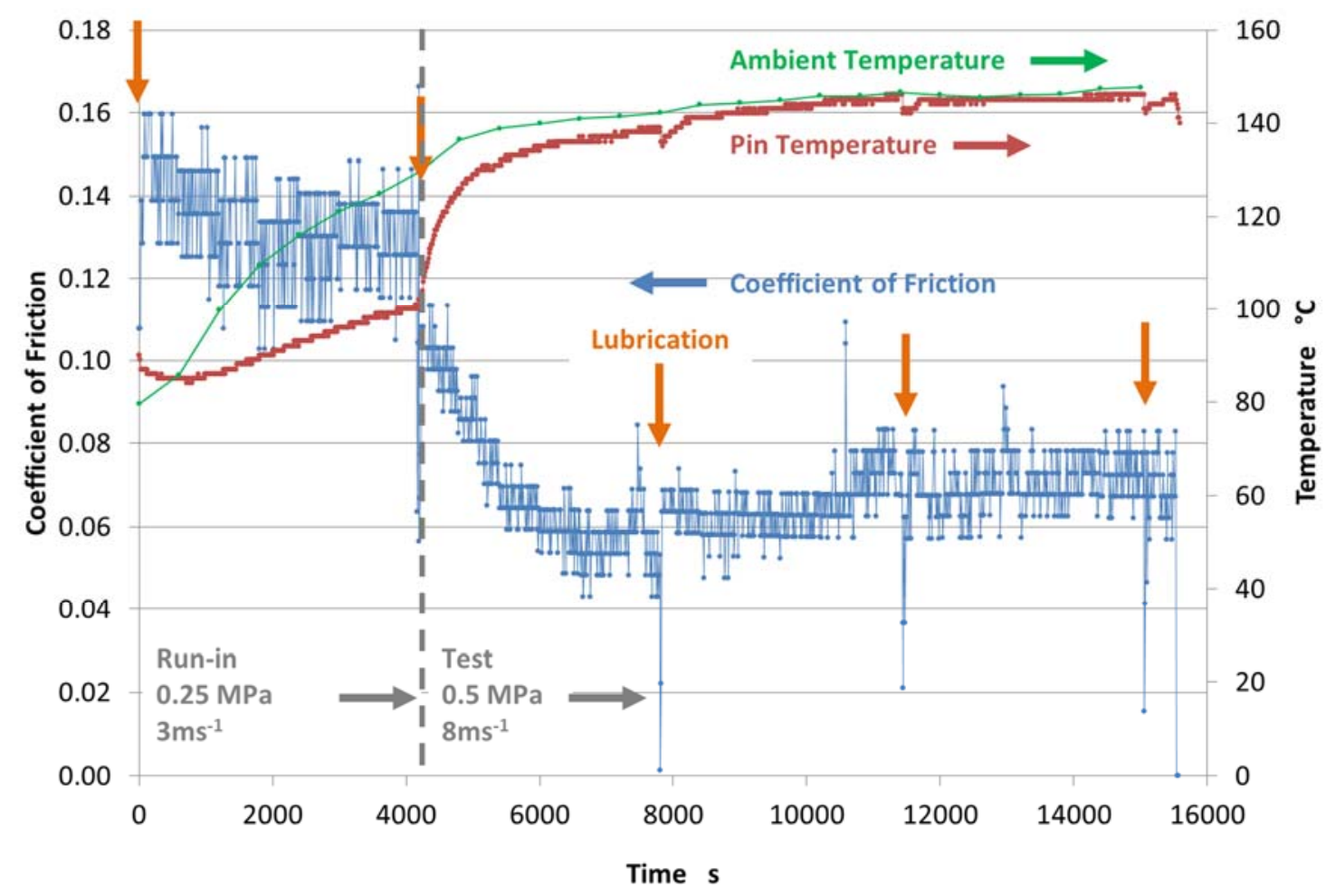

Figure 4: A Typical Test Cycle: Trimellitate Ester on Carbon Fibre-Reinforced PEK at $0.5 \mathrm{MPa}, 150^{\circ} \mathrm{C}$ and $8 \mathrm{~ms}^{-1}$

Values of the friction coefficient, the PEK pin near contact temperature and the enclosure air temperature were recorded throughout the test. The reported average friction coefficient value for each test is an average of 100 s within the steady state region at the end of the third hour of the test phase.

The PEK pin near-contact temperature was measured by a thermocouple placed in a hole drilled to the centre axis of the pin at an axial distance of $2.0 \mathrm{~mm}$ from the running surface of the pin, Figure 3, measuring pin temperatures behind the contact area. In previous work the near-contact temperature was found to have a significant effect on the material properties of PEK around its glass transition in an unlubricated system [28]. In lubricated contacts under steady state conditions for different loads, the near-contact temperature had a significant effect on the friction coefficient under what were understood to be mixed lubrication conditions.

Wear was not considered in detail because it was negligible under these lubricated conditions in such a short test and because wear rate behaviour is difficult to determine when tribological conditions vary significantly through the test. Wear is not a significant factor for industrial systems operating under these conditions. In these tests, the specific wear rates under stable conditions were in the order of $10^{-16-17} \mathrm{~m}^{3} / \mathrm{Nm}$. These are at low compared to other published 
studies on reinforced PAEKs: $10^{-14-16} \mathrm{~m}^{3} / \mathrm{Nm}$ [14], $10^{-15} \mathrm{~m}^{3} / \mathrm{Nm}$ [27, 38-40], albeit sometimes using different materials, contacts and conditions. However, when lubrication failed in these tests, the resulting wear was often catastrophic: Where failure occurred, specific wear rates were in the order of $10^{-15} \mathrm{~m}^{3} / \mathrm{Nm}$. This binary wear behaviour underlines the sensitivity of the system to lubrication but also shows how wear measurement was not a useful comparative parameter.

To replicate the typical conditions of industrial systems, the reference test conditions were an average sliding speed of $8 \mathrm{~ms}^{-1}$, contact pressure of $0.5 \mathrm{MPa}$ and $150^{\circ} \mathrm{C}$ enclosure temperature. The key tribological parameters were systematically varied from these values:

- To speeds of $6 \mathrm{~ms}^{-1}$ and $10 \mathrm{~ms}^{-1}$,

- To contact pressures of $0.25 \mathrm{MPa}, 1.0 \mathrm{MPa}$ and $1.5 \mathrm{MPa}$,

- To enclosure temperatures of $100^{\circ} \mathrm{C}$ and $125^{\circ} \mathrm{C}$.

Contact pressures were also varied for unreinforced PEK.

The PV values for these conditions range from $2-12 \times 10^{6} \mathrm{~Pa}-\mathrm{m} / \mathrm{s}$. Relevant published values for limiting PV are $\sim 7 \times 10^{6} \mathrm{~Pa}-\mathrm{m} / \mathrm{s}$ for both unfilled PEK and unfilled PEEK [14], 6x10

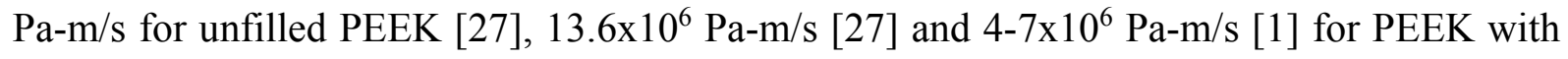
$30 \%$ wt carbon fibres. It is noted that these latter values [1] are reported for unlubricated conditions at $\mu=0.23-0.27$ : Greater limiting PV values for composites are achieved at lower values of $\mu$.

The experimental test matrix derived from the variations in PEK materials, lubricants, contact pressures, speeds and enclosure temperatures is shown in Table 3 . Tests were repeated and $95 \%$ confidence intervals calculated and shown on the plots; all error bars and statements on statistical significance are made with references to these values. 
Table 3: Test Matrix

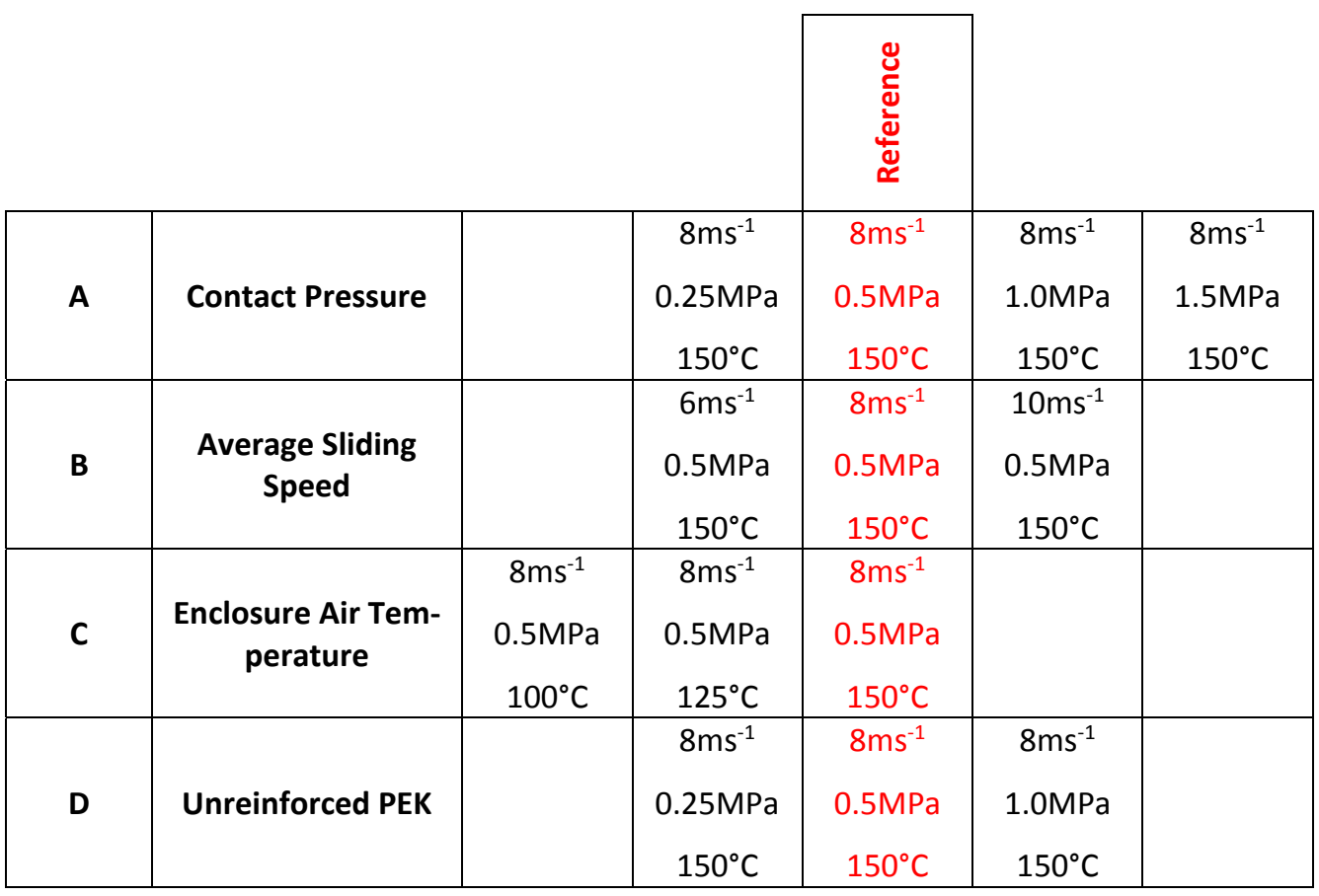

\subsection{Test Materials}

As typically used in industrial systems, the PEK used in this study was reinforced with $30 \% \mathrm{wt}$ carbon fibre whiskers, Table 4 , length $\sim 200 \mu \mathrm{m}$, diameter $\sim 15 \mu \mathrm{m}$, Figure 5 . In some tests, unreinforced PEK was used, Table 4.

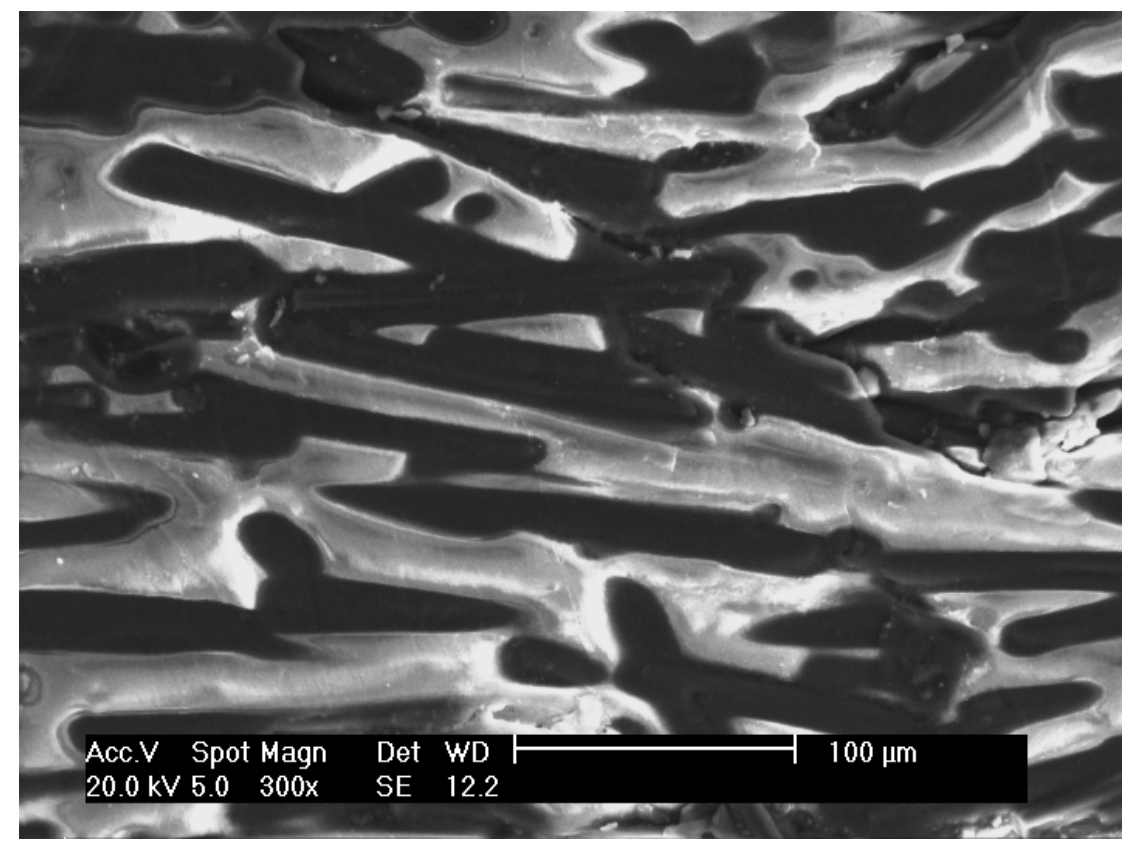

Figure 5: SEM Image of Fresh Surface of PEK + 30\%wt Carbon Fibres 
Table 4: Physical and Mechanical Properties of PEK Materials Studied [1]

\begin{tabular}{|c|c|c|}
\hline Property & PEK & $\begin{array}{c}\text { PEK + 30\%wt } \\
\text { Carbon Fibres }\end{array}$ \\
\hline Tensile Strength $@ 23^{\circ} \mathrm{C}, \mathrm{MPa}$ & 110 & 250 \\
\hline Tensile Strain at Break, $\%$ & $20 \%$ & $2.2 \%$ \\
\hline Tensile Modulus, $\mathrm{GPa}$ & 3.9 & 25 \\
\hline Thermal Expansion Coefficient, $<\mathrm{T}_{\mathrm{G}} \&>\mathrm{T}_{\mathrm{G}}\left(\mu \mathrm{m}^{\circ} \mathrm{C}^{-1}\right)$ & $45 / 75$ & $5 / 5$ \\
\hline Thermal Conductivity, $\mathrm{Wm}^{-1} \mathrm{~K}^{-1} @ 23^{\circ} \mathrm{C}$ & 0.29 & 0.95 \\
\hline
\end{tabular}

The two test lubricants were synthetic esters of differing chemistry, a trinonyl trimellitate ester and a pentaerythritol ester,

Table 5. They are typical of base oils used in many high temperature industrial systems and chosen to have similar viscosities at test temperatures. They were unformulated so that the effect of additive chemistry was not considered. The pentaerythritol ester was more thermally stable than the trinonyl trimellitate ester, measured using Differential Scanning Calorimetry, DSC, for the oxidation onset of a $5 \mathrm{mg}$ sample heated at $10^{\circ} \mathrm{C} / \mathrm{min}$. The molecular structures of these two esters are significantly different: the trinonyl trimellitate ester structure has an aromatic ring and three substituent ester groups; the pentaerithritol non-aromatic ester has four ester groups. For further reference, unlubricated tests were conducted at $8 \mathrm{~ms}^{-1}, 150^{\circ} \mathrm{C}$ and at contact pressures of $0.25,0.5,1.0$ and $1.5 \mathrm{MPa}$.

Table 5: Key Physical Properties of the Test Lubricants

\begin{tabular}{|c|c|c|}
\hline & $\begin{array}{c}\text { Trinonyl } \\
\text { Trimellitate } \\
\text { Ester }\end{array}$ & $\begin{array}{c}\text { Pentaerythritol } \\
\text { Ester }\end{array}$ \\
\hline Kinematic Viscosity @ $40^{\circ} \mathrm{C}, \mathrm{cSt}$ & 92 & 94 \\
\hline Kinematic Viscosity @100 $\mathrm{C}, \mathrm{cSt}$ & 10.2 & 10.2 \\
\hline Viscosity Index & 90 & 88 \\
\hline Density @ $20^{\circ} \mathrm{C}, \mathrm{g} / \mathrm{cm}^{3}$ & 0.983 & 0.955 \\
\hline TGA Onset of Oxidation @ $10^{\circ} \mathrm{C} / \mathrm{min},{ }^{\circ} \mathrm{C}$ & 258 & 275 \\
\hline
\end{tabular}




\section{Results}

Friction coefficient and pin temperature results are presented for test combinations of speed, contact pressure and enclosure temperature, as described in the test matrix, Rows A-D, Table 3 , for both lubricants.

\subsection{Variation of Friction Coefficient and Pin Temperature with Contact Pressure, Table 3}

The variations in friction coefficient and pin temperature with contact pressures between 0.25 and 1.5MPa for both lubricated and dry tests, Table 3, are shown in Figure 6.

3.1.1 Dry Reference Tests: The unlubricated, dry reference tests show significant variation with contact pressure. For $0.25 \mathrm{MPa}$ the system temperature is significantly lower than $\mathrm{T}_{\mathrm{g}}$ for PEK and the friction coefficient is exceptionally low at 0.04 due to the formation of a stable transfer film of PEK composite on the steel counterface, Figure 7, shown in the lower set of images. Using the method of Bhushan [7] under the "high shear stress condition", the contact surface temperature was estimated from the friction energy dissipation: This indicated a surface temperature only $2-3^{\circ} \mathrm{C}$ higher than the near-contact temperature. As described in previous work [28], the unlubricated $0.25 \mathrm{MPa}$ contact pressure test contact is effectively a PEK composite on PEK composite system and behaviour correlates more closely with the near-contact temperature than the contact surface temperature [28].

The Figure 8 images (for optical images) and Figure 9 (for SEM images) show that the unlubricated pin interface for $0.25 \mathrm{MPa}$ contact has a high degree of fibre alignment in the sliding direction but with little visible fibre pull-out and the PEK matrix is abundant at the interface, i.e. there is no significant material removal. 


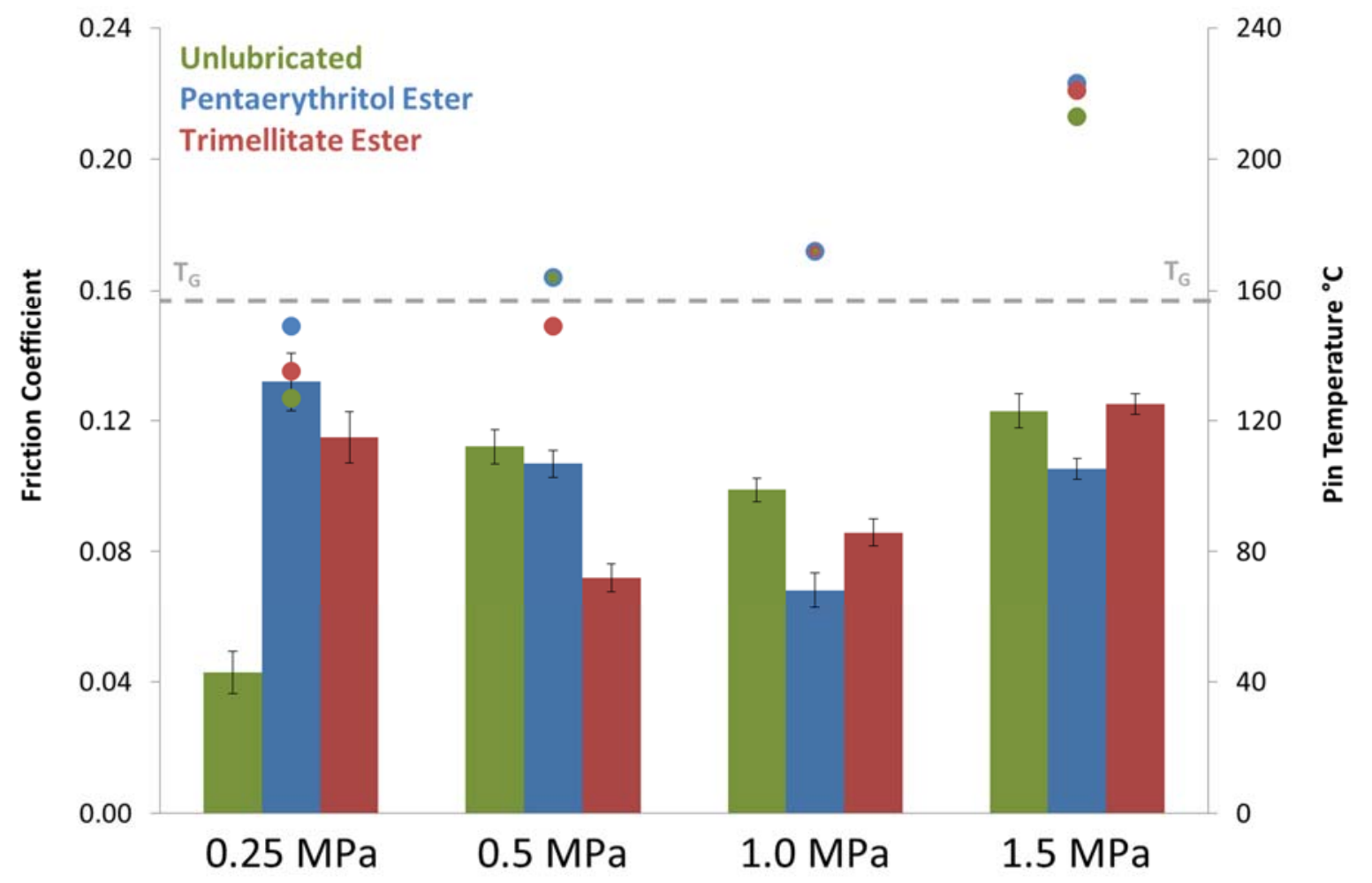

Figure 6: Variations in Friction Coefficients and Pin Temperatures with Contact Pressure, $8 \mathrm{~ms}^{-1}$ and $150^{\circ} \mathrm{C}$ : Columns $=$ Friction Coefficient; Dots $=$ Pin Temperature

From 0.5MPa to $1.5 \mathrm{MPa}$, as described in a previous study [28], the PEK composite transfer film on the steel disc is not as stable as for the case of $0.25 \mathrm{MPa}$ because the system temperature is around or above $T_{g}$. This instability leads to various degrees of interfacial shear between the PEK composite and steel surfaces, causing higher friction coefficients of $0.11,0.10$ and 0.12 . At $0.5 \mathrm{MPa}$, greater large-scale deformation can be seen at the interface, Figure 8 and also in Figure 9; at 1.5MPa there is a large extent of fibre pull-out and removal of the PEK matrix, implying greater abrasive wear, Figure 9. Nevertheless, the transfer films are still present and relatively stable; there is little evidence of significant material ejection from the contact, nor any excessive plastic deformation or melting of the pin surface and transfer film, which would often be seen as a trailing 'plume' of polymer from the pin, Figure 7. 


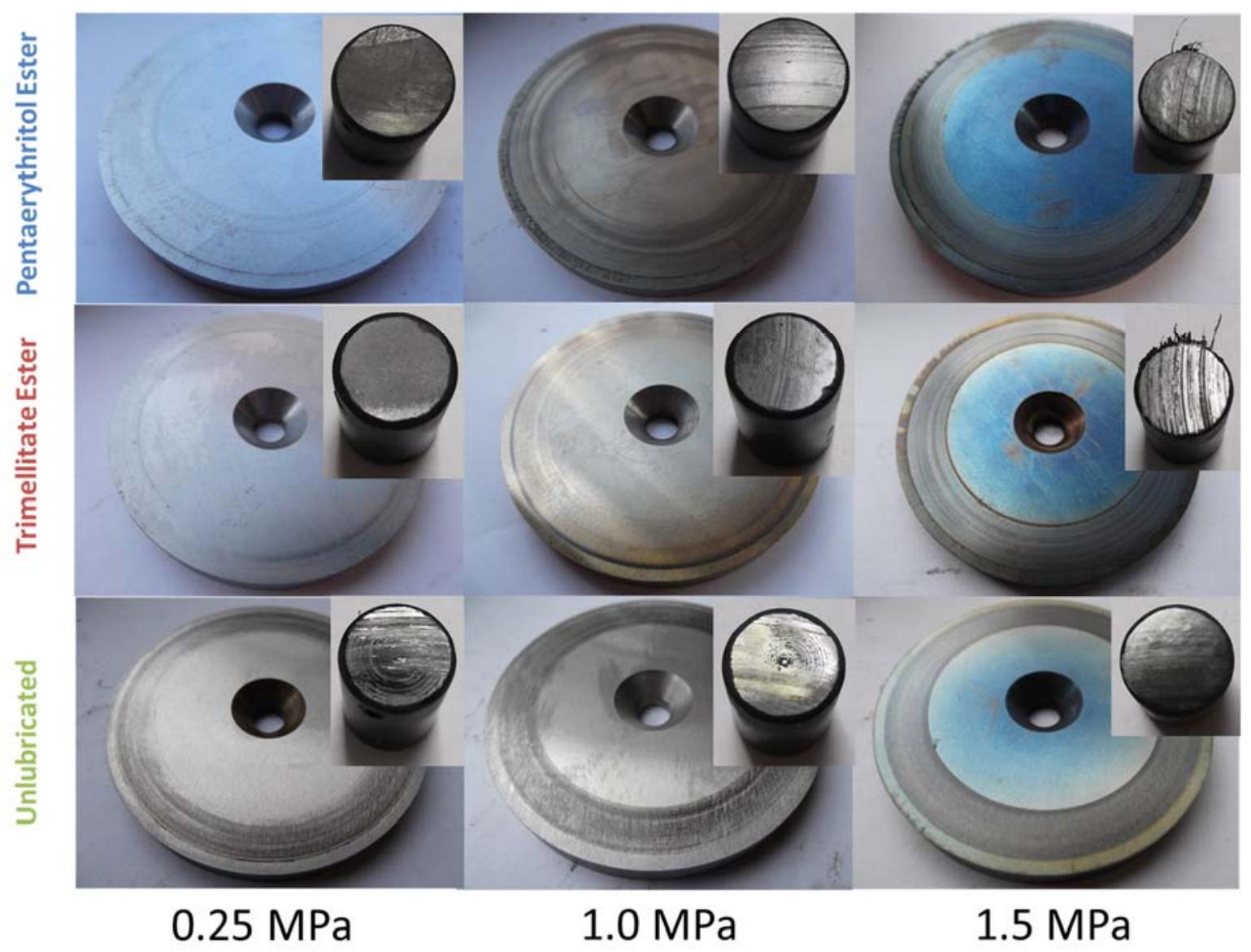

Figure 7: Disc and Pin Images - Effect of Varying Contact Pressure, 0.25 to 1.5MPa, at $8 \mathrm{~ms}^{-1}$ and $150^{\circ} \mathrm{C}$ Air Temperature 


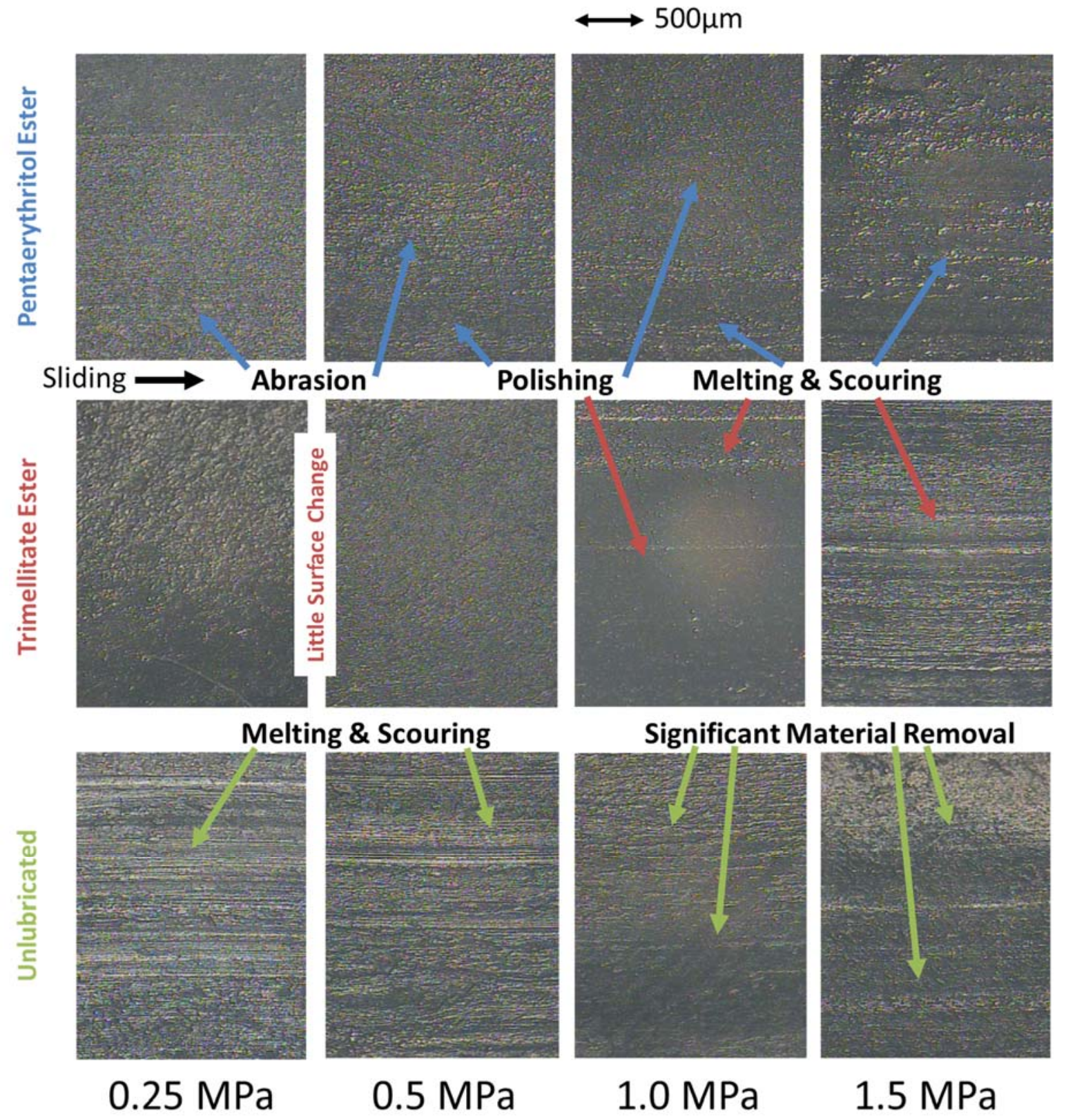

Figure 8: Optical Microscope Images of Pin Surfaces: Effect of Varying Contact Pressure at $8 \mathrm{~ms}^{-1}$ and $150^{\circ} \mathrm{C}$ Air Temperature 

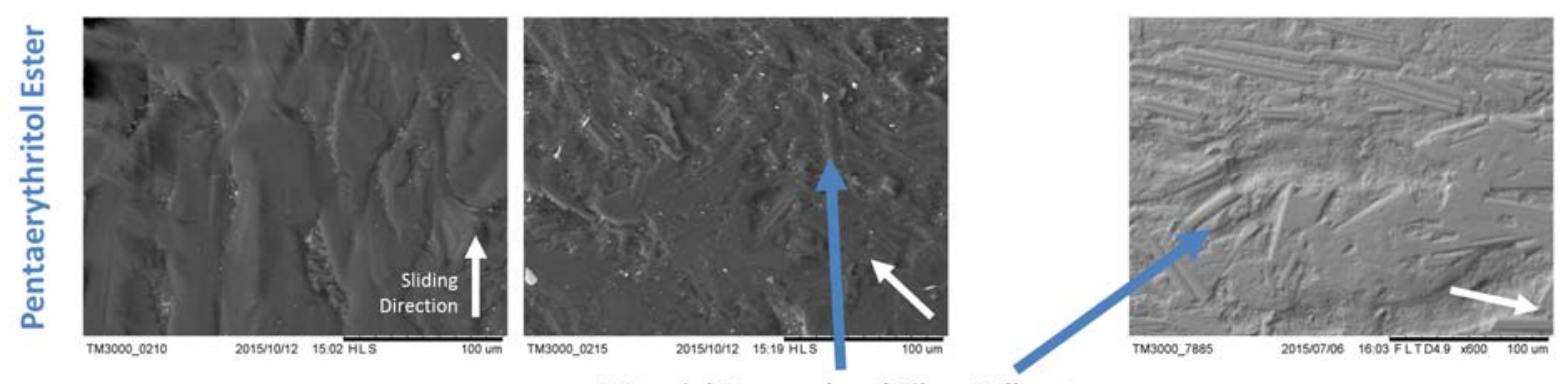

Material Removal and Fibre Pull-out
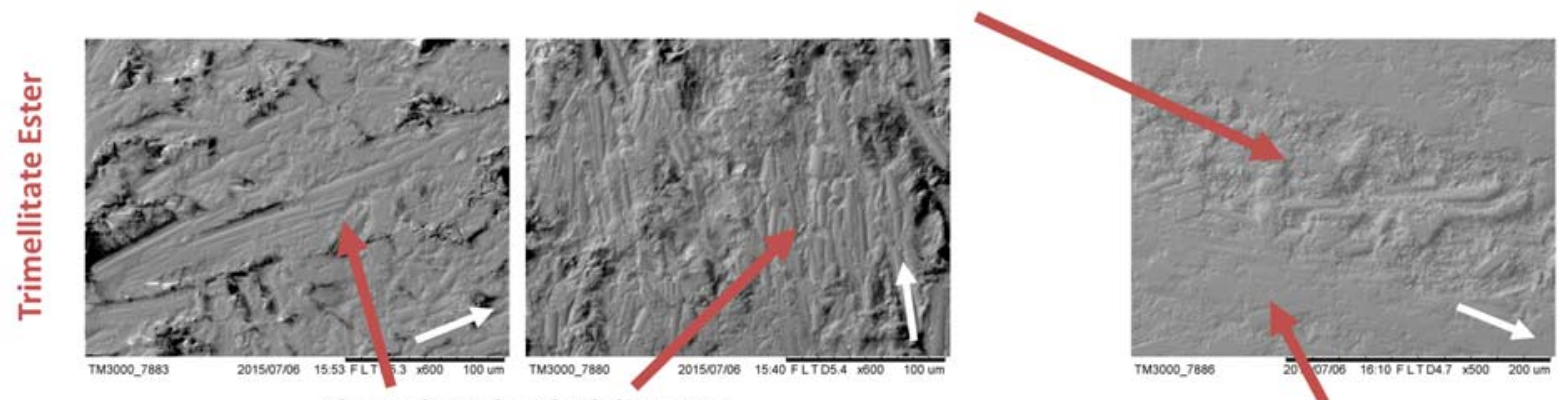

Fibres Aligned with Sliding Axis
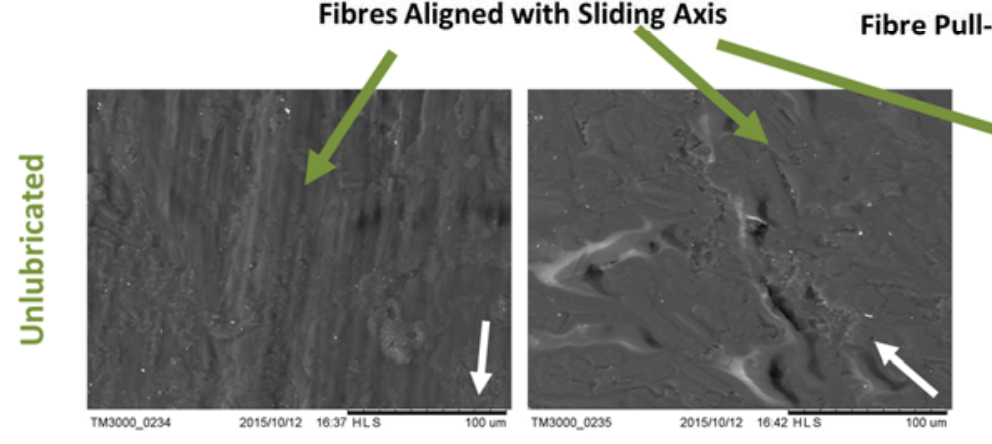

Smooth Region - Possible Melting

Figure 9: SEM Images of Pin Surfaces: Effect of Varying Contact Pressure at $8 \mathrm{~ms}^{-1}$ and $150^{\circ} \mathrm{C}$ Air Temperature

3.1.2 Lubricated Contacts at Contact Pressures of 0.25 and 0.5MPa: For the lubricated contacts using $0.25 \mathrm{MPa}$ and $0.5 \mathrm{MPa}$ contact pressures, the trimellitate ester produces lower friction coefficients, $\mu=0.12$ and 0.07 , than the pentaerythritol ester, $\mu=0.13$ and 0.11 . At $0.5 \mathrm{MPa}$, the pentaerythritol ester produces a comparable friction coefficient and system temperature to dry conditions. The surfaces of the pentaerythritol ester-lubricated pins under these conditions show significant plastic deformation of the pin surface and some removed fibres at the surface aligned to the sliding direction, Figure 8 and Figure 9.

However, for the trimellitate ester lubricated pins at 0.25 and $0.5 \mathrm{MPa}$ contact pressure conditions, little change in the surface has occurred, Figure 8, indicating low levels of PEK composite-steel interaction. Only a mild polishing of the top layer of the surface is seen, where the carbon fibres are worn to a flat surface rather than pulled-out, Figure 9. The trimellitate ester has a greater polarity than the pentaerythritol ester and therefore has a greater ability to form a 
physically absorbed lubricant film on the surface. The trimellitate ester lubricant film allows the wear process to produce a more conformal surface, increasing average surface separation, rather than producing significant surface deformation, Figure 9. Because the lubricated conditions here are marginal or starved, this produces a significant differentiation between the two lubricants under these conditions.

3.1.3 Lubricated Contacts at Contact Pressures of 1.0 and 1.5MPa: However, for 1.0MPa and $1.5 \mathrm{MPa}$ contact pressures, the previous trend reverses; the pentaerythritol ester produces lower friction coefficients, 0.07 and 0.11 , than both the trimellitate ester, 0.09 and 0.13 , and the dry condition, 0.10 and 0.12 .

Microscope images of the pentaerythritol-lubricated pin surfaces show that surface melting occurs at $1.0 \mathrm{MPa}$ in a similar manner to that at $0.25 \mathrm{MPa}$ and $0.5 \mathrm{MPa}$, but also that the scouring of the surface is more severe at $1.5 \mathrm{MPa}$, Figure 8 . At $1.5 \mathrm{MPa}$ there is greater evidence of bulk removal of the surface, exposing regions of fibres, Figure 9. At 1.5MPa the trimellitate ester gives a friction coefficient of 0.13 , close to the dry condition of 0.12 , and the pin surface images indicate significant melting and scouring of the PEK and fibre pull-out, i.e. bulk material removal, Figure 8 and Figure 9.

3.1.4 The Pattern of Lubrication Cycles: Figure 10 shows a single lubrication cycle for both trimellitate ester and pentaerythritol ester under $1.5 \mathrm{MPa}$ contact pressure. It shows that for both lubricants there is a large initial reduction in friction coefficient when the lubricant is supplied into the contact, where hydrodynamic lubrication is increasingly possible. As the excess lubricant drains from the system to leave a thin film, friction coefficients increase: This will produce mixed or boundary lubrication depending on the speed, load and level of lubricant starvation. The initial pentaerythritol ester friction coefficient value is unstable but then stabilises at $\sim 0.10$ for the rest of the lubricating cycle test. For the trimellitate ester the initial stable region persists for around 10 minutes after which the friction coefficient increases for around 3 minutes before settling to a value of $\sim 0.12$. The variation of friction coefficient indicates that the initial lubricant film formation breaks down but, because this is a PEK/steel contact rather than steel/steel, it does not lead to failure, seizure or galling.

Because the lubricant film breaks down, the contact changes through a second run-in process, from mixed PEK composite-steel lubrication to an unlubricated PEK composite-steel contact with an unstable transfer film. This is shown by the extensive melting and scouring of the PEK composite pin surface, Figure 8 , hence the correlation to the dry condition at $1.5 \mathrm{MPa}$. 
At $1.5 \mathrm{MPa}$ contact pressure the disc surfaces of both trimellitate ester and pentaerythritol esterlubricated tests show a significant quantity of adhered polymer in the wear track, Figure 7, but insufficient to form a full transfer film. Surface images for an unlubricated test are shown for comparison in Figure 7, Figure 8 and Figure 9.

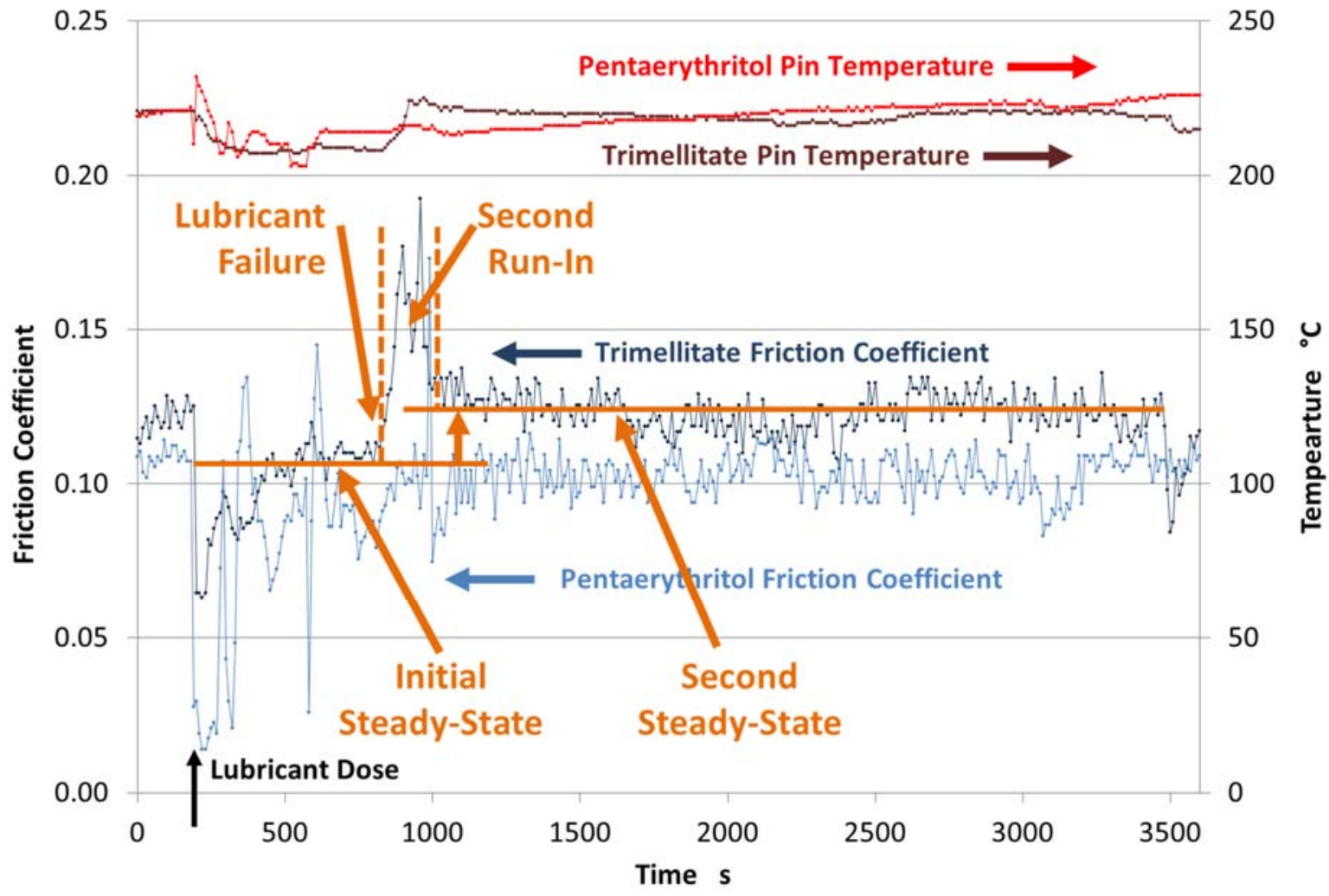

Figure 10: Friction Coefficient and Pin Temperature over a Single Lubrication Cycle. PEK + 30\%wt Carbon Fibres at $8 \mathrm{~ms}^{-1}, 150^{\circ} \mathrm{C}, 1.5 \mathrm{MPa}$, Lubricated with Trimellitate Ester and Pentaerythritol Ester.

At 1.0MPa, the extent of lubricant film failure is not as complete, which means that the trimellitate ester still produces a lower friction coefficient, 0.09 , to the dry condition, 0.10 , indicating some residual lubricant at the interface, thus not a completely dry PEK composite-steel contact. A brown tinge on the disc wear track area is regarded as thermally decomposed trimellitate lubricant, which is not seen for the pentaerythritol ester, Figure 7. Breakdown of the trimellitate lubricant results in polishing of the PEK composite surface with some localised melting, Figure 8.

3.1.5 Pin Temperatures: As pin temperatures increase with contact pressure, the shear strength of the PEK at the interface reduces [5], hence the reduction in friction coefficient with lower 
and intermediate loads under both dry and lubricated conditions. However, above $\mathrm{T}_{\mathrm{g}}$, increasing temperature increases the instability of any PEK composite transfer film, which causes the subsequent increase in friction coefficient from 1.0MPa to 1.5MPa for the dry condition. Similarly, instability in the lubricant film produces an increase in the friction coefficient at higher loads, caused by a greater degree of PEK composite -steel contact. Therefore, whilst use of the pentaerythritol ester produces no improvement in performance over the dry condition at $0.5 \mathrm{MPa}$, the increased instability in the transfer film under dry conditions at $1.0 \mathrm{MPa}$ and $1.5 \mathrm{MPa}$ means that the marginal boundary lubrication provided by the pentaerythritol ester produces beneficial performance over the dry condition under these conditions.

It is clear that for high load conditions at temperatures above $T_{g}$ where the polymer at the interface and near-contact region is less stable, the contact tends towards predominantly PEK composite-steel sliding: yet the lubricant still has a significant and distinct effect on the tribological mechanisms. Therefore, even at $1.5 \mathrm{MPa}$ where there is significant transfer of PEK composite to the steel surface, Figure 7, a full transfer film is not formed. The breakdown of the trimellitate ester in the contact causes an increase in friction coefficient. The small quantity of pentaerythritol present in the interface preserves a boundary film that keeps the lubrication regime relatively stable. There may be conditions under which these boundary films of lubricant (whether decomposed or intact) break down completely, but these were not encountered during this test programme.

3.1.6 Conclusion for Variation of Contact Pressures: The trends in friction coefficients and pin temperatures for PEK, unlubricated or lubricated, for increase in contact pressure are complex and related to the glass transition temperature of the reinforced PEK, as:

- For low contact pressures, unlubricated PEK composite had a low friction coefficient with the pin temperature below $\mathrm{T}_{\mathrm{g}}$ with little surface modification. For higher contact pressures, the friction coefficient of unlubricated PEK composite increased with increasing contact temperature to, or around, $\mathrm{Tg}_{\mathrm{g}}$. These surfaces were significantly changed,

- For low contact pressures, the lubricated PEK composite friction coefficient was lower for the trimellitate than the pentaerythritol ester. At higher contact pressures, this reversed for the PEK composite friction coefficient lubricated with pentaerythritol ester was lower than for the trimellitate ester, with surface modification, 
- For PEK composite surface temperatures greater than $\mathrm{T}_{\mathrm{g}}$, the interfacial shear strength was reduced. At lower and intermediate contact pressures, this produced a reduction in friction coefficient with increasing load, for both dry and lubricated conditions. However, temperatures above $\mathrm{T}_{\mathrm{g}}$ destabilised the dry PEK composite transfer films, causing friction coefficients to increase with increasing contact pressure for $1.0 \mathrm{MPa} / 1.5 \mathrm{MPa}$. Similarly, lubricant film instability caused friction coefficients to increase with contact pressure at higher contact pressures, caused by a greater degree of PEK composite-steel contact.

- Pentaerythritol ester lubrication did not improve performance over the dry condition at $0.5 \mathrm{MPa}$. However, at higher contact pressures, marginal boundary lubrication of the pentaerythritol ester produced beneficial performance over the dry condition under these conditions because of increased dry transfer film instability.

- When the contact is unlubricated, stable tribological conditions are dependent on the formation of a stable transfer film of polymer on the steel counterface. Stable tribological conditions are limited by the stability of this transfer film, which is limited by the glass transition of near-contact region and transfer film, [28]. The factors that cause an increase in the near-contact temperature (increased friction coefficient, higher speed, higher system temperature) will have a large influence on this: reaching this limit results in an increased friction coefficient, greater abrasion and fibre pull-out of the polymer surface, Figure 9.

\subsection{Variation of Friction Coefficient and Pin Temperature with Average Sliding Speed,}

\section{Table 3}

Variations in friction coefficients and pin temperatures with average sliding speeds are shown in Figure 11.

3.2.1 Trimellitate Ester as Lubricant: The trimellitate ester produces a low, stable, friction coefficient both at $6 \mathrm{~ms}^{-1}, \mu=0.07$ and $8 \mathrm{~ms}^{-1}, \mu=0.07$, increasing significantly to $\mu=0.10$ at $10 \mathrm{~ms}^{-1}$. The pin temperatures for the trimellitate ester results increase linearly from below $\mathrm{T}_{\mathrm{g}}$ at $6 \mathrm{~ms}^{-1}$, through $8 \mathrm{~ms}^{-1}$ to the PEK $\mathrm{T}_{\mathrm{g}}$ at $10 \mathrm{~ms}^{-1}$. The increase in friction coefficients and pin 
temperature suggests that the lubricant film has begun to break down at $10 \mathrm{~ms}^{-1}$ either by formation of a thinner lubricant film on the disc surface due to the greater disc inertia i.e. lubricant spin-off, lubricant breakdown from higher frictional energy dissipation and higher contact temperatures, or a combination of all the above.

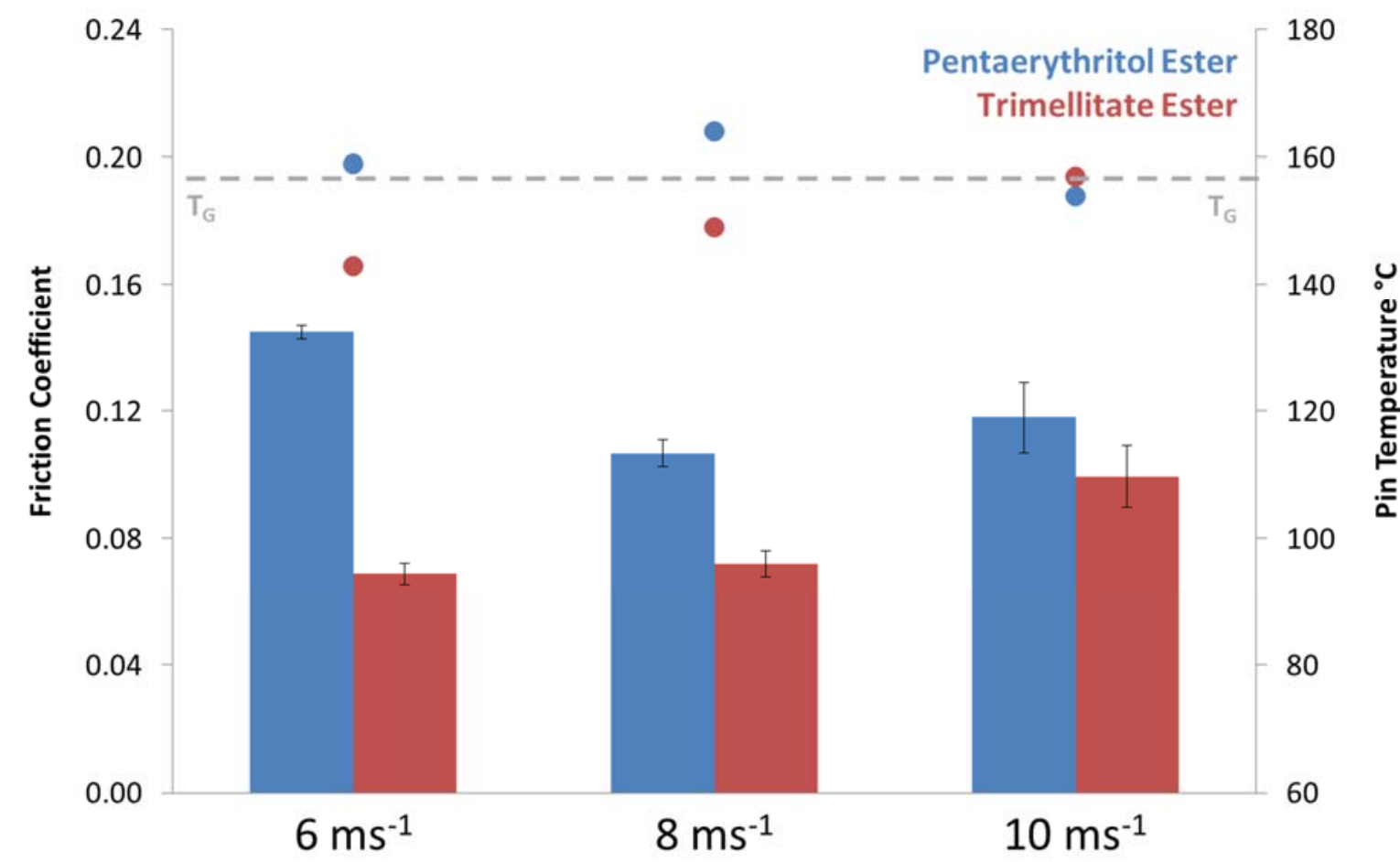

Figure 11: Variations in Friction Coefficients and Pin Temperatures with Average Sliding Speed at 0.5MPa and $150^{\circ} \mathrm{C}$. (Columns - Friction Coefficient, Dots - Pin Temperature)

3.2.2 Pentaerythritol Ester as Lubricant: The pentaerythritol ester tests at $6 \mathrm{~ms}^{-1}, \mu=0.15$, and $8 \mathrm{~ms}^{-1}, \mu=0.11$, has significantly higher coefficients of friction than the trimellitate ester, reflecting this lubricant's reduced ability to sustain an effective lubricant film in the contact. The friction coefficient reduces between $6 \mathrm{~ms}^{-1}$ and $8 \mathrm{~ms}^{-1}$ when pentaerythritol ester is used which, considering the magnitude of the friction coefficient, suggests that lubrication is towards the limit of the boundary end of the mixed lubrication regime. The reduction in friction coefficient with increasing sliding speed is probably caused by the higher contact temperatures, $159^{\circ} \mathrm{C}$, at $6 \mathrm{~ms}^{-1}$ just above $\mathrm{T}_{\mathrm{g}}$, to $164^{\circ} \mathrm{C}$ at $8 \mathrm{~ms}^{-1}$ which reduces the shear strength of the PEK at the interface. The pentaerythritol ester lubricated surfaces show more exposed and aligned fibres on the surface, indicating greater wear of the PEK matrix and, therefore, more extensive PEK-steel contact, Figure 12. 
At $10 \mathrm{~ms}^{-1}$, the friction coefficient using pentaerythritol ester increases to $\mu=0.12$, a value close to the trimellitate ester value, $\mu=0.10$, indicating that both lubricants are experiencing some degree of failure under these conditions. The changes in convection cooling of the disc with changes in speed had an influence on the pin temperature, but it is difficult to deconvolute these effects from the other effects discussed.

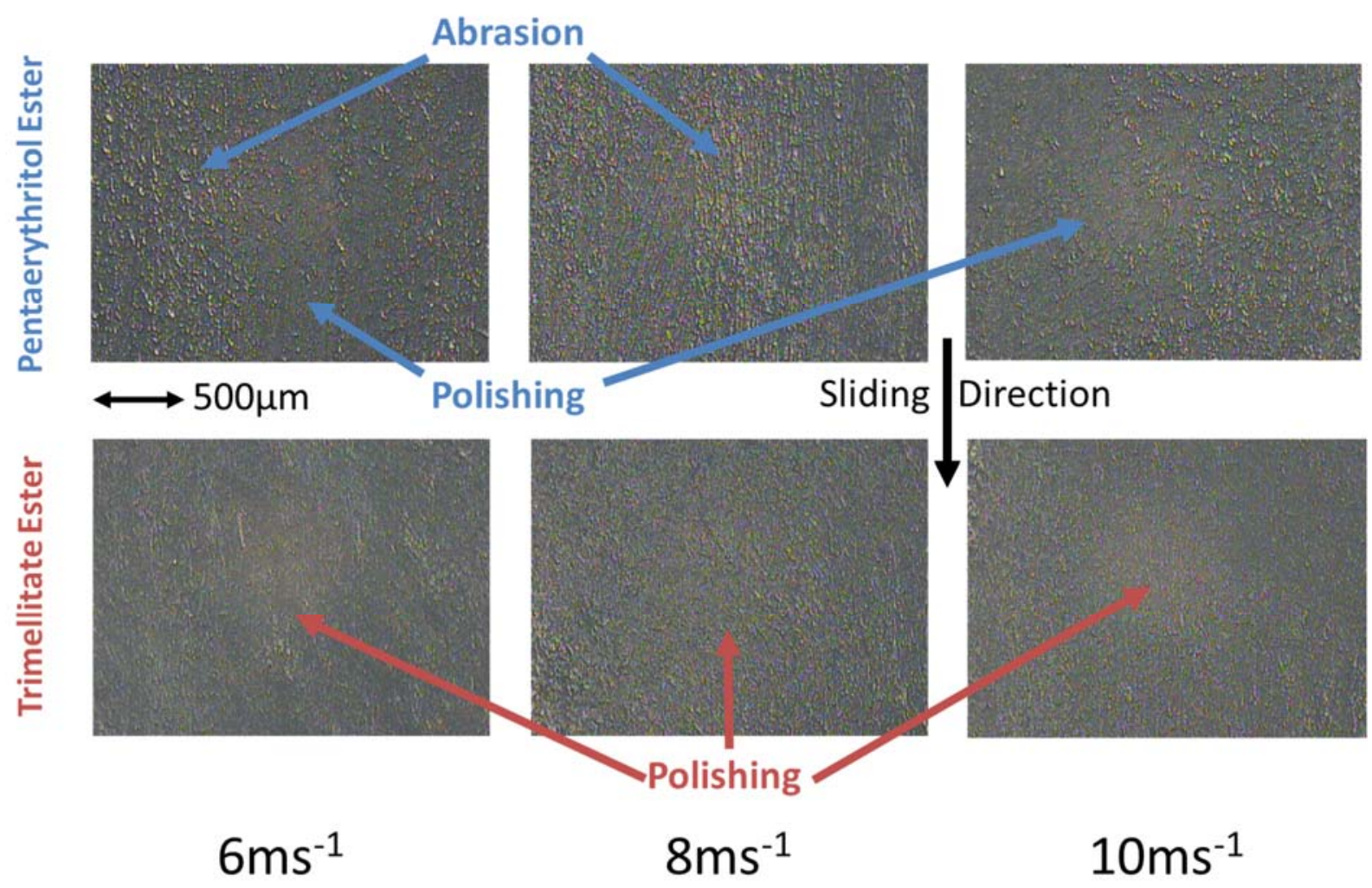

Figure 12: Optical Microscope Images of Pin Surfaces: The Effect of Varying Average Speed at $0.5 \mathrm{MPa}$ and $150^{\circ} \mathrm{C}$ Air Temperature

3.2.3 Conclusions for Varying the Contact Speed: Friction coefficients for the pentaerythritol ester-lubricated contact at all average speeds are always higher than those for the trimellitate ester-lubricated contacts. Whereas the pentaerythritol ester lubricated contacts initially decrease friction coefficients then increase slightly for the highest speed, the trimellitate ester lubricated contacts are unaffected at lower speeds but increase slightly at the highest speeds. At the highest speed, $10 \mathrm{~ms}^{-1}$, the friction coefficients for the two lubricants are very close in value.

3.3 Friction Coefficient and Pin Temperature Variation with Enclosure Air Temperature, Table 3 
3.3.1 Trimellitate Ester Lubrication: The trimellitate ester has lower friction coefficients and lower pin temperatures than the pentaerythritol ester under all three temperature conditions, Figure 13. The trimellitate ester gives significantly lower friction coefficients, from $\mu=0.09$ at $100^{\circ} \mathrm{C}$ through $\mu=0.06$ at $125^{\circ} \mathrm{C}$, increasing to $\mu=0.07$ at $150^{\circ} \mathrm{C}$, indicating that it forms a more effective and thicker lubricant film than the pentaerythritol ester, producing a lower degree of direct interaction between the PEK composite and steel surfaces. The pin temperatures increase almost linearly but remain below $\mathrm{T}_{\mathrm{g}}$.

There is a decreased extent of abrasion and fibre pull-out and more extensive polishing of the PEK composite surface when the trimellitate ester is used as lubricant, compared to the pentaerythritol ester under these conditions, particularly at $100^{\circ} \mathrm{C}$, where only mild polishing and smoothing of the surface occurs, Figure 14 and Figure 15. This is particularly shown in Figure 15 where the fibres are seen to be still in their original orientation rather than being aligned to the sliding direction, suggesting extremely low plastic deformation of the interface material. However, at $150^{\circ} \mathrm{C}$, the friction coefficient increases slightly for the trimellitate ester which indicates that the extent of PEK composite-steel interaction has increased, either by lubricant degradation in the contact or a reduction in lubricant supply to the contact. Whilst the surface still shows good fibre alignment and low pull-out and also a large quantity of the PEK matrix at the surface, it is clear to see that more material has been removed at $150^{\circ} \mathrm{C}$ compared to the same conditions at $100^{\circ} \mathrm{C}$, Figure 15 . 


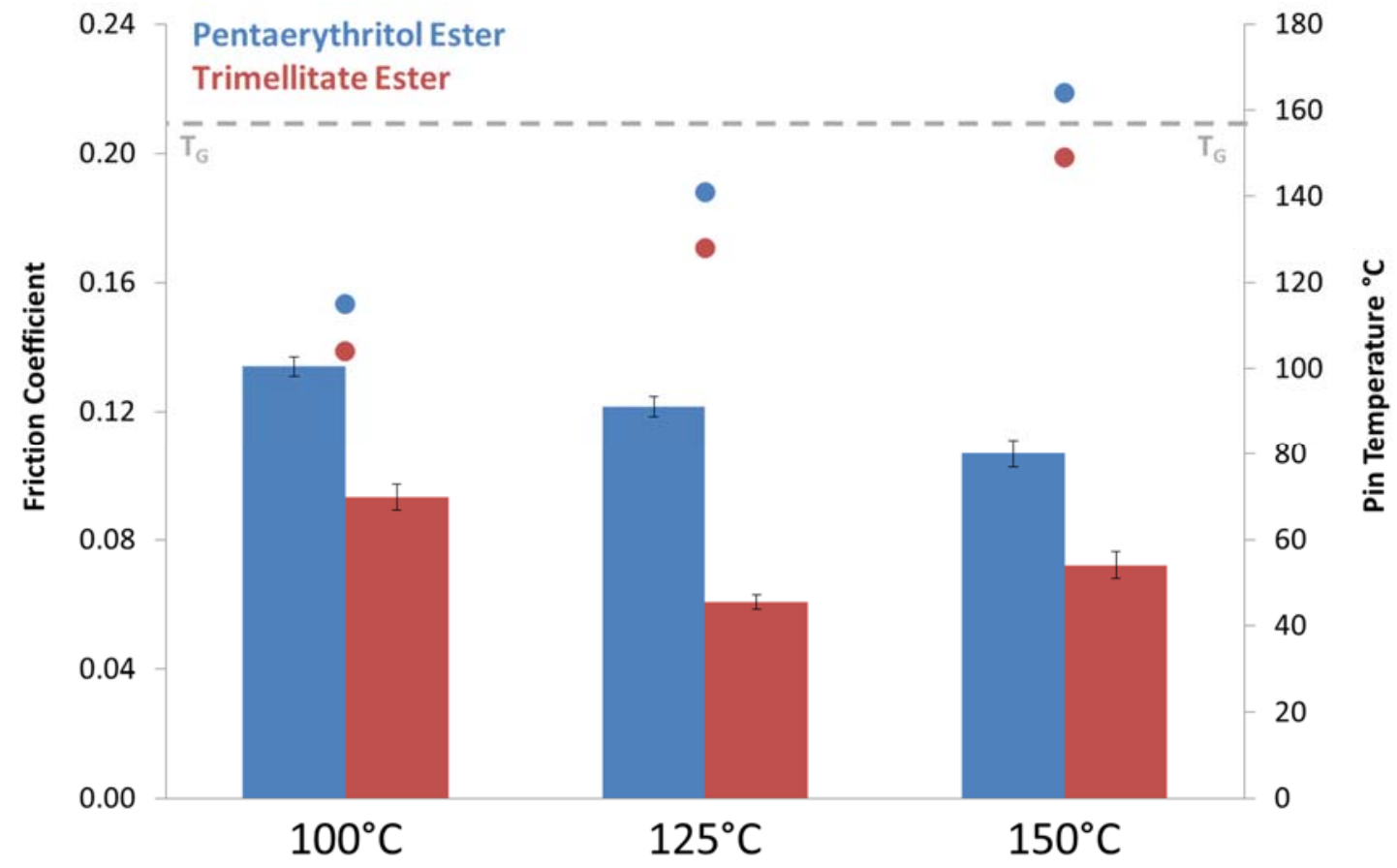

Figure 13: Variations in Friction Coefficients and Pin Temperatures with Enclosure Air Temperature at $0.5 \mathrm{MPa}$ and $8 \mathrm{~ms}^{-1}:$ Columns $=$ Friction Coefficient, Dots $=$ Pin Temperature

3.3.2 Pentaerythritol Ester Lubrication: Using the pentaerythritol ester as lubricant gives a linearly decreasing friction coefficient, from $\mu=0.13$ at $100^{\circ} \mathrm{C}$ to $\mu=0.11$ at $150^{\circ} \mathrm{C}$. Extensive abrasion, surface melting and fibre-pull-out effects were observed on the PEK composite pin surfaces for this lubricant, Figure 14 and Figure 15. The reduction in friction coefficient with enclosure temperature and pin temperature indicates a reduction in the shear strength of the PEK composite in the contact region; this effect has a greater effect on friction coefficient than the effect of temperature on evaporation and supply to the contact due to variation in viscosity. 


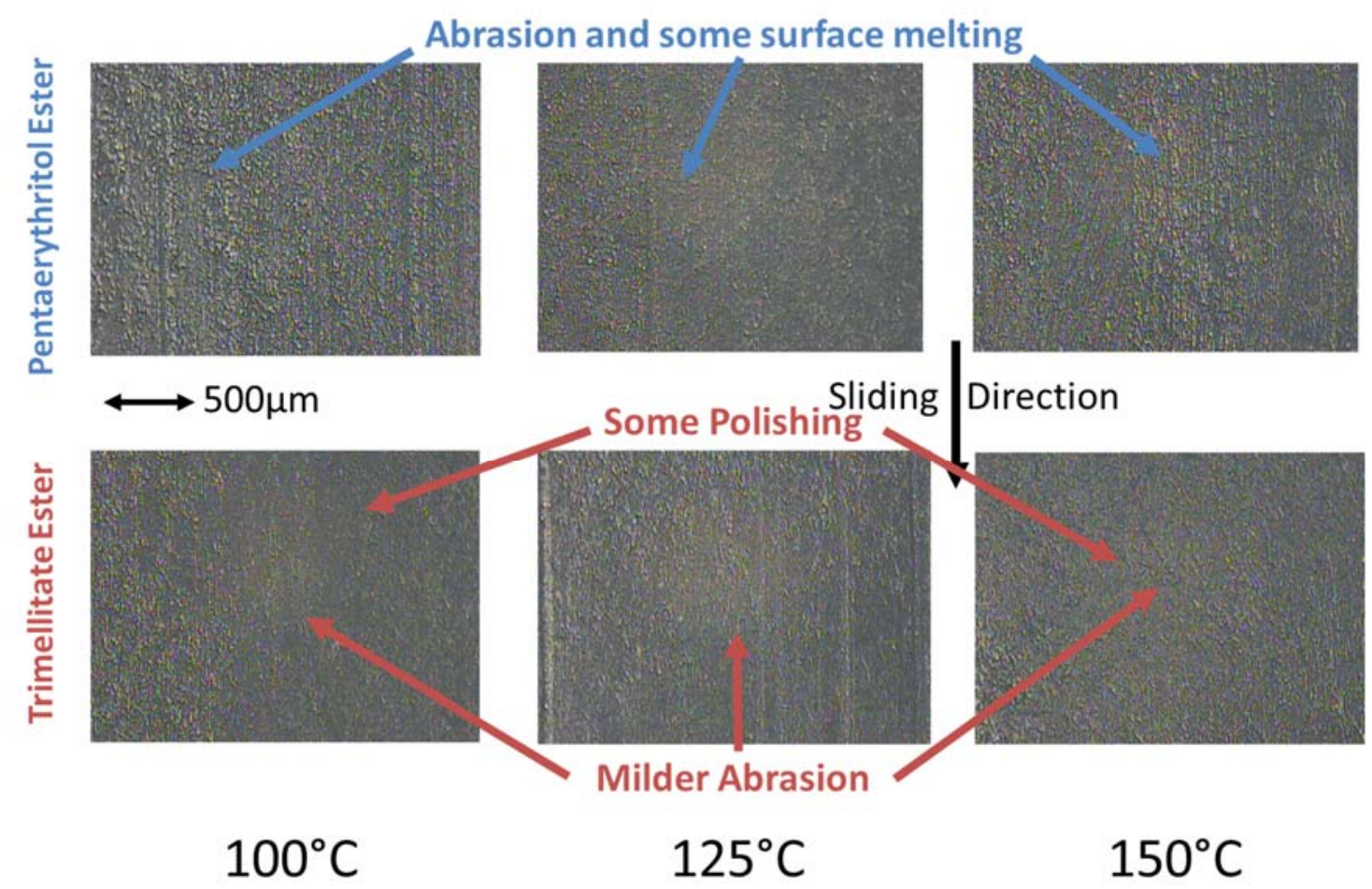

Figure 14: Optical Microscope Images of Pin Surfaces: The Effect of Varying Air Temperature at $0.5 \mathrm{MPa}$ and $8 \mathrm{~ms}^{-1}$ Average Sliding Speed
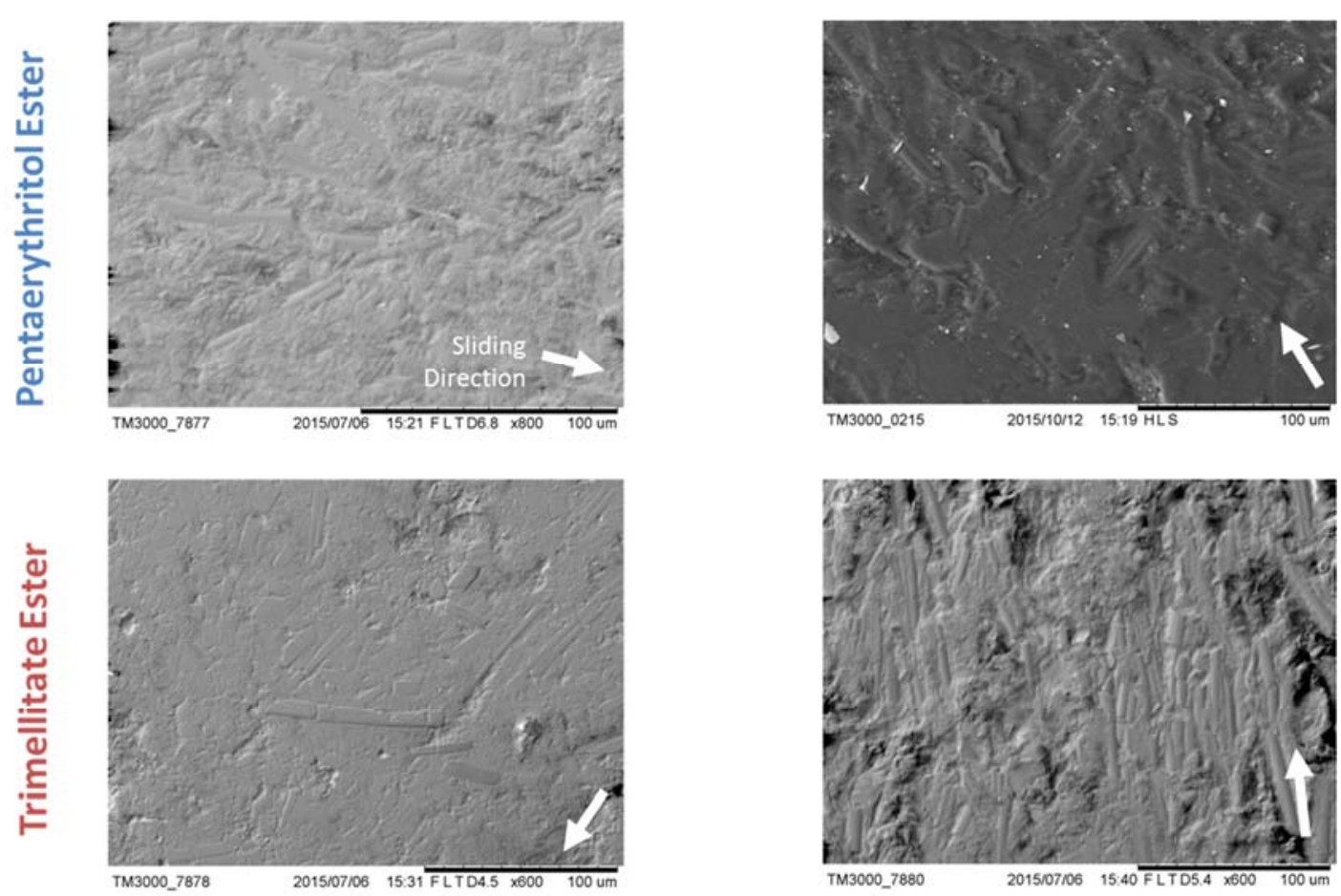

$100^{\circ} \mathrm{C}$

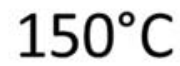

Figure 15: SEM Images: The Effect of Varying Air Temperature at $0.5 \mathrm{MPa}$ and $8 \mathrm{~ms}^{-1}$ Average Sliding Speed 
3.3.3 Conclusions for Different Enclosure Temperatures: (i) The trimellitate ester produced significantly lower friction coefficients, from $\mu=0.09$ at $100^{\circ} \mathrm{C}$, through $\mu=0.05$ at $125^{\circ} \mathrm{C}$, increasing to $\mu=0.067$ at $150^{\circ} \mathrm{C}$, indicating formation of a thicker, more effective lubricant film than the pentaerythritol ester. This film caused lower direct interaction between the PEK composite and steel surfaces: Lower abrasion, less fibre pull-out and more extensive polishing of the PEK composite surface occurs with the trimellitate ester compared to pentaerythritol under these conditions, particularly at $100^{\circ} \mathrm{C}$ where only mild surface polishing and smoothing occur. When the trimellitate ester was used as the lubricant, the near contact temperature was significantly lower than for the pentaerythritol ester under equivalent condition. This is a result of the lower frictional energy dissipation of the contact. In turn, this lower temperature provides greater stability to the lubrication of the tribological system, particularly at $150^{\circ} \mathrm{C}$ where the trimellitate ester is able to keep the near contact temperature below $\mathrm{T}_{\mathrm{g}}$ whereas the pentaerythritol could not.

(ii) The pentaerythritol ester produced higher friction coefficients which linearly decreased from $100^{\circ} \mathrm{C}$ to $150^{\circ} \mathrm{C}$. Similarly, pin temperatures increase linearly with increase in the enclosure temperature to just above $\mathrm{T}_{\mathrm{g}}$ : This was not the case when the trimellitate ester was used, indicating that other factors had an influence on pin temperature.

\subsection{Variation in Friction Coefficient with Contact Pressures at $150^{\circ} \mathrm{C}$ and $8 \mathrm{~ms}^{-1}$ for Un-Reinforced and 30\% Carbon Fibre-Reinforced PEK/Steel Contacts.}

\subsubsection{Variation in Friction Coefficient with Contact Pressure for Lubricated PEK and Reinforced PEK/Steel}

At $150^{\circ} \mathrm{C}$ the friction coefficients for neat PEK and PEK reinforced with $30 \%$ wt carbon fibres vary with contact pressure, Figure 16 . For both $0.5 \mathrm{MPa}$ and $1.0 \mathrm{MPa}$ at $150^{\circ} \mathrm{C}$, neat $\mathrm{PEK}$ failed when lubricated with the pentaerythritol ester due to melting and flow of the polymer at the contact surface. The failure mode is excessive wear, Figure 17, indicating by contrast that under these conditions, the contribution of the carbon fibre filler in the $30 \%$ carbon-fibre filled PEK is to increase thermal conductivity and inhibit plastic flow of the PEK matrix, is sufficient to retain stable but marginal lubrication. 
As previously established, Figure 8 and Figure 9, the higher degree of PEK-steel interaction when a pentaerythritol ester is used means that heat build-up and plastic flow is greater than when neat PEK is used. The thermal conductivity of neat PEK is a factor of 3 lower than when $30 \%$ wt carbon fibres are included, Table 4, meaning that for the neat PEK test under the same conditions there is a greater concentration of frictional heat at the PEK/steel interface and nearcontact region than with 30\% carbon reinforced PEK. The lower thermal conductivity of PEK means lower dissipation of heat energy and lower ability to retain stable but marginal lubrication.

At $0.25 \mathrm{MPa}$, the friction coefficient of neat PEK lubricated with pentaerythritol ester at $\mu=$ 0.07 is significantly reduced compared to the $30 \%$ carbon-reinforced equivalent with $\mu=0.13$. Under these conditions, the pin surface of reinforced PEK is abraded, Figure 8, and neat PEK pins show signs of surface melting, Figure 17. These observations indicate that the interface temperature is higher for neat PEK (though the near contact temperature is lower, probably a thermal conductivity effect), Figure 16, and that neat PEK has lower resistance to plastic flow under these conditions. Thus, the shear strength of the PEK-steel interface is lower when neat PEK is used, hence the lower coefficient of friction. Clearly, this lower coefficient of friction is not a positive result due to the more severe wear mechanisms and higher operating temperature. Figure 18 shows that for neat PEK under these marginal lubrication conditions, the flow of PEK was not uniform across the surface; there are pockets in the surface where PEK has flowed, Figure 16. This suggests either local heating or cracking/weaknesses in planes normal to the interface that cause small volumes of PEK to plastically deform more readily. 


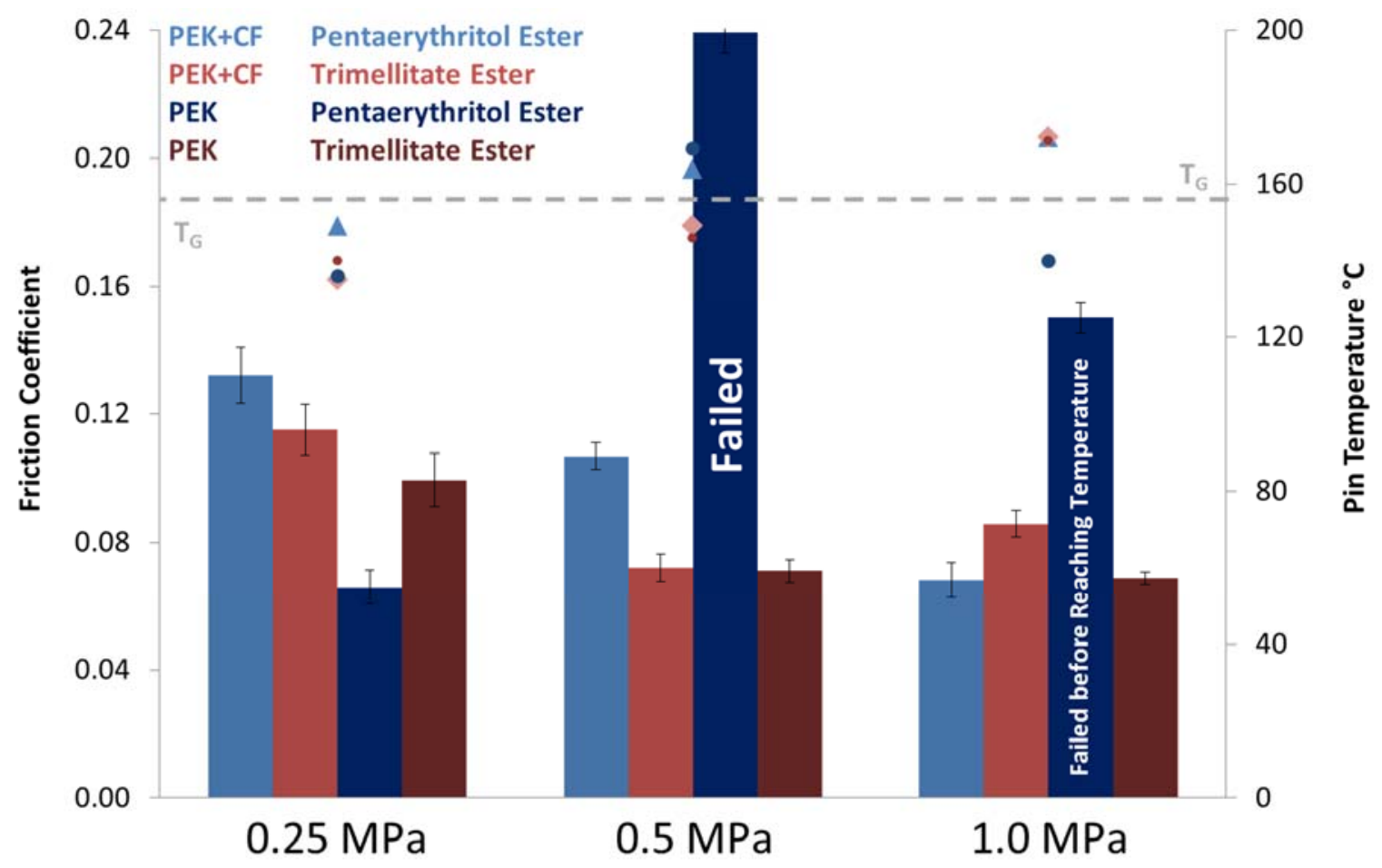

Figure 16: Variations in Friction Coefficients with Contact Pressures and PEK Reinforcement at $150^{\circ} \mathrm{C}$ and $8 \mathrm{~ms}^{-1}$. Columns $=$ Friction Coefficients, Dots $=$ Temperatures Data for Reinforced PEK is as Figure 6.

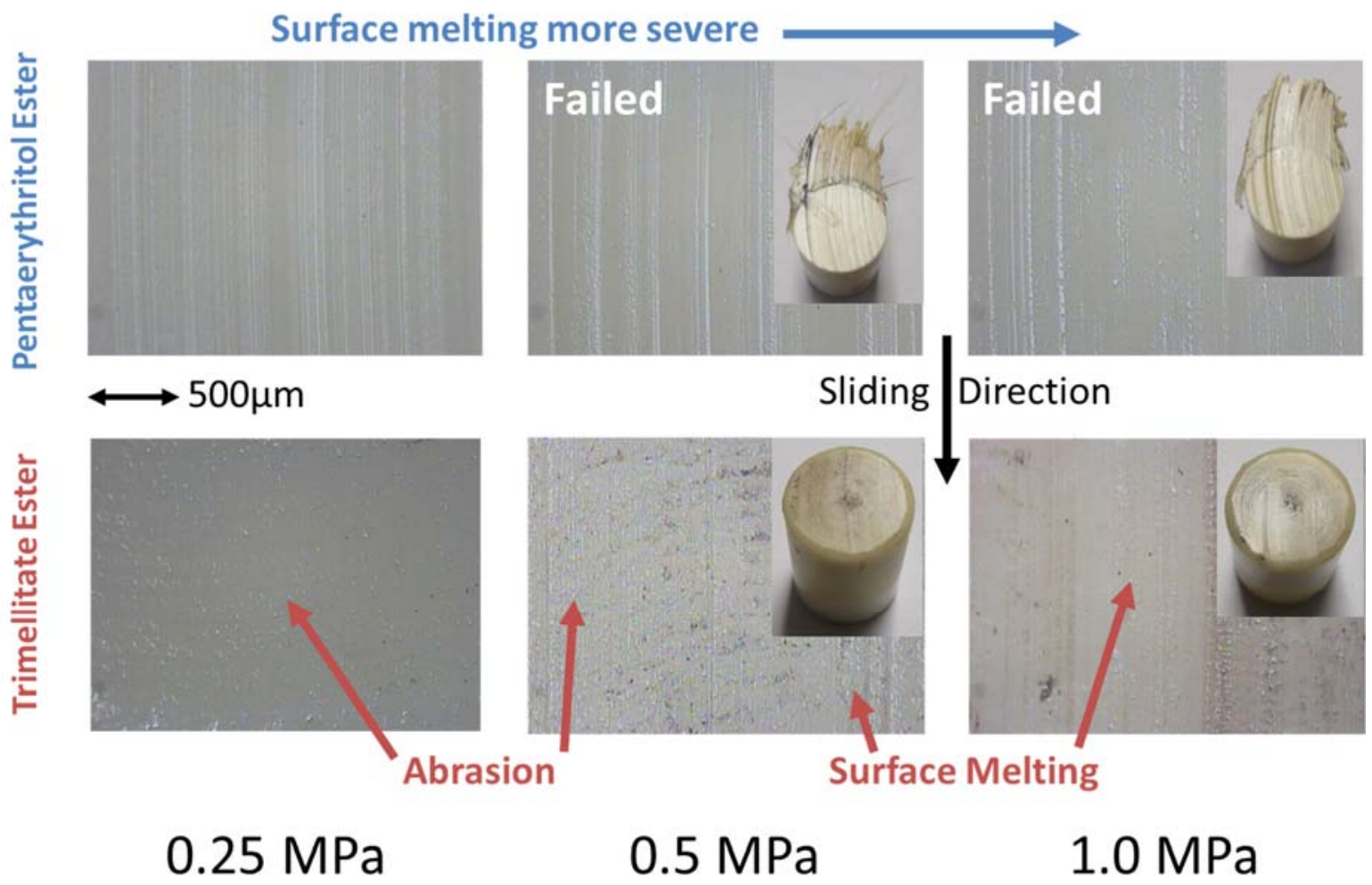

Figure 17: Optical Microscope Images of Pin Surfaces: Effect of Varying Contact Pressure on Unreinforced PEK at $8 \mathrm{~ms}^{-1}, 150^{\circ} \mathrm{C}$ Air Temperature 

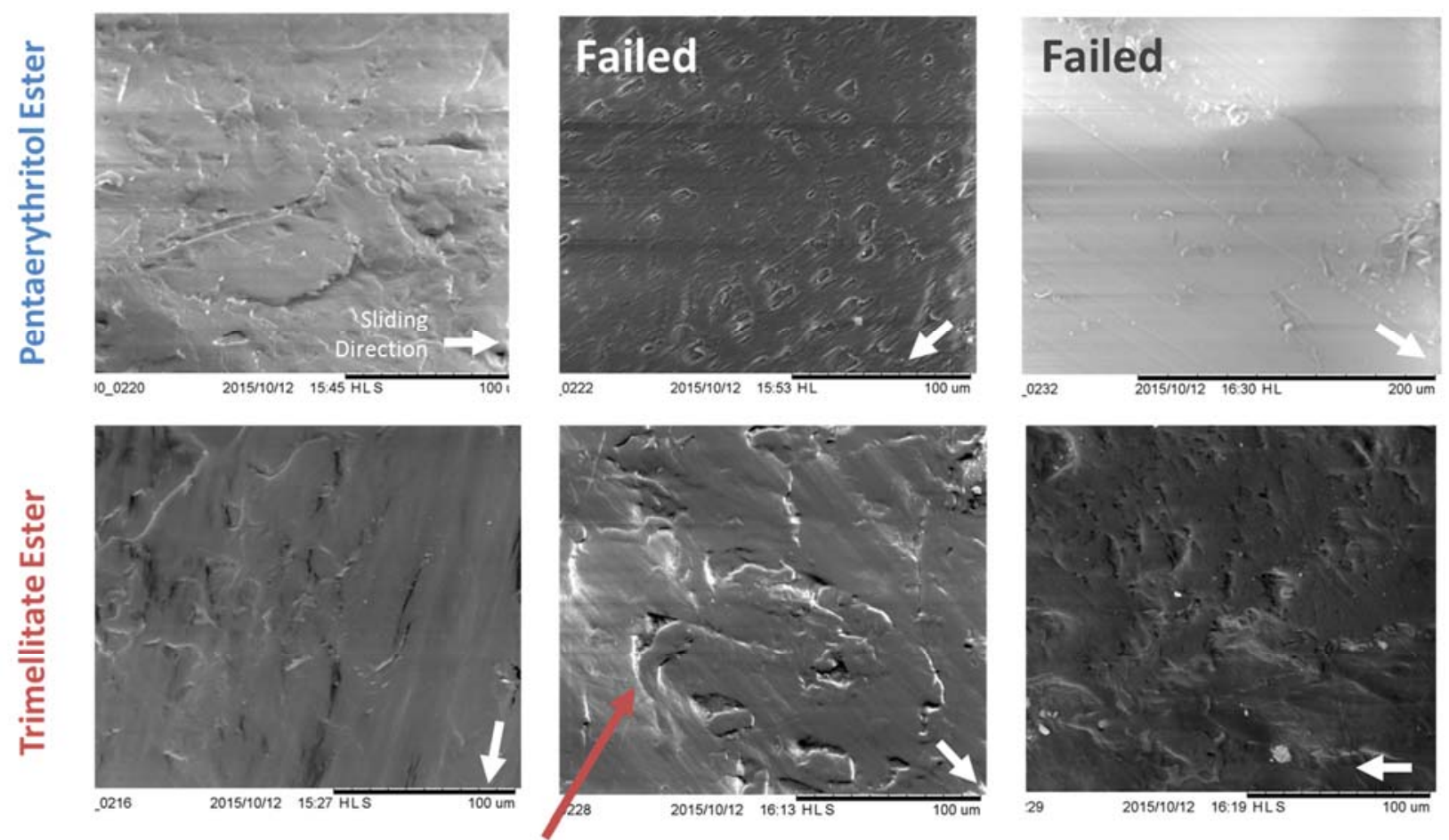

\subsection{MPa Localised $\quad 0.5 \mathrm{MPa}$ Material Flow}

\section{0 $\mathrm{MPa}$}

Figure 18: SEM Images: The Effect of Varying Contact Pressure on Unreinforced PEK at $8 \mathrm{~ms}^{-1}$ and $150^{\circ} \mathrm{C}$ Air Temperature

Evidence for local surface or subsurface cracking at planes normal to the interface is also seen with trimellitate ester at $0.5 \mathrm{MPa}$, seen as apparent pockets or gouges in the surface, Figure 18. The straight edges of some of the surface pocket regions suggests a cracking or plane of weakness in the unreinforced PEK. It is unusual for both plastic deformation and planes of weakness, normally a brittle mechanism, to occur in the same tribological mechanism. This could be a fatigue wear process: Such mechanisms have been reported and observed for unfilled polymers $[12,41-43]$, but have not previously been reported for PAEKs. This illustrates the complexity of material behaviour when there are large local gradients in temperature, shear and material properties, in addition to the transient effects of intermittent lubrication. This phenomenon is not observed with reinforced PEK where the carbon fibres physically limit plastic flow, reduce temperature gradients by higher thermal conductivity and do not produce the same planes of weakness when the polymer is injection moulded. This emphasises the importance of fibre reinforcement for the tribological applications of polymers.

When trimellitate ester is used as lubricant there is no significant difference between the friction coefficient of neat PEK and reinforced PEK under the $0.25 \mathrm{MPa}$ and $0.5 \mathrm{MPa}$ contact pressure conditions, suggesting that the lubrication film is sufficiently stable and the PEK-steel 
interaction sufficiently low for the lubricant to define the tribological response than when pentaerythritol ester is used, Figure 16. However, it is clear that the tribological mechanisms at work are significantly different for unreinforced PEK than reinforced PEK: The former shows pockets on the surface arising from plastic deformation and planes of weakness, the latter also shows plastic deformation but, when the fibres are aligned, the extent of plastic flow is limited and there are no cracks, Figure 9, Figure 18.

For neat $\mathrm{PEK}$ at $1.0 \mathrm{MPa}$ contact pressure lubricated by trimellitate ester, the friction coefficient is significantly lower, at $\mu=0.07$, than for reinforced PEK, $\mu=0.09$. For both materials, the pin surfaces at $1.0 \mathrm{MPa}$ indicated melting. When pentaerythritol ester is used, melting occurs over the whole pin surface, causing failure due to excessive temperature and friction. However, when trimellitate ester is used, there is still some plastic flow and evidence of flow around planes of weakness in the subsurface, Figure 18, which indicates that the lubricant is still controlling friction.

The reduced friction coefficient for neat PEK at $1.0 \mathrm{MPa}$ relative to reinforced PEK when lubricated by trimellitate ester is due to a greater PEK-steel interaction caused by a less stable lubricant film than at $0.5 \mathrm{MPa}$. Neat PEK will produce lower interfacial shear strength than reinforced PEK under these conditions. Even at 1.0MPa, lubrication of even neat PEK is fairly stable. Stable lubrication of neat PEK was not achievable at 1.5MPa for either lubricant. The greater polarity and, therefore, the stronger the physical bonds of the trimellitate ester to the component surfaces makes it a more effective lubricant under marginal conditions than the pentaerythritol ester which does not have the aromatic ring in its structure. Conversely, the pentaerythritol structure has a higher thermal and oxidative stability because of the absence of an aromatic ring structure.

\subsection{Supply of Lubricant to the Contact}

When a lubricant is applied intermittently, following that application an initially thick film of lubricant will rapidly form a thin film which, if properly chosen and suitably applied, can produce stable tribological conditions for a practicable duration before re-lubrication is required, Figure 10. Under the test conditions used in this work, the thin film of lubricant allows the contact to operate in the mixed lubrication regime at lower contact pressures and in the boundary regime at higher contact pressures. This underlines the sensitivity of thin-film lubrication, especially when it is applied intermittently.

3.5.1 For Trimellitate Ester Lubrication: A lubricant that forms an effective thin film, such 
as the trimellitate ester, appeared to be limited by its thermal stability when the contact temperature was high: thermal decomposition caused the lubricating film to be ineffective. This failure was observed as an extremely short period of steady operation after re-lubrication, Figure 10, with a higher friction coefficient and increased bulk material removal from the polymer surface, Figure 9, with deposits of thermally decomposed lubricant in the wear track and/or the transfer of polymer material to the steel counterface, Figure 7. Intermittent lubrication is likely to limit the effectiveness of such residence-time-limited lubrication: if properly applied, continuous lubrication at the same average rate can increase the quantity of the supplied lubricant that passes through the contact. The stability of lubrication is then limited by the supply rate than the decomposition rate of a marginal steady-state lubrication film.

Figure 19 shows the complexities of the above observations. For a PEK composite pin with $30 \%$ wt carbon-fibre against steel at $8 \mathrm{~ms}^{-1}$, at $1 \mathrm{MPa}$ contact pressure at $150^{\circ} \mathrm{C}$, lubricated using the trimellitate ester described above, the lubricant supply rate is varied for both continuous and intermittent lubrication. There appears to be an optimum quantity for intermittent lubrication, above which there is an increase in friction coefficient.

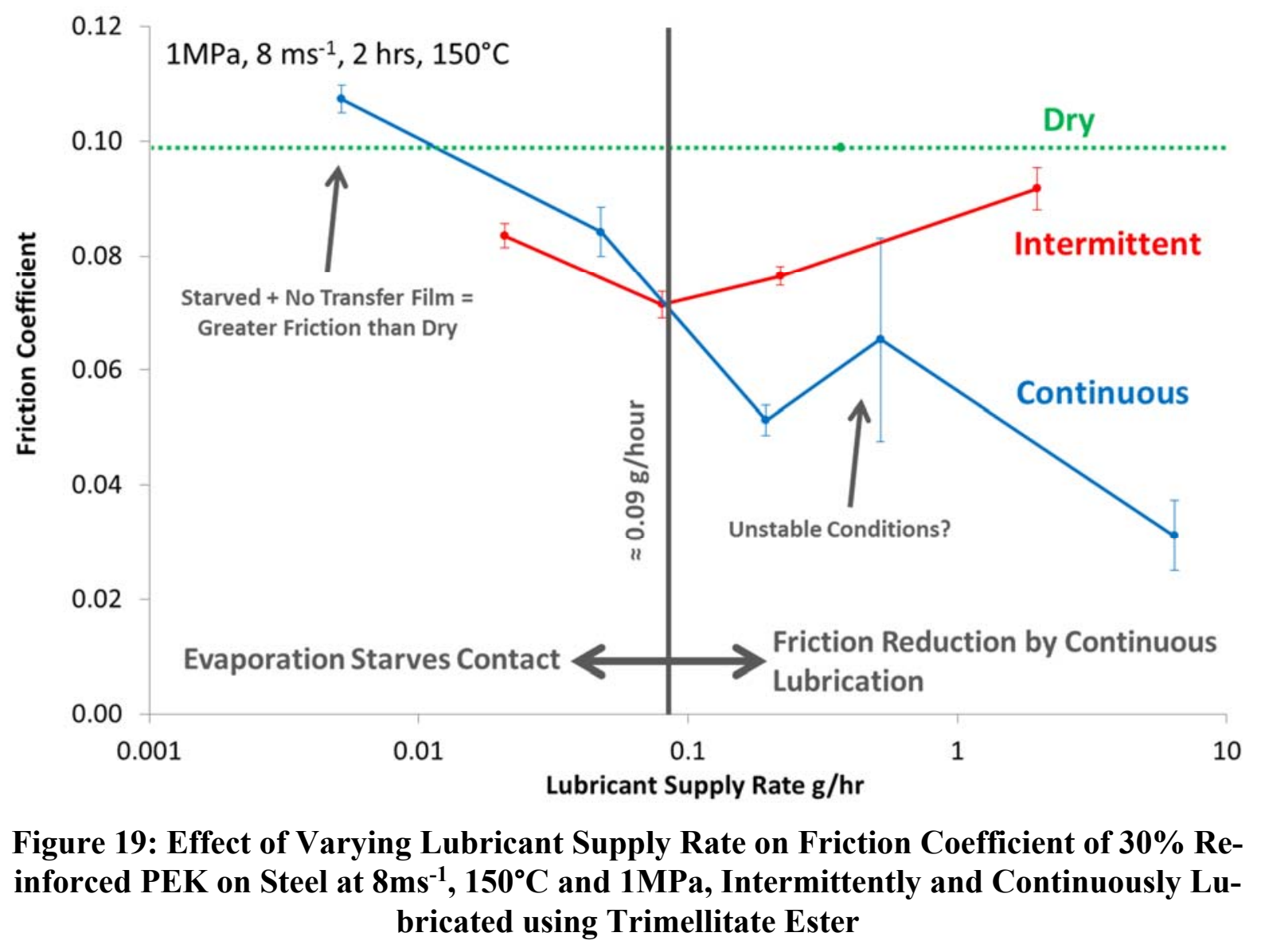


Continuous lubrication is highly sensitive to flow rate. At high flow rates, the film thickness is very high and friction coefficients are extremely low. At very low flow rates, friction coefficients are higher than for an unlubricated contact under these conditions: at $1 \mathrm{MPa}$, the transfer film in unstable. Therefore, the small quantity of continuous lubricant supply must further destabilise the transfer film, probably reducing the adhesion of the polymer to the steel counterface, producing a deleterious effect. There is therefore a critical supply rate for this lubricant under these conditions below which continuous lubrication is less effective at reducing friction than intermittent lubrication: the intermittent flooding of the contact produced can replenish the boundary film in way that the continual starvation of the continuously lubricated contact cannot. Above the critical flow rate, continuous lubrication is more effective at reducing friction: continuous lubrication produces a higher and steady film thickness ratio ( $\lambda$, see [7]), whereas increasing the supply rate of intermittent lubrication has negligible benefit as the steady-state film thickness will not increase significantly, only the quantity of lubricant that initially flushes the contact will increase. In an industrial context, the flushing effect may be advantageous in removing debris, decomposed lubrication and contaminants from the contact; a larger flushing volume may be required for larger components. Nonetheless, continuous lubrication appears to provide the most stable and tuneable lubrication.

3.5.2 For Pentaerythritol: When pentaerythritol ester is used as the lubricant, higher contact temperatures can be reached before failure of the lubricant by thermal and oxidative decomposition, as indicated by the onset of oxidation being higher than for the trimellitate ester. However, it is apparent that because the pentaerythritol ester has a lower polarity, it does not wet the steel surface as effectively as the trimellitate ester and, therefore, forms a thinner and less strongly adsorbed film. Under thin film, marginal conditions, this produces greater interaction between the polymer and steel surface. This causes more fibre pull-out and plastic deformation, giving a higher friction coefficient due to the greater energy dissipation in these processes, Figure 9. It is clear that the steady state lubricant film is marginal or starved, depending on the conditions. Lubrication is limited by the inability of a lubricant to form a well-adsorbed film, especially in boundary regions, and will manifest as higher friction and greater material removal from the polymer surface when under steady state and apparently stable lubrication conditions. This may also produce shortened component wear life.

Because the mechanical and tribological properties of PEK composite and its composites are highly dependent on temperature, especially around $\mathrm{T}_{\mathrm{g}}$, the system temperature has a significant 
effect on lubrication. In addition, an increased system temperature when the lubricant is present as a thin film gives an increase in evaporation, reduced viscosity. The higher surface-area-tovolume ratio will increase the rate of chemical and/or physical reactions with the air and steel. Because of all these factors, increasing system temperatures will tend to make lubricant films more marginal or starved: lubrication limited by system temperature will limit the energy that can be added tribologically into the system before either starvation, surface melting or thermal decomposition of the lubricant occurs. In theory, reducing the system temperature may allow higher loads, speeds or lubricant supply rates to be achieved (i.e. more capacity for tribological energy input): however, the frictional energy at lower temperatures may be higher if lubrication is marginal, as PEK and PEK composites have higher shear strength at lower temperature. Essentially, the optimisation of a high temperature lubricated polymer-steel contact is not straightforward.

As with temperature, lubrication limited by speed is not a trivial problem. Broadly, there is lower variation in friction coefficient and lubrication with speed than with contact pressure. However, lubrication limited by speed will manifest in several potential ways seen here: Firstly, higher speed contacts may reach a starved state more quickly if lubricant is flung-off or rapidly sheared out of the contact area. Secondly, as increasing the speed increases the frictional energy input, higher speed contacts can cause higher contact temperatures, Figure 11, which will accelerate the rate of thermal decomposition of the lubricant, which will be seen by a disproportionately higher friction power loss and, perhaps, the second-run-in behaviour observed when thermal stability limits lubrication, Figure 11,

Because of the nature of intermittent lubrication, the limiting factor is the effectiveness of the steady-state lubricant film that can form after re-lubrication. In an industrial context, this is defined by, firstly, whether this film can provide sufficiently low friction and sufficiently low damage to component surfaces, and, secondly, whether this steady-state will last an acceptable duration before re-lubrication is required so that lubricant consumption is practical and economical. Therefore, if intermittent lubrication is limiting the machine performance, this will manifest as excessive lubricant consumption (either increasing quantities in each dose, or frequency is too high) without significant reduction in friction or increase in component life. If intermittent lubrication is the limiting factor, then continuous lubrication may improve the effectiveness of operation, albeit intermittent lubricant flushes may be required for debris and deposit control. 


\section{Implications for Industrial Lubrication}

\subsection{Effective Lubrication of PEK/Steel Contacts}

This study indicates that PEK, whilst not an ideal tribomaterial under conditions around its glass transition, $T_{g}$, can be made effective by suitable lubrication whilst still retaining some of the benefits of a polymer-steel system e.g. lack of seizure and galling at lubrication breakdown.

Most tribological systems containing PEK use fibre-reinforcement, for which $30 \% \mathrm{wt}$ carbon fibre whiskers appears to be the most widely used combination. The reasons for this are clearly seen: carbon fibre reinforcement improves the thermal conductivity of the PEK and, therefore, reduces the interface temperature by allowing greater heat dissipation. Also, fibre reinforcement improves the resistance of the composite to plastic flow under high temperature shear and when the polymer is molten.

Several other studies on lubricated PEEK-steel contacts report excessively high wear when a lubricant is used, $[22,26]$. This is because the lubricants these researchers used, often water, were not able to support a stable lubricating film under the test conditions. However, as shown here, judicious lubricant selection can produce stable friction under representative conditions. For high temperature sliding PEK-steel systems, trimellitate esters and other polyol esters are suitable lubricants.

\subsection{Differentiation Between Synthetic Ester Lubricants}

It is clear that, under all but the most extreme conditions, the trimellitate ester outperforms the pentaerythritol ester in terms of friction reduction and prevention of unstable wear mechanisms. This is due to the high polarity of the trimellitate structure, which allows a stable and resilient film to form at the interface, even under marginal and starved conditions. However, at extreme conditions, where the thermal stability of the lubricant is more critical, the pentaerythritol ester is more effective. Therefore, judicious selection of base ester for high temperature PEK-steel systems is required or an optimised formulation of both.

\subsection{The Lubrication Cycle and Marginal Lubrication}

The lubrication cycle used here, using regular doses leading to marginal lubrication, is often seen in industry. Whilst such an approach often allows other lubrication-related factors (e.g. evaporation) to be controlled, intermittent and marginal lubrication is not ideal from the perspective of controlling friction. Continuously supplied lubricant can provide more stable friction [28]. Lubricant consumption can be reduced if continuous lubrication is used effectively, 
as more of the applied lubricant passes usefully through the contact. Intermittent lubrication can produce steady conditions but a lower friction coefficient and, therefore, lower friction power loss can be achieved using continuous lubrication. Nonetheless, some industrial systems may benefit from occasional flushes of lubricant to remove debris and contamination.

The use of PEK composite in high temperature lubricated contacts has to be carefully managed. When unlubricated, operation in the glass transition region can be extremely unstable, especially with regard to friction variation with temperature [28]. Generally, if lubrication is marginal or starved, operation in the $\mathrm{T}_{\mathrm{g}}$ region is not recommended for polymer systems. However, a suitable lubricant can produce stable friction behaviour if the system can operate at the higher film thickness ratio $(\lambda)$ end of the mixed lubrication regime. This reduces the influence of polymer-steel interaction on the overall behaviour of the system and, therefore, reduces or removes the instability caused by the glass transition of the polymer. 


\section{Conclusions}

High temperature, high speed PEK composite-steel sliding contacts were lubricated intermittently with different synthetic esters under a range of conditions. Many of these conditions were in the $\mathrm{T}_{\mathrm{g}}$ region of $\mathrm{PEK}$.

(i) Under many conditions, trimellitate ester was found to be a more effective lubricant for PEK composite-steel systems as it was able to form a stable lubrication film, even under marginal conditions. However, it was limited at very high temperatures by thermal and oxidative decomposition,

(ii) The higher thermal stability of pentaerythritol ester meant that it was able to provide lubrication under more extreme conditions than trimellitate ester. However, as the thermally stable pentaerythritol structure meant that it was less polar, it did not form as high a quality lubricant film under less extreme conditions,

(iii) Suitable operation of high-speed, high temperature PEK composite-steel contacts is possible using a suitable lubricant. In marginal lubrication, a lubricant that produced sufficient of a film on the component surfaces and at the interface kept the lubrication at the higher $\lambda$ end of the mixed lubrication regime. This reduced the PEK composite-steel interaction and, therefore, reduced the instability of this interaction under these conditions, particularly around $\mathrm{T}_{\mathrm{g}}$ and particularly with regard to temperature sensitivity. 


\section{Acknowledgements}

This research was initiated as part of an industrial-academic collaboration between ROCOL and the University of Leeds, financially supported and facilitated by an Innovate UK Knowledge Transfer Partnership (KTP) grant, No. 8092. The PEK materials were supplied by Victrex PLC. 


\section{$7 \quad$ References}

1. Data from Victrex plc. www.victrex.com, 2013.

2. Data from Arkema France. www.arkema.com, 2013.

3. Goyal, R.K., et al., Dynamic Mechanical Properties of Al2O3/Poly(ether ether ketone) Composites. Journal of Applied Polymer Sciences, 2007. 104: p. 568-575.

4. Lin, Y.-X., C. Gao, and M. Chen, Thermomechanical Properties and Tribological Behaviour of CaCO3 Whisker-Reinforced Polyetheretherketone Composites. Proceedings of the IMechE Part J: Journal of Engineering Tribology, 2009. 223: p. 1013-1018.

5. Briscoe, B.J., B.H. Stuart, and S. Sebastian, The Failure of Poly(Ether Ether Ketone) in High Speed Contacts. Wear, 1993. 162-164: p. 407-417.

6. Stachowiak, G.W. and A.W. Batchelor, Engineering Tribology2005: Elsevier Butterworth-Heinemann.

7. $\quad$ Bhushan, B., Introduction to Tribology2002: Wiley \& Sons.

8. Glaesser, W.A., Materials for Tribology. Tribology Series Number 201992: Elsevier.

9. Davim, J.P. and R. Cardoso, Effect of the Reinforcement (Carbon or Glass Fibres) on Friction and Wear Behaviour of the PEEK against Steel Surface at Long Dry Sliding. Wear, 2009. 266: p. 795-799.

10. Friedrich, K., Z. Lu, and A.M. Hager, Overview on Polymer Composites for Friction and Wear Application. Theoretical and Applied Fracture Mechanics, 1993. 19: p. 1-11.

11. Friedrich, K., Z. Lu, and A.M. Hager, Recent Advances in Polymer Composites' Tribology. Wear, 1995. 190: p. 139-144.

12. Rabinowicz, E., Friction and Wear of Materials1995: Wiley.

13. Bijwe, J. and Nidhi, Potential of Fibers and Solid Lubricants to Enhance the Tribo-Uility of PEEK in Adverse Operating Conditions. Industrial Lubrication and Tribology, 2007. 59(4): p. 156-165.

14. Bijwe, J., S. Sharma, and M. Sharma, Exploration of Potential of Solid Lubricant and Short Fibers in Polyetherketone (PEK) Composites. Wear, 2013. 301(1-2): p. 810-819.

15. Jacobs, O., et al., On the Effect of Counterface Material and Aqueous Environment on the Sliding Wear of Various PEEK Materials. Tribology Letters, 2005. 18(3): p. 359-372.

16. Schelling, A., H.H. Kausch, and A.C. Roulin, Friction Behaviour of Polyetheretherketone under Dry Reciprocating Movement. Wear, 1991. 151: p. 129-142.

17. Theiler, G. and T. Gradt, Friction and Wear of PEEK Composites in Vacuum Environment. Wear, 2010. 269: p. 278-284.

18. Zhang, Z., et al., Wear of PEEK Composites Related to their Mechanical Performances. Tribology International, 2004. 37: p. 271-277.

19. Theiler, G. and T. Gradt, Influence of the Temperature on the Tribological Performance of PEEK Composites in Vacuum Environment. IOP Journal of Physics: Conference Series, 2008. 100: p. 1-4.

20. Cannaday, M.L. and A.A. Polycarpou, Tribology of Unfilled and Filled Polymeric Surfaces in Refrigerant Environment for Compressor Applications. Tribology Letters, 2005. 19(4): p. 249-262.

21. Chiu, P.Y., et al., Design of Low Wear Polymer Composites. Tribology Letters, 2012. 45: p. 79-87.

22. Mens, J.W.M. and A.W.J. De-Gee, Friction and Wear behaviour of 18 Polymers in Contact with Steel in Environments of Air and Water. Wear, 1991. 149: p. 255-268.

23. Sinmazcelik, T. and T. Yilmaz, Thermal Aging Effects on Mechanical and Tribological Performance of PEEK and Short Fiber Reinforced PEEK Composites. Materials and Design, 2007. 28: p. 641-648.

24. Briscoe, B.J., T.A. Stolarski, and G.J. Davies, Boundary Lubrication of Thermoplastic Polymers in Model Fluids. Tribology International, 1984. 17(3): p. 129-137.

25. Stolarski, T.A., Wear of Water-Lubricated Composite Materials. Wear, 1980. 58: p. 103-108.

26. Yamamoto, Y. and T. Takashima, Friction and Wear of Water Lubricated PEEK and PPS Sliding Contacts. Wear, 2002. 253: p. 820-826.

27. Booser, E.R., Tribology Data Handbook: An Excellent Friction, Lubrication and Wear Resource1997: CRC Press.

28. Dyson, C.J., et al., The Tribological Behaviour of Carbon Fibre Reinforced Polyaryletherketones (PAEKs) through their Glass Transitions. Proceedings of the IMechE Part J: Journal of Engineering Tribology, 2015.

29. Hanchi, J. and N.S. Eiss, Preliminary Study of the Elevated Temperature Tribological Behavior of Poly(Ether-Ether-Ketone)-Based In Situ Composites Under Unlubricated Sliding Conditions. Tribology Transactions, 1995. 38(2): p. 305-310.

30. Hanchi, J. and N.S. Eiss, Dry Sliding Friction and Wear of Short Carbon-Fiber-Reinforced Polyetheretherketone (PEEK) at Elevated Temperatures. Wear, 1997. 203-204: p. 380-386. 
31. Zhang, G., et al., Temperature Dependence of the Tribological Mechanisms of Amorphous PEEK (Polyetheretherketone) under Dry Sliding Conditions. Acta Materialia, 2008. 55: p. 2182.

32. Davim, J.P., N. Marques, and A.M. Baptista, Effect of Carbon Fibre Reinforcement in the Friction Behaviour of PEEK in a Water Lubricated Enviornment. Wear, 2001. 251: p. 1100-1104.

33. Stolarski, T.A., Tribology of Polyetheretherketone. Wear, 1992. 158: p. 71-78.

34. Zhang, G. and A.K. Schlarb, Morphologies of the Wear Debris of Polyetheretherketone Produced Under Dry Sliding Conditions: Correlation with Wear Mechanisms. Wear, 2009. 266: p. 745-752.

35. Briscoe, B.J. and S.K. Sinha, Wear of Polymers. Proceedings of the IMechE Part J: Journal of Engineering Tribology, 2002. 216: p. 401-413.

36. Dyson, C.J., et al., High Speed and High Temperature Lubrication of PEK/Steel Sliding Contacts, in STLE Annual Meeting, 2012, St Louis, Missouri, USA2012.

37. Tabata, H., M. Yamane, and M. Sano, High-Speed Sliding Wear Behavior of PEEK Coating, in 5th World Tribology Congress, Torino, Italy2013.

38. Harsha, A.P. and U.S. Tewari, Tribological Studies on Glass FIber Reinforced Polyetherketone Composites. Journal of Reinforces Plastics and Composites, 2004. 23(1).

39. Harsha, A.P., R. Waesche, and M. Hartelt, Tribological Studies on Polyetherketone Composite under Reciprocating Sliding Condition Against Steel Cylinder. Proceedings of the IMechE Part J: Journal of Engineering Tribology, 2015. 229(7): p. 795-806.

40. Scholes, S.C. and A. Unsworth, The Wear Performance of PEEK-OPTIMA Based Self-Mating Couples. Wear, 2010. 268: p. 380-387.

41. Bely, V.A., A.I. Sviridenok, and M.I. Metrokovets, Friction and Wear in Polymer-Based Materials1982: Franklin Book Co.

42. Brostow, W. and R. Corneliusson, Failure of Plastics 1987: Hanser MacMillan.

43. Swallowe, G.M., Mechanical Properties and Testing of Polymers: An A-Z Reference 1999: Springer. 


\section{Figures}

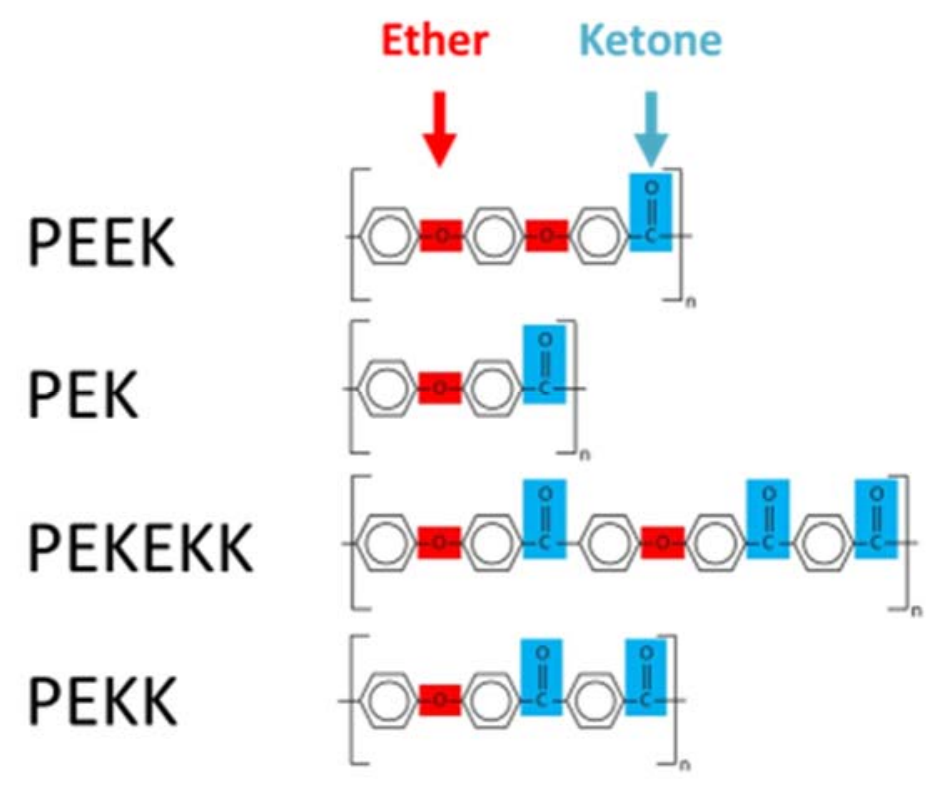

Figure 1: Fundamental Units for the PolyArylEtherKetone (PAEK) Family

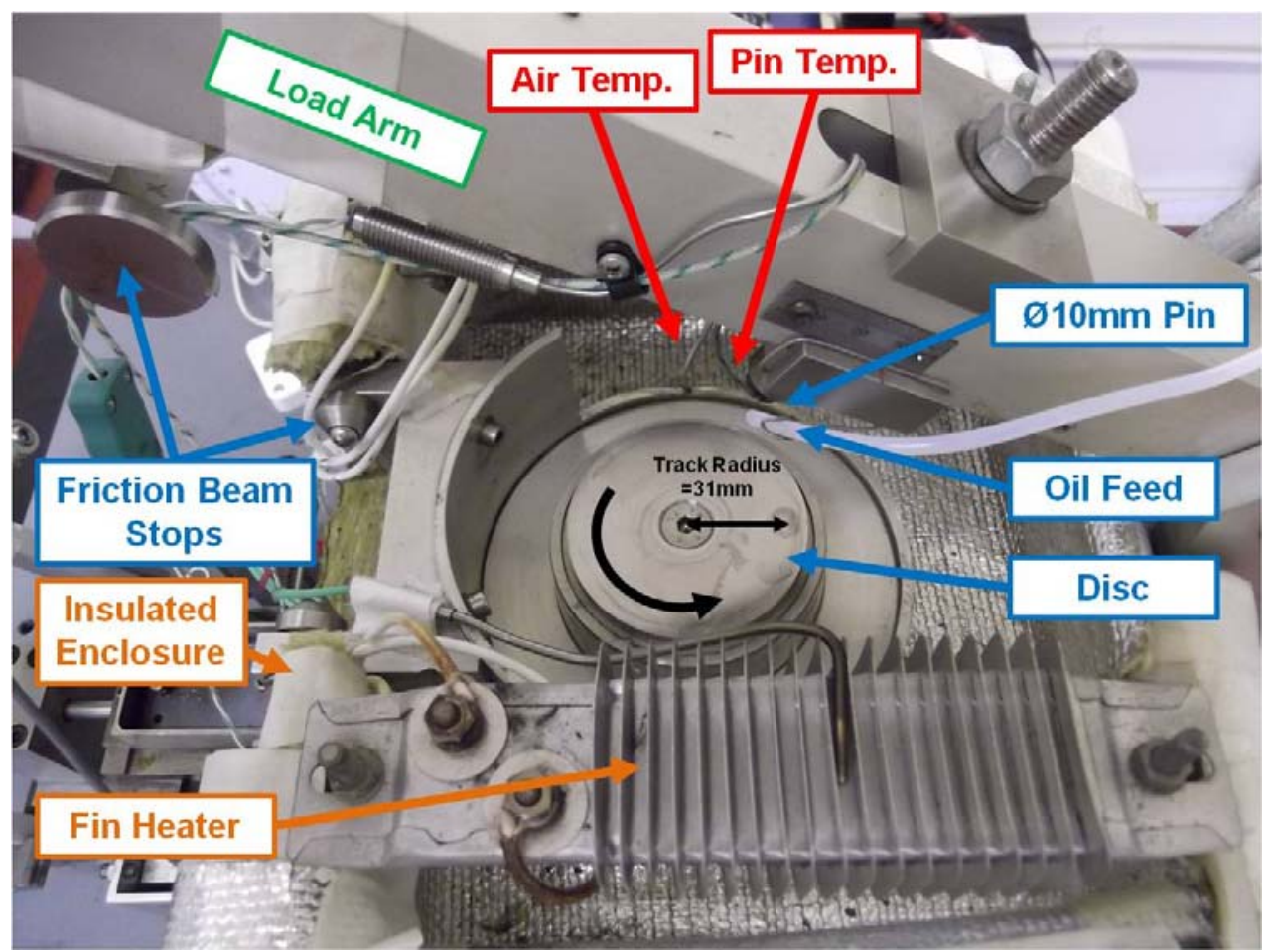

Figure 2: Pin-on-Disc Tribometer 


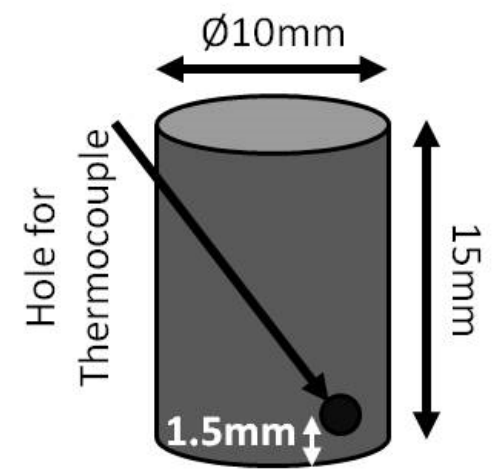

Figure 3: PEK Test Pin Geometry

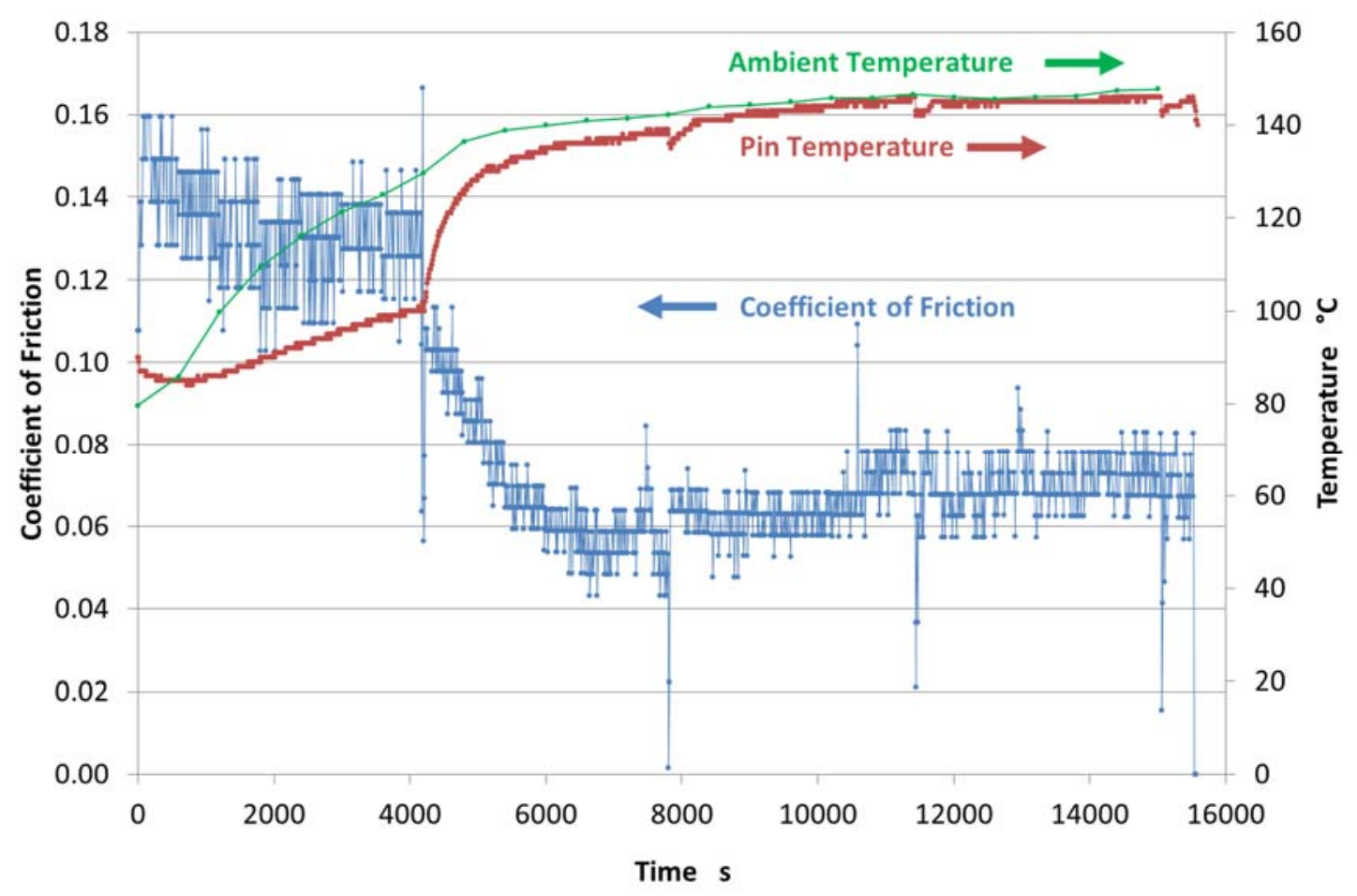

Figure 4: Typical Test Cycle: Trimellitate Ester on Carbon Fibre-Reinforced PEK at $0.5 \mathrm{MPa}, 150^{\circ} \mathrm{C}$ and $8 \mathrm{~ms}^{-1}$ 


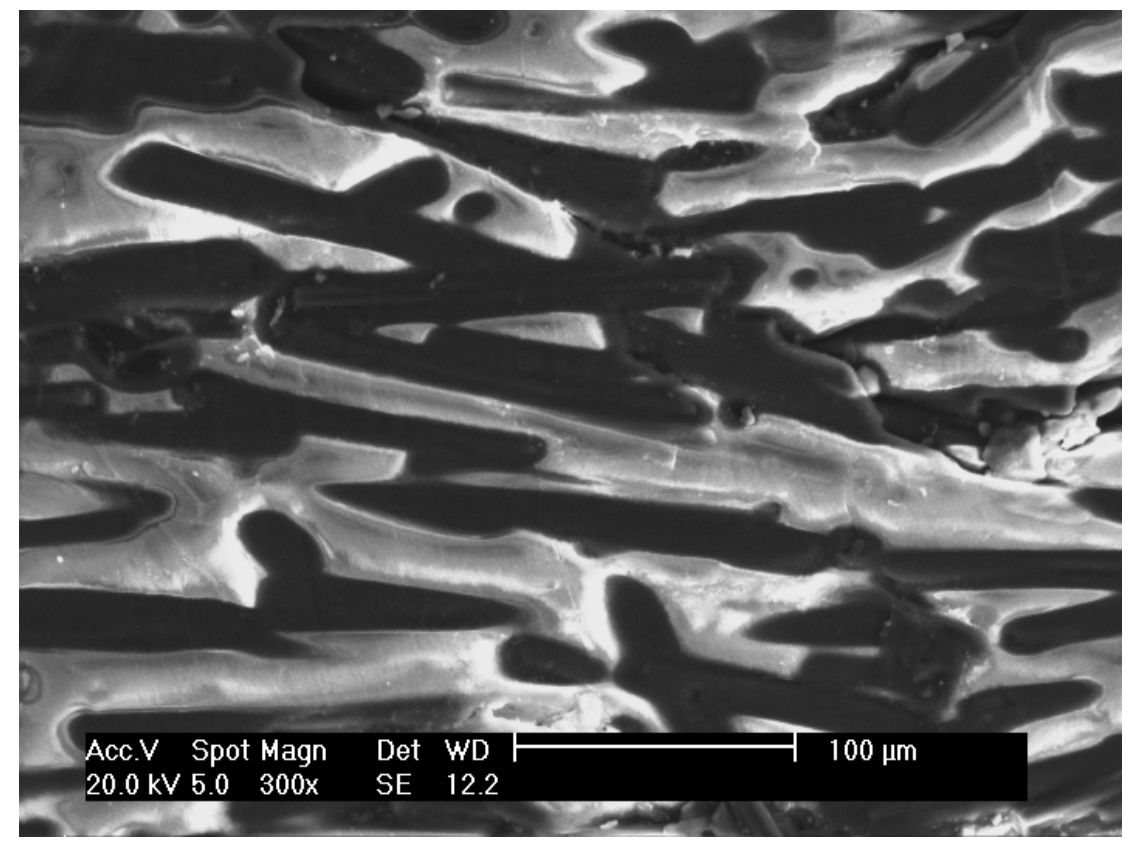

Figure 5: SEM Image of Fresh PEK + 30\% Carbon Fibre Surface Showing Carbon Fibres 


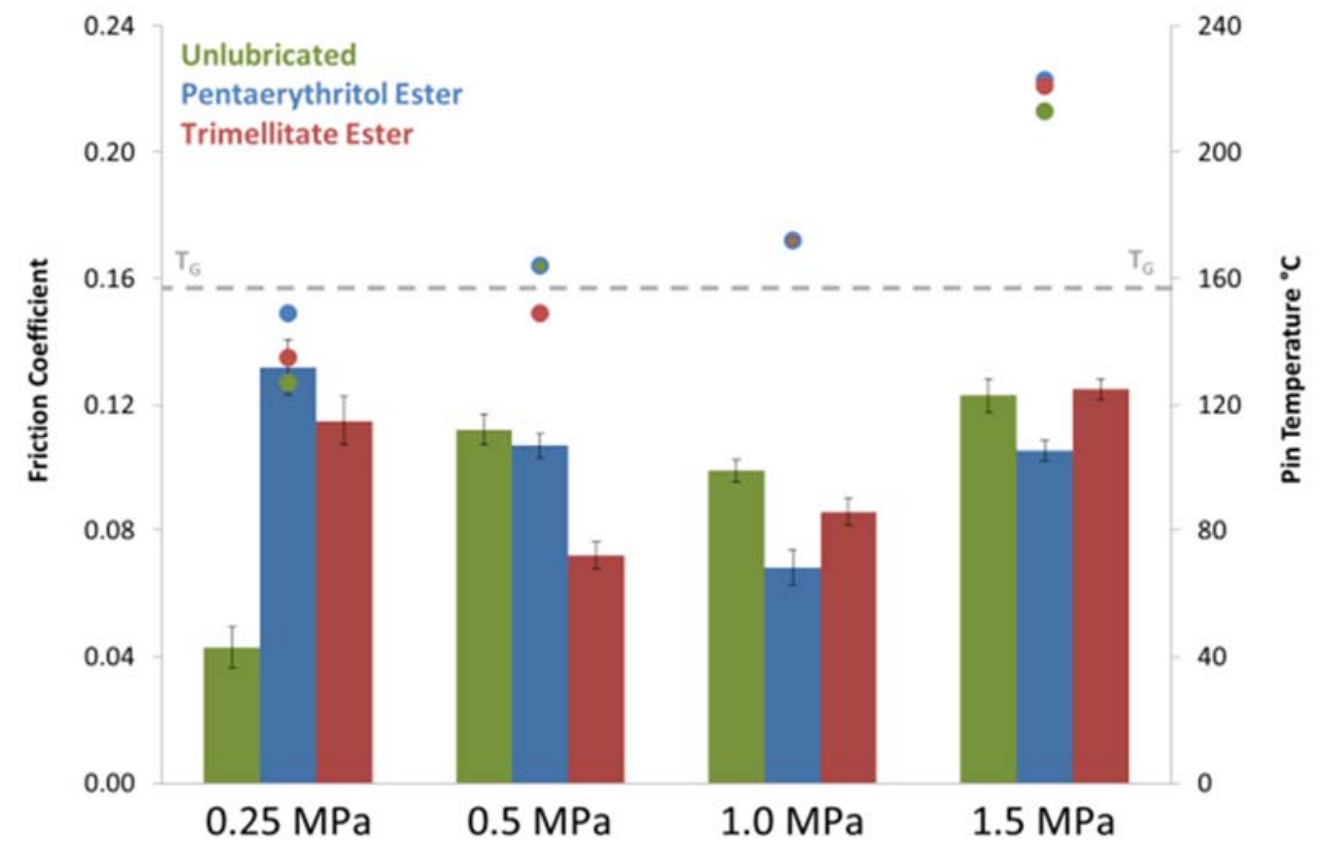

Figure 6: Variations in Friction Coefficients and Pin Temperatures with Contact Pressure, $8 \mathrm{~ms}^{-1}$ and $150^{\circ} \mathrm{C}$ (Columns - Friction Coefficient; Dots - Pin Temperature)

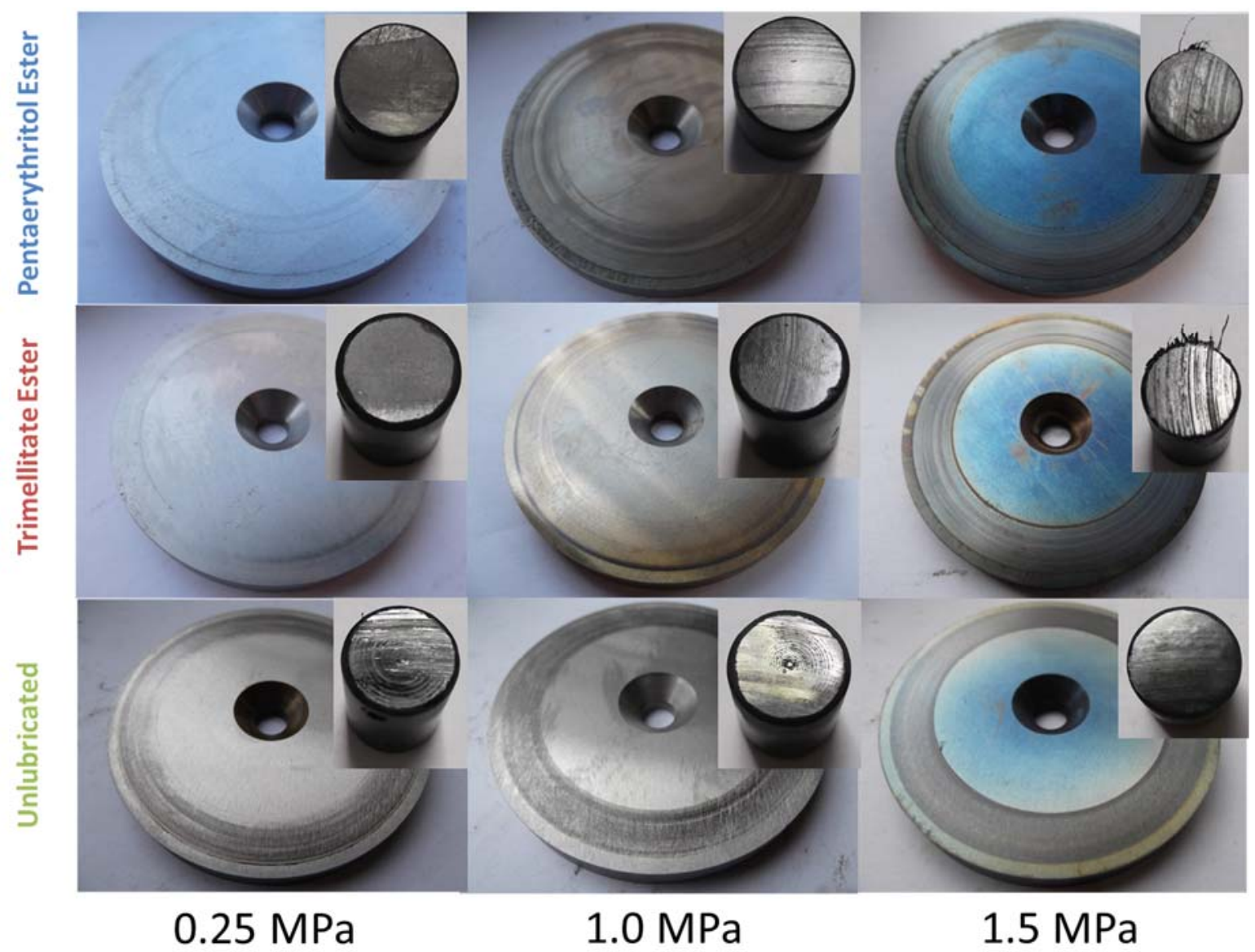

Figure 7: Disc and Pin Images - Effect of Varying Contact Pressure, 0.25 to 1.5MPa, at $8 \mathrm{~ms}^{-1}$ and $150^{\circ} \mathrm{C}$ Air Temperature 

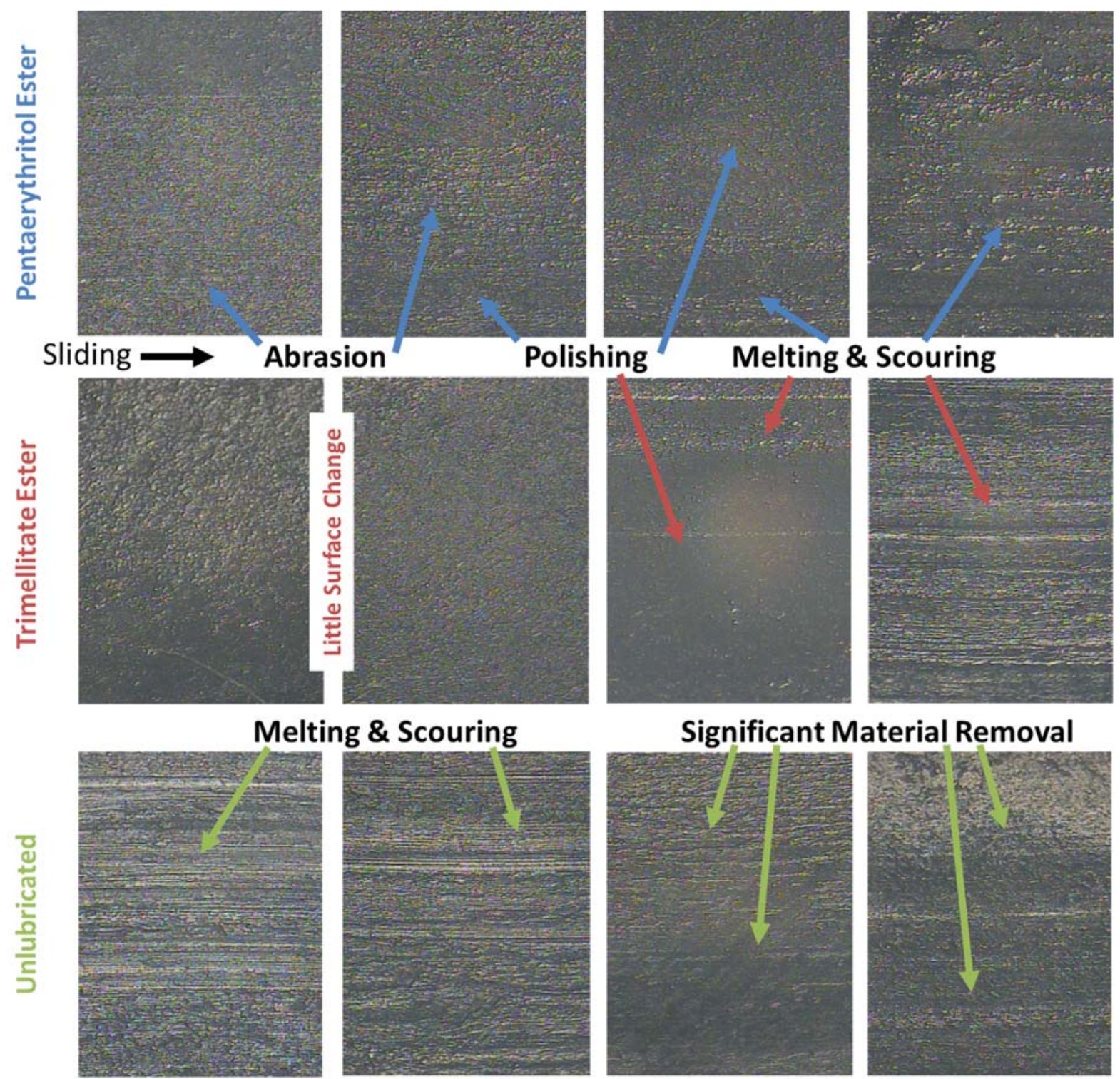

Significant Material Removal
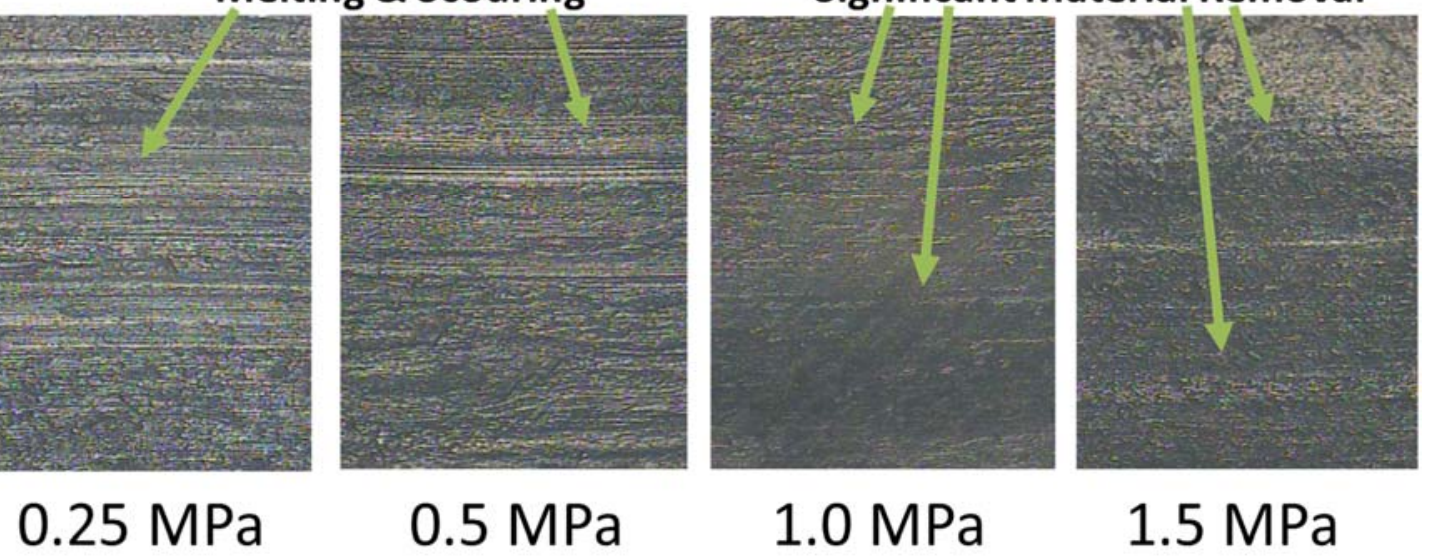

$1.5 \mathrm{MPa}$

Figure 8: Optical Microscope Images of Pin Surfaces: Effect of Varying Contact Pressure at $8 \mathrm{~ms}^{-1}$ and $150^{\circ} \mathrm{C}$ Air Temperature 

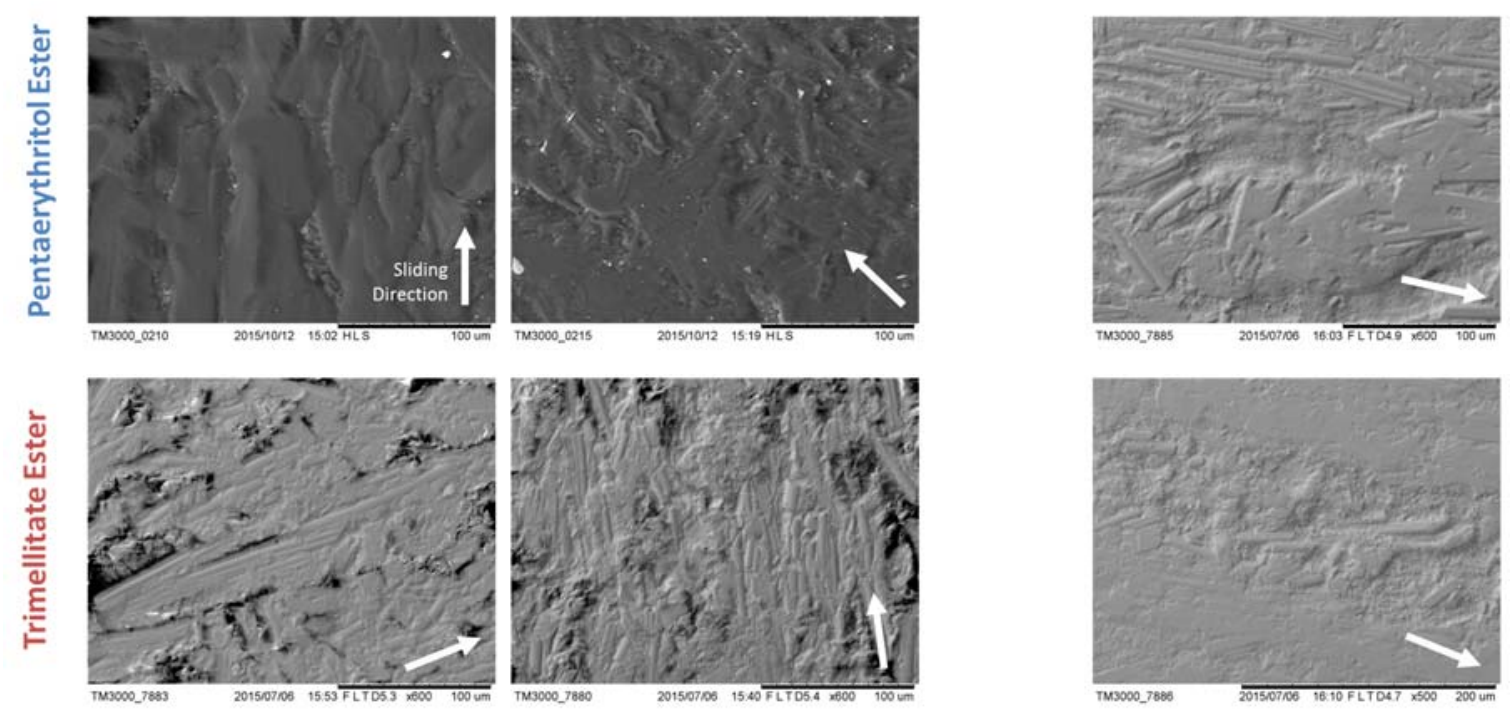

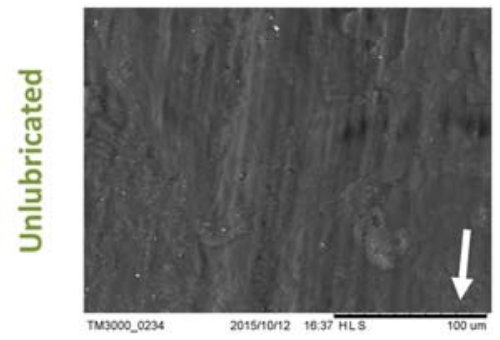

$0.25 \mathrm{MPa}$

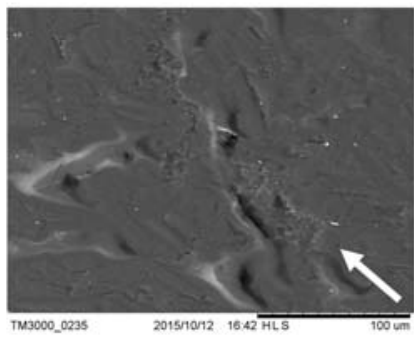

$0.5 \mathrm{MPa}$

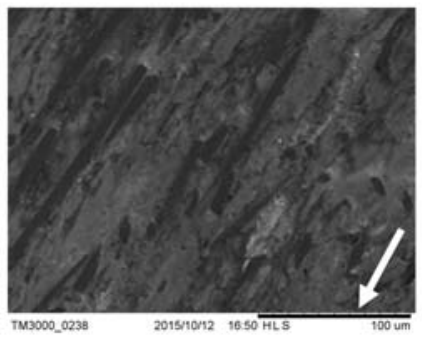

$1.5 \mathrm{MPa}$

Figure 9: SEM Images of Pin Surfaces: Effect of Varying Contact Pressure at $8 \mathrm{~ms}^{-1}$ and $150^{\circ} \mathrm{C}$ Air Temperature

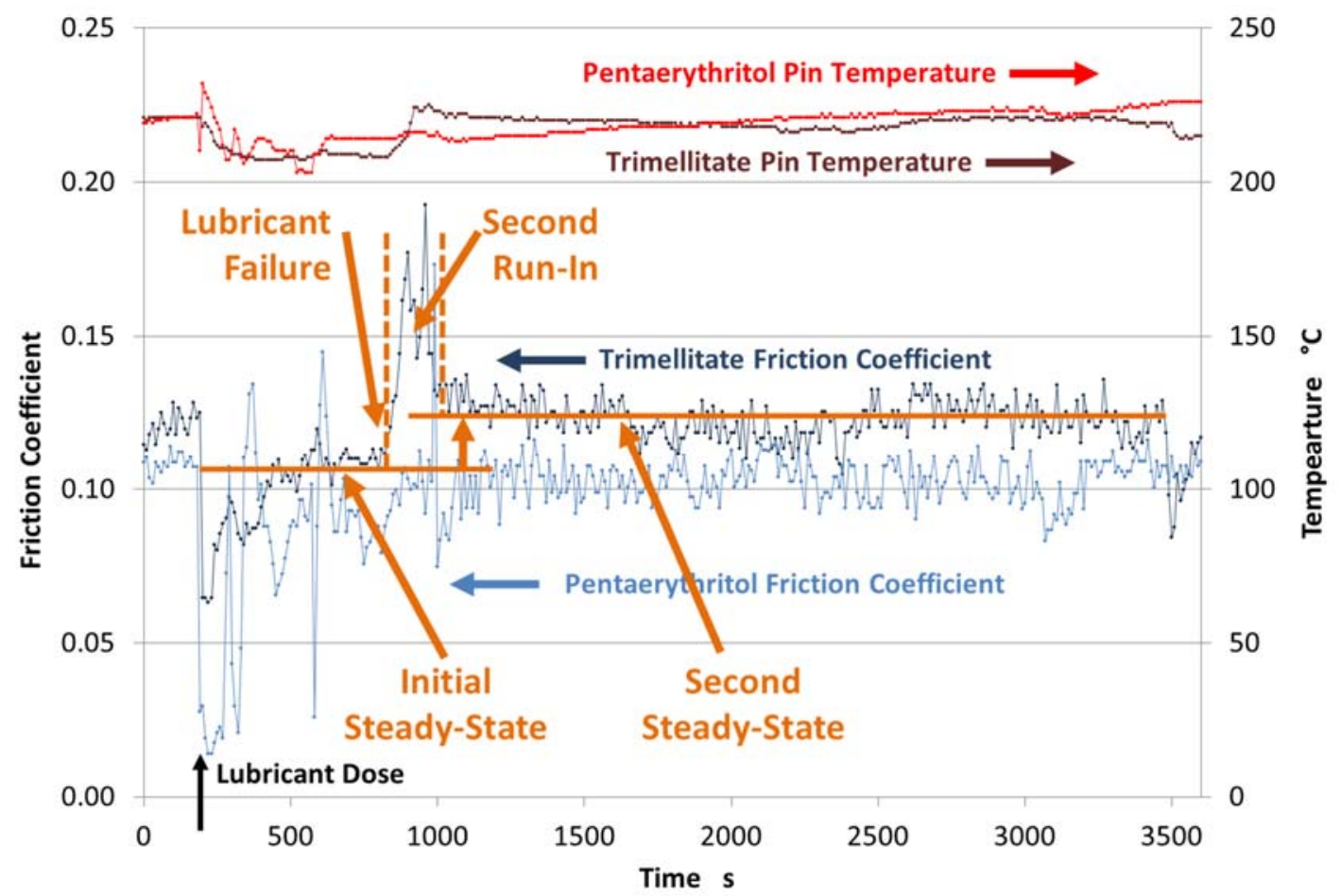

Figure 10: Friction Coefficient and Pin Temperature over a Single Lubrication Cycle 


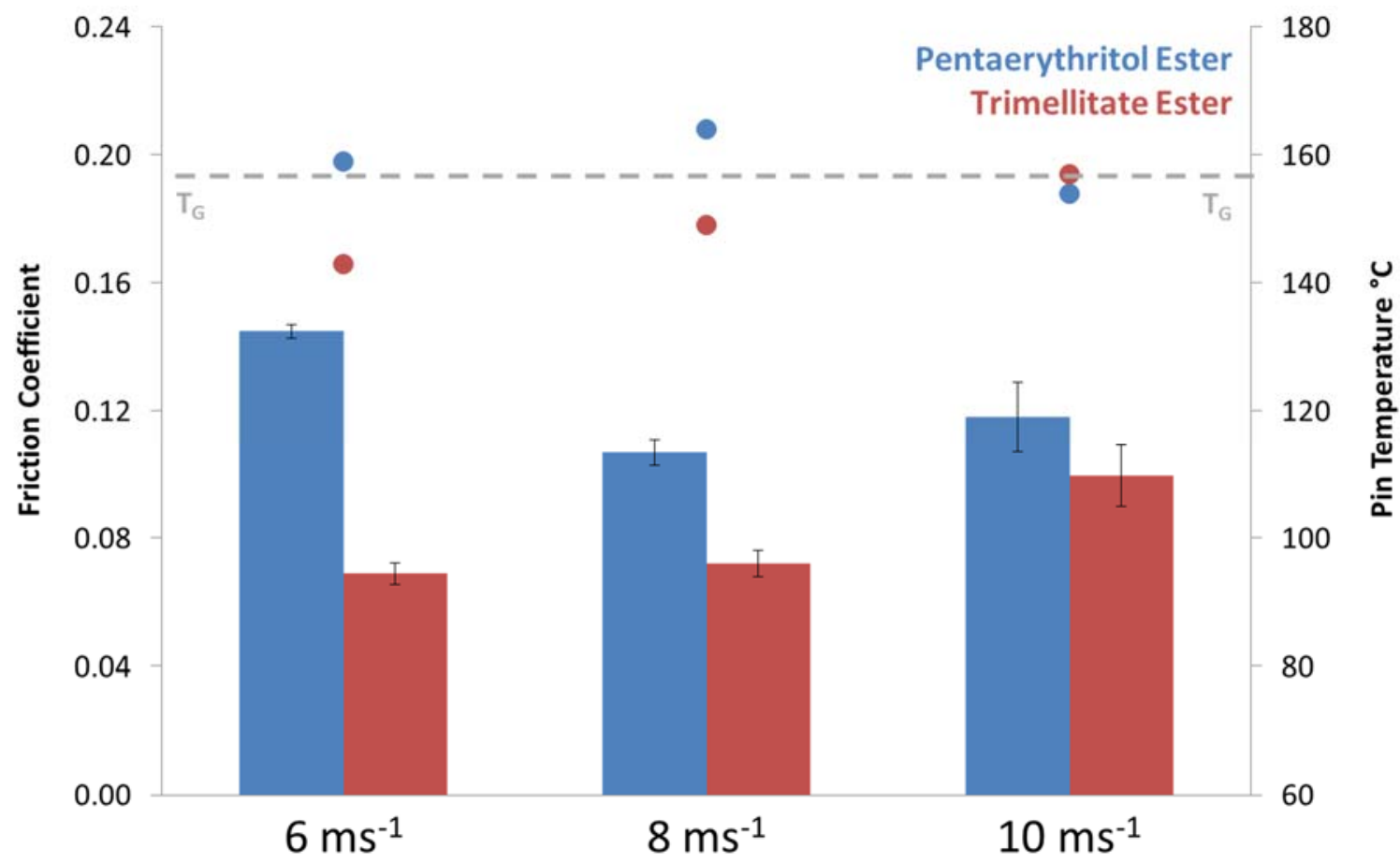

Figure 11: Variations in Friction Coefficients and Pin Temperatures with Average Sliding Speed at $0.5 \mathrm{MPa}$ and $150^{\circ} \mathrm{C}$. (Columns - Friction Coefficient, Dots - Pin Temperature)

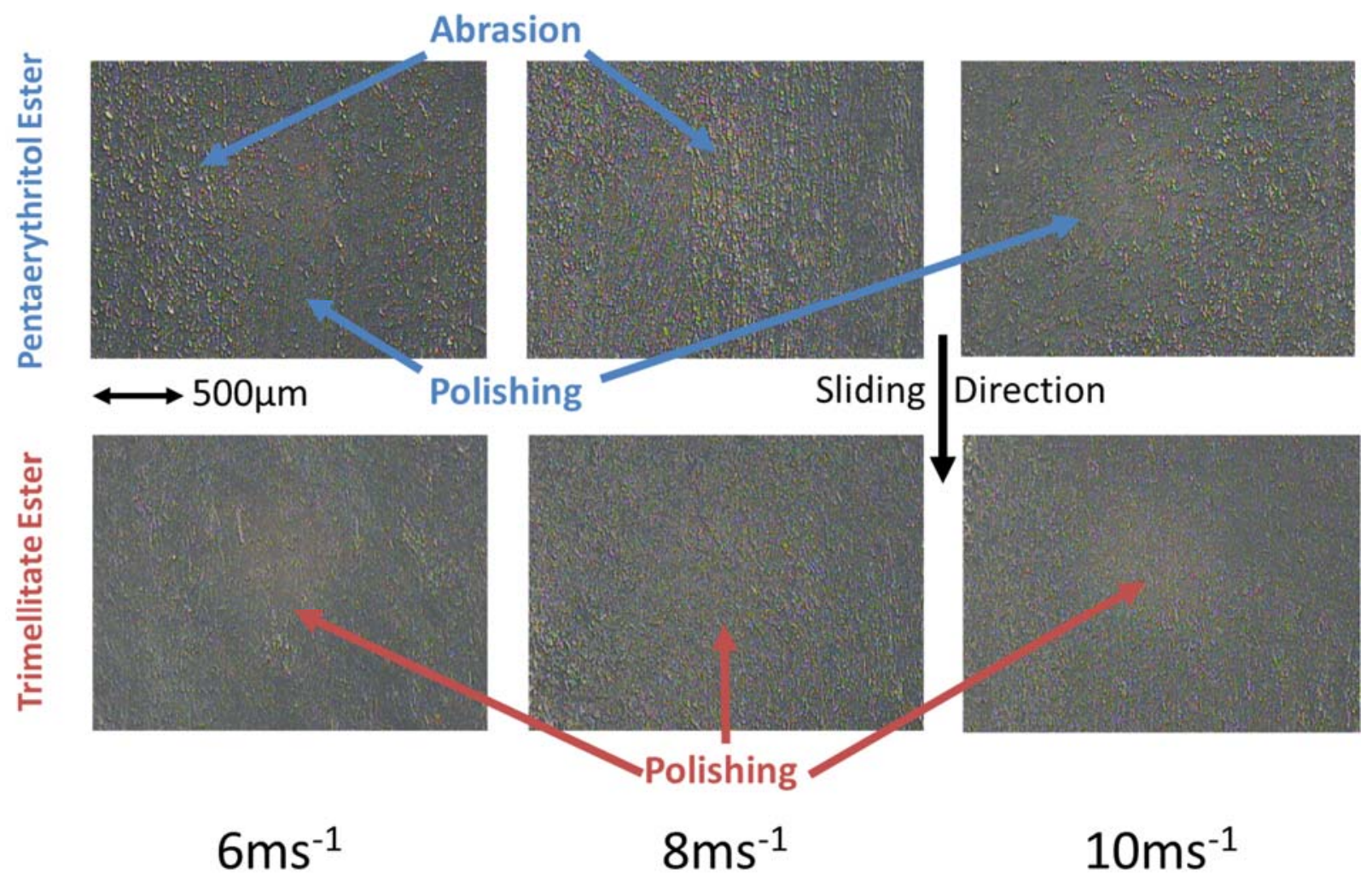

Figure 12: Optical Microscope Images of Pin Surfaces: The Effect of Varying Average Speed at $0.5 \mathrm{MPa}$ and $150^{\circ} \mathrm{C}$ Air Temperature 


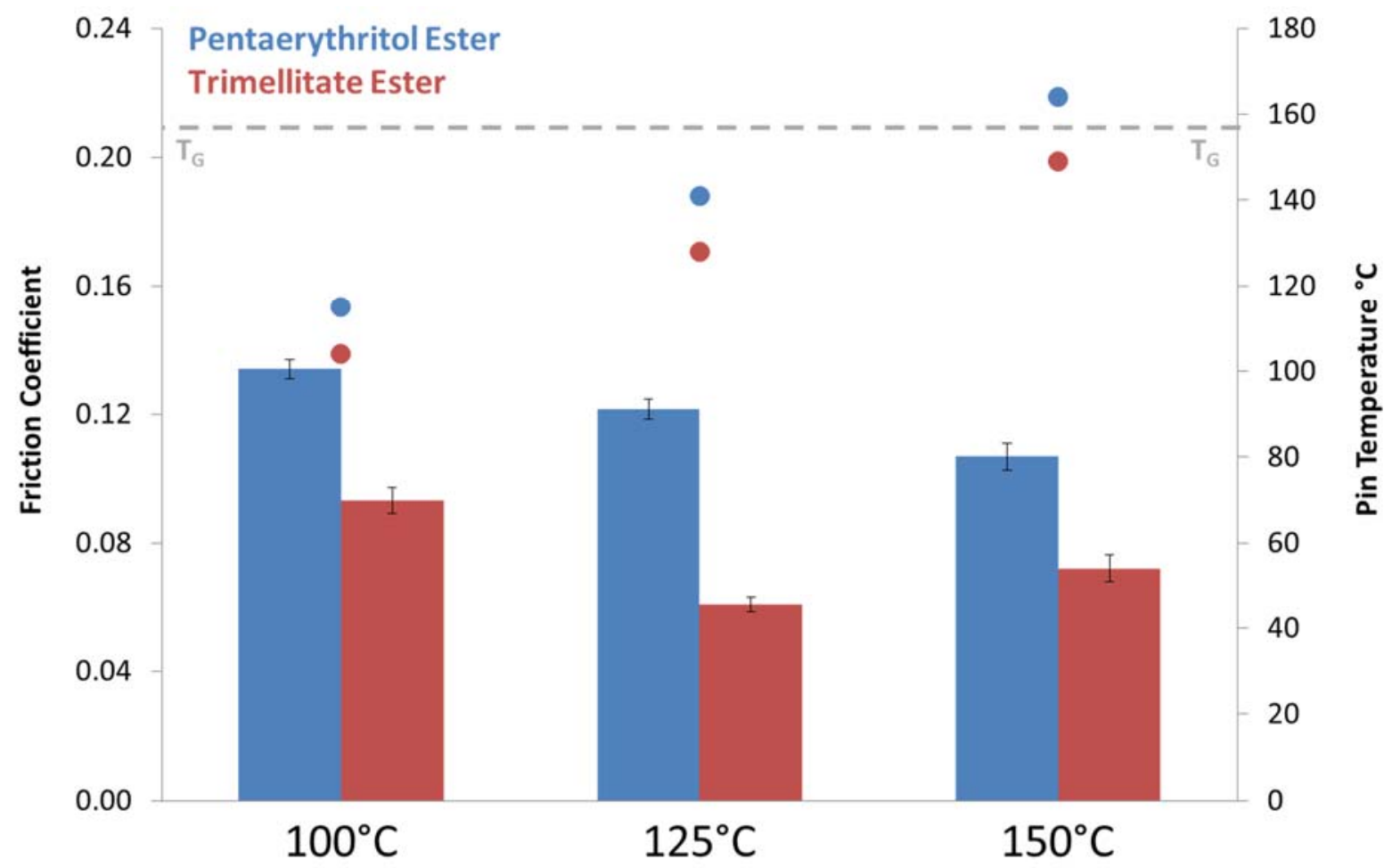

Figure 13: Variations in Friction Coefficients and Pin Temperatures with Enclosure Air

Temperature at 0.5MPa and $8 \mathrm{~ms}^{-1}$. (Columns - Friction Coefficients, Dots - Pin Temperature)

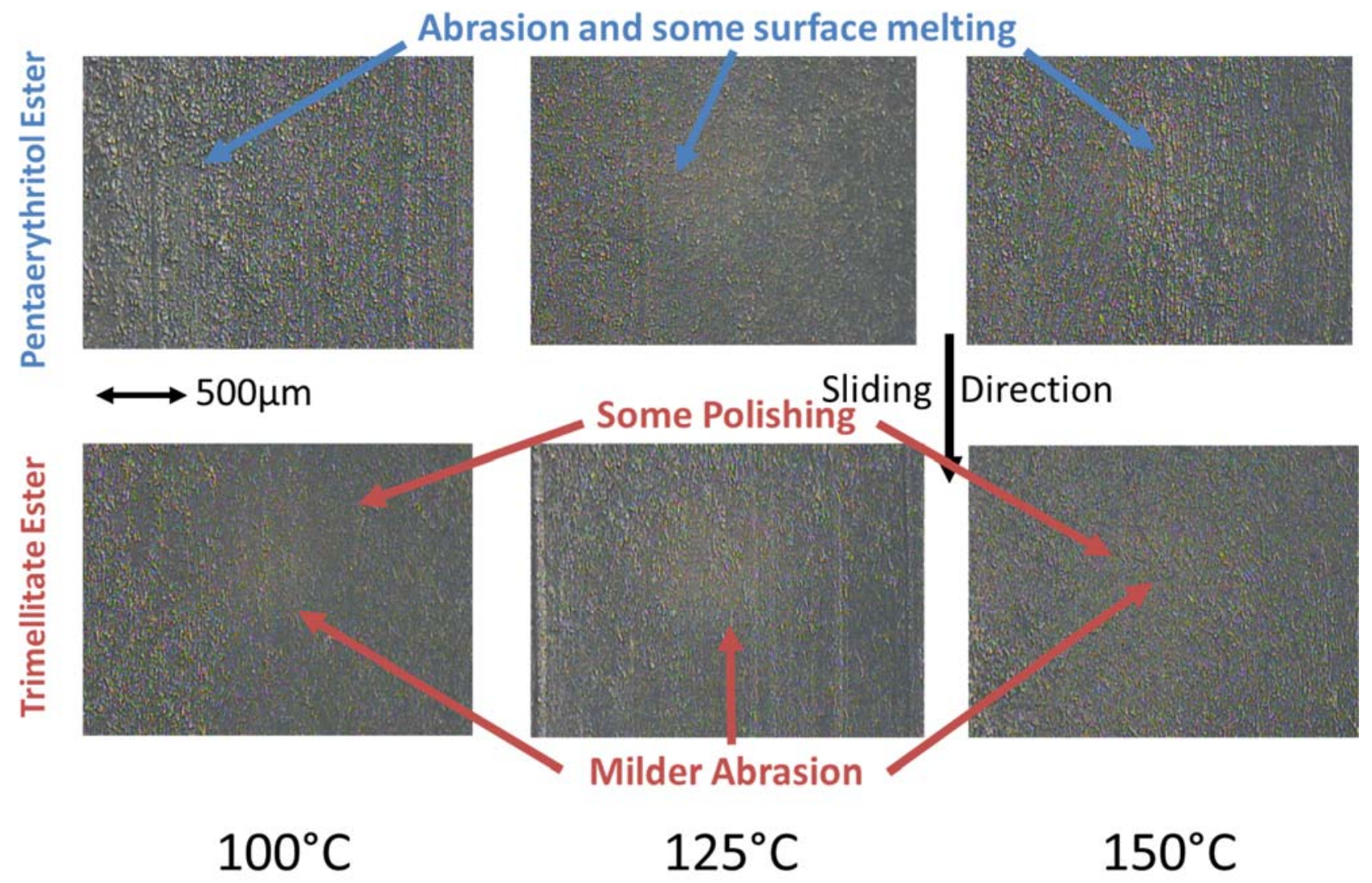

Figure 14: Optical Microscope Images of Pin Surfaces: The Effect of Varying Air Temperature at 0.5MPa and $8 \mathrm{~ms}^{-1}$ Average Sliding Speed 

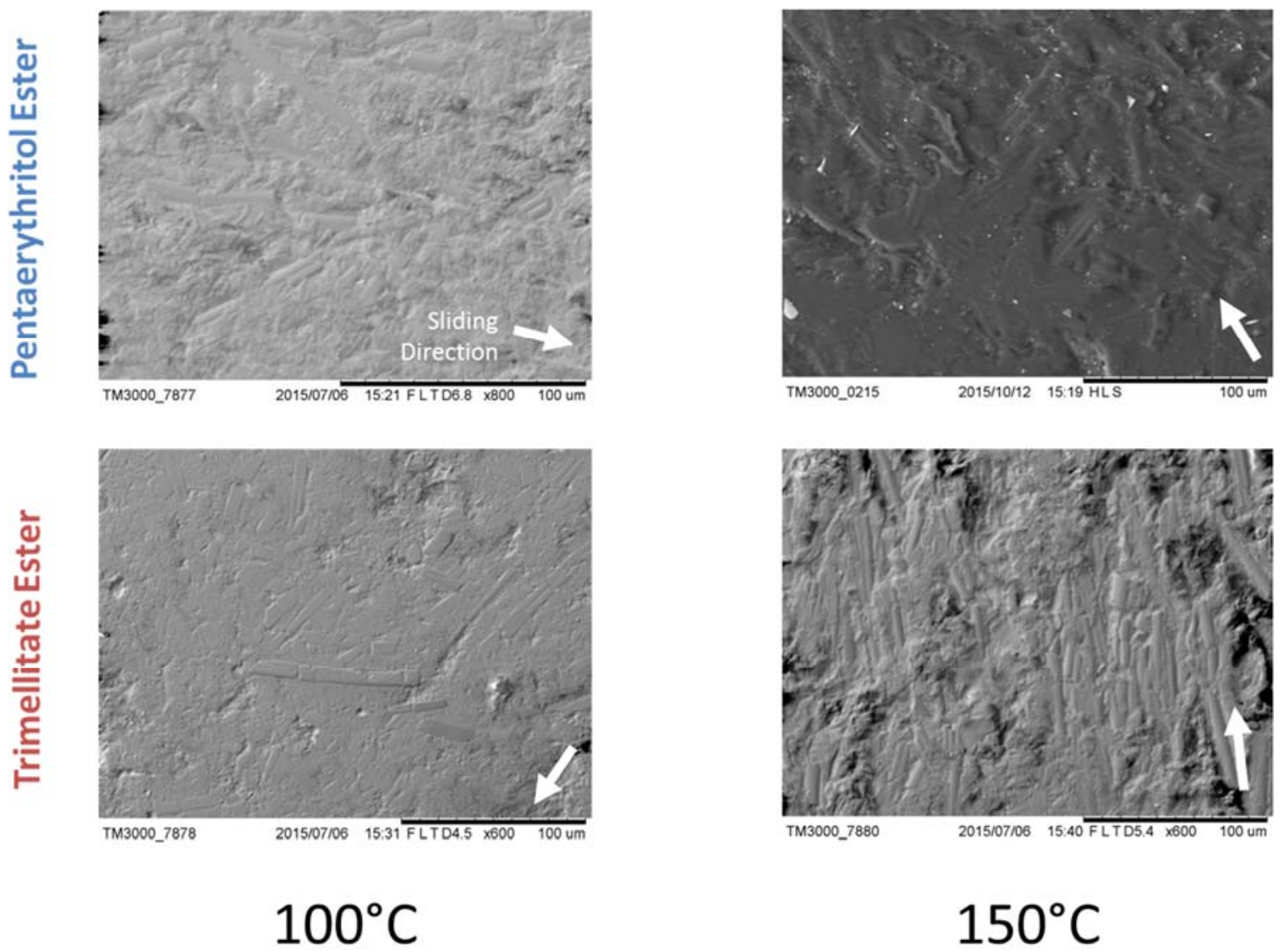

Figure 15: SEM Images: The Effect of Varying Air Temperature at $0.5 \mathrm{MPa}$ and $8 \mathrm{~ms}^{-1}$ Average Sliding Speed 


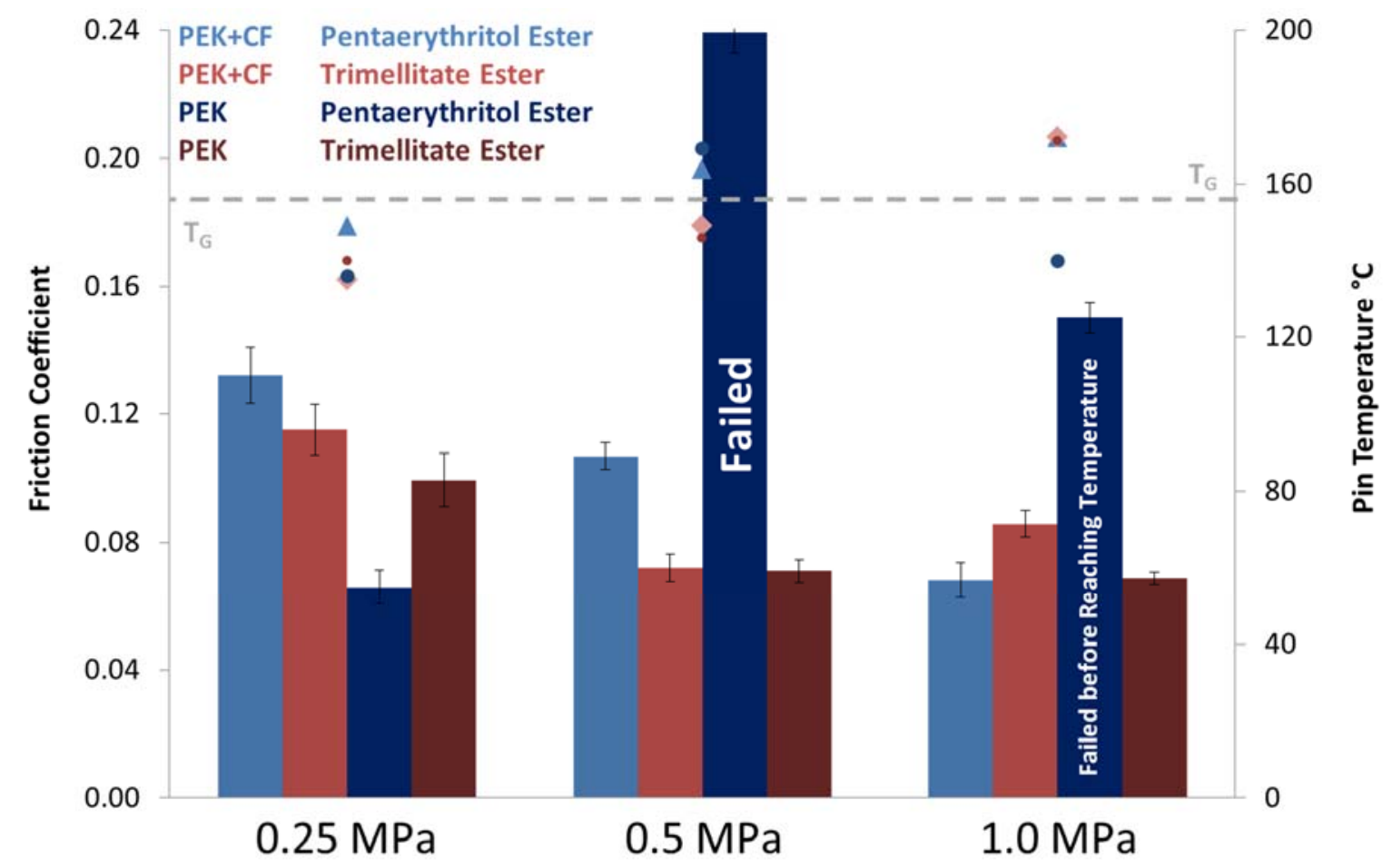

Figure 16: Variations in Friction Coefficients with Contact Pressures and PEK Reinforcement at $150^{\circ} \mathrm{C}$ and $8 \mathrm{~ms}^{-1}$. (Columns - Friction Coefficients, Dots - Temperatures). Data for Reinforced PEK is as Figure 6.

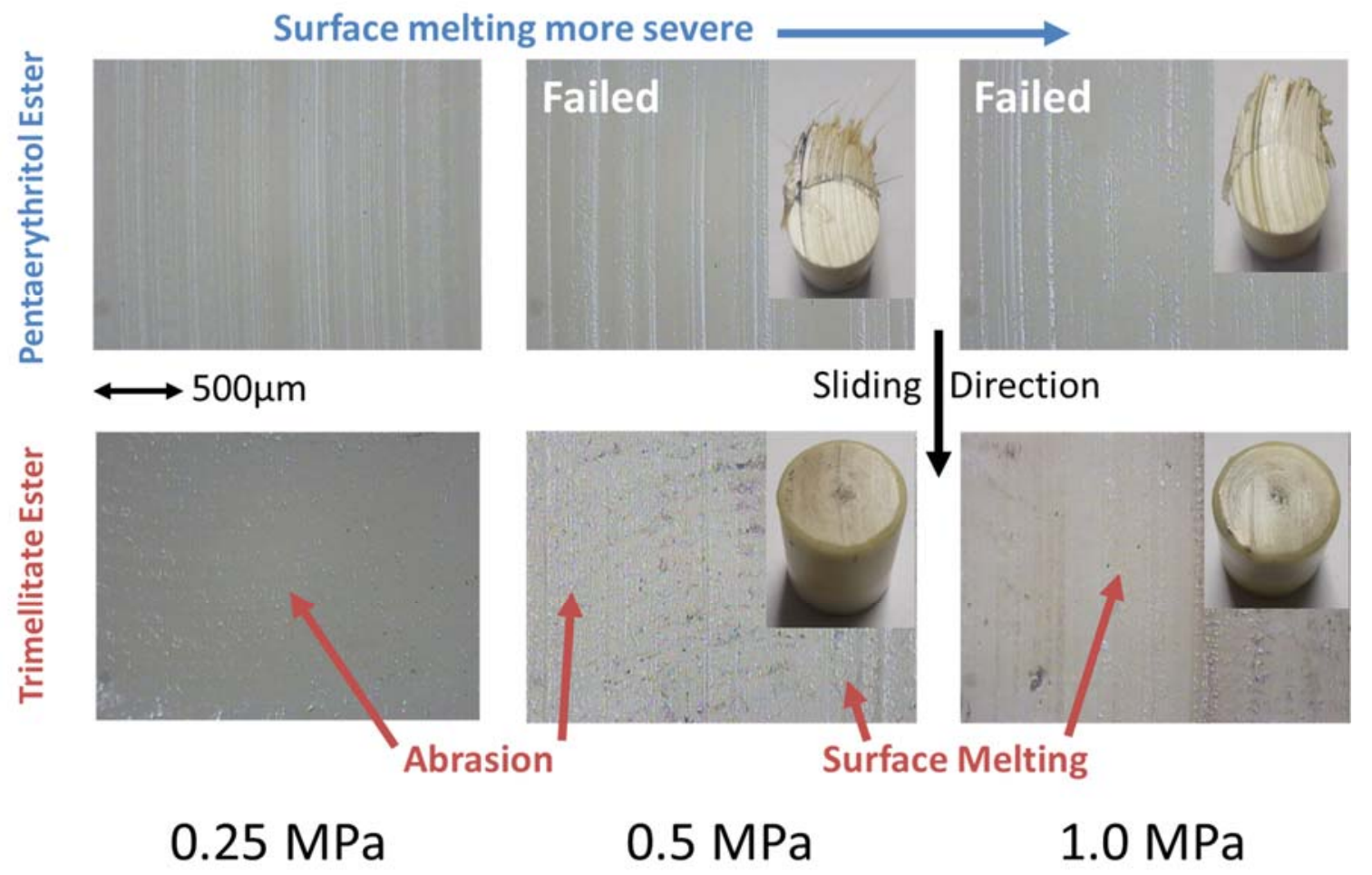

Figure 17: Optical Microscope Images of Pin Surfaces: Effect of Varying Contact Pressure on Unreinforced PEK at $8 \mathrm{~ms}^{-1}, 150^{\circ} \mathrm{C}$ Air Temperature 

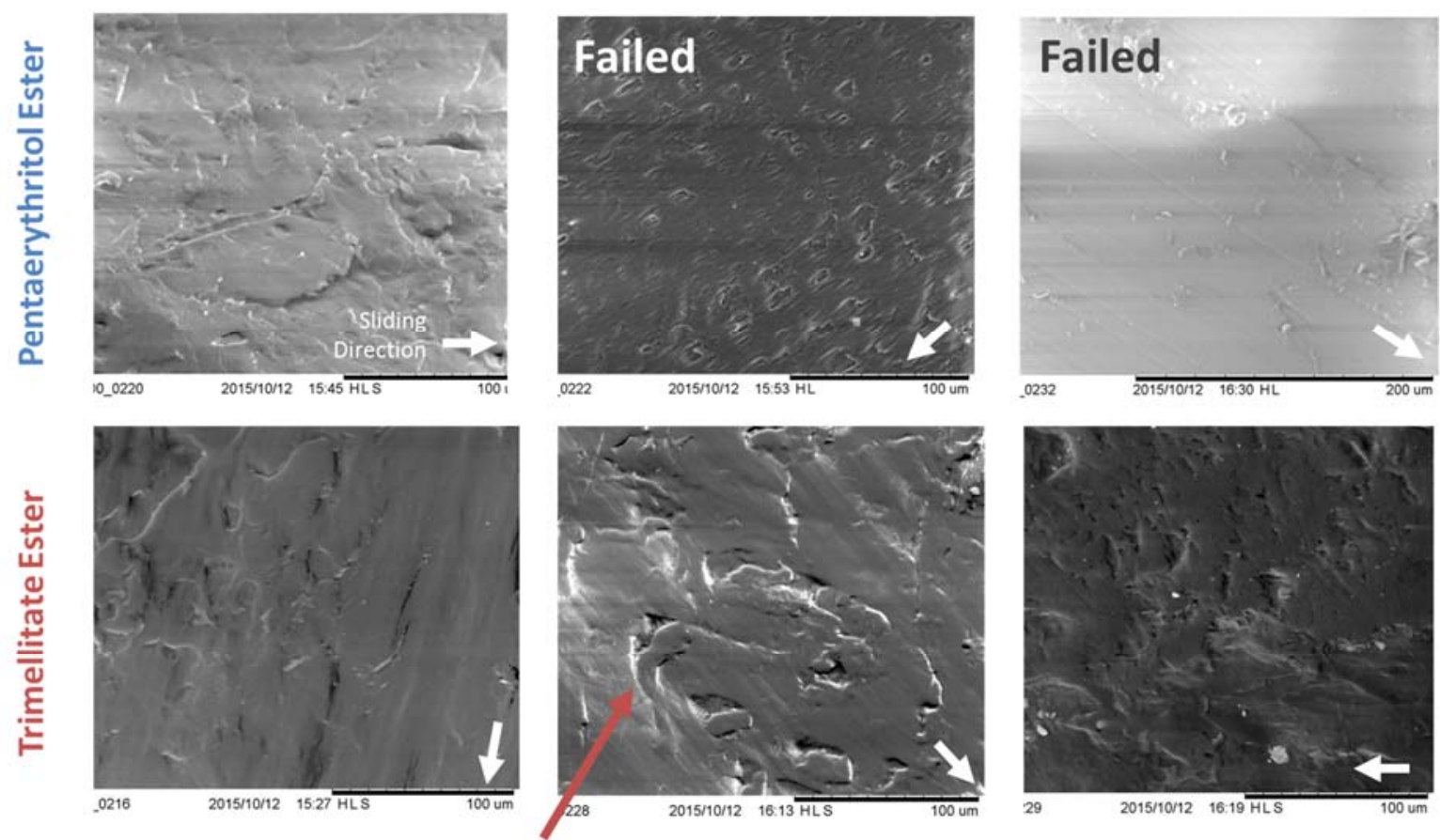

\subsection{MPa Localised 0.5 MPa Material Flow}

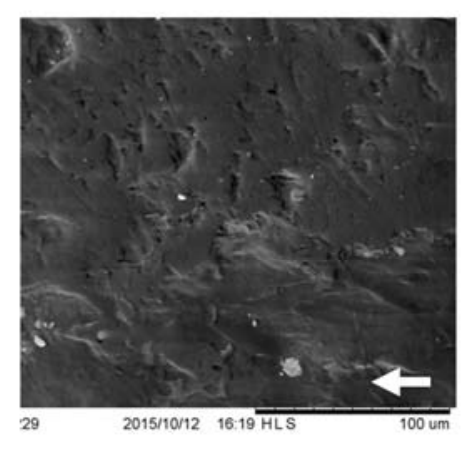

\section{0 $\mathrm{MPa}$}

Figure 18: SEM Images: The Effect of Varying Contact Pressure on Unreinforced PEK at $8 \mathrm{~ms}^{-1}$ and $150^{\circ} \mathrm{C}$ Air Temperature

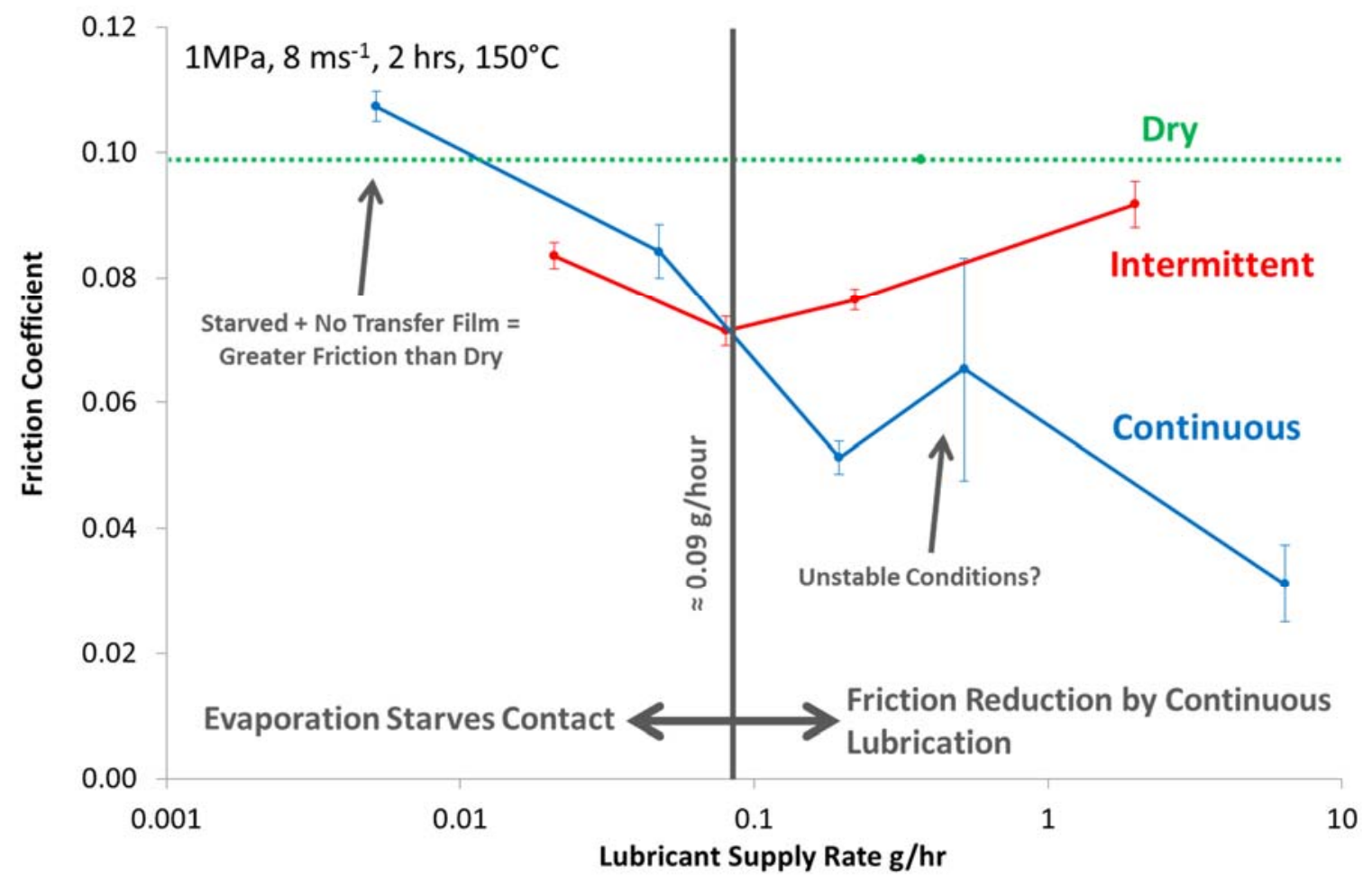

Figure 19: Effect of Varying Lubricant Supply Rate on Friction Coefficient for Intermittently and Continuously Lubricated Contact of 30\% Reinforced PEK on Steel at $8 \mathrm{~ms}^{-1}, 150 \mathrm{C}$ and $1 \mathrm{MPa}$ 


\section{Tables}

Table 1: Glass Transition and Melting Point for Various PAEK Polymers, where $T_{m}$ is the Melting Point and $T_{g}$ is the Glass Transition Temperature of each Polymer

\begin{tabular}{|c|c|c|c|}
\hline PAEK & Ether/Ketone Ratio & $\mathbf{T}_{\mathbf{g}}\left({ }^{\circ} \mathbf{C}\right)$ & $\mathbf{T}_{\mathbf{m}}\left({ }^{\circ} \mathbf{C}\right)$ \\
\hline PEEK [1] & 2 & 143 & 343 \\
\hline PEK [1] & 1 & 157 & 374 \\
\hline PEKEKK [1] & 0.67 & 162 & 387 \\
\hline PEKK [2] & 0.5 & 165 & 357 \\
\hline
\end{tabular}

Table 2: Previous Friction and Wear Studies of PEEK around $T_{g}$

\begin{tabular}{|c|c|c|c|c|c|}
\hline \multirow{2}{*}{ Reinforcement } & \multirow{2}{*}{ Material } & \multirow{2}{*}{$\begin{array}{l}\text { Contact Ge- } \\
\text { ometry }\end{array}$} & \multicolumn{2}{|c|}{$\begin{array}{l}\text { Performance Above } T_{g} \\
\text { versus Below }\end{array}$} & \multirow{2}{*}{ Source } \\
\hline & & & $\begin{array}{c}\text { Friction } \\
\text { Coefficient }\end{array}$ & Wear Rate & \\
\hline Carbon Fibres & $\begin{array}{l}\text { PEEK and PEK with } \\
\text { PTFE, Graphite }\end{array}$ & $\begin{array}{l}\text { PAEK Block } \\
\text { on Steel Disc }\end{array}$ & Lower & Higher & Friedrich et al [10] \\
\hline Carbon Fibres & PEEK & $\begin{array}{l}\text { Steel Ball on } \\
\text { PEEK Disc }\end{array}$ & Lower & Higher & Hanchi and Eiss [30] \\
\hline Unreinforced & $\begin{array}{c}\text { PEEK with PTFE and } \\
\text { Graphite }\end{array}$ & $\begin{array}{l}\text { PEEK Block } \\
\text { on Steel Disc }\end{array}$ & Lower & Higher & Friedrich et al [10] \\
\hline Unreinforced & PEEK & $\begin{array}{l}\text { Steel Ball on } \\
\text { PEEK, PEEK } \\
\text { coated Disc }\end{array}$ & Higher & Higher & $\begin{array}{c}\text { Hanchi and Eiss [29] [30], } \\
\text { Zhang et al [31] }\end{array}$ \\
\hline
\end{tabular}

\section{Table 3: Test Matrix}

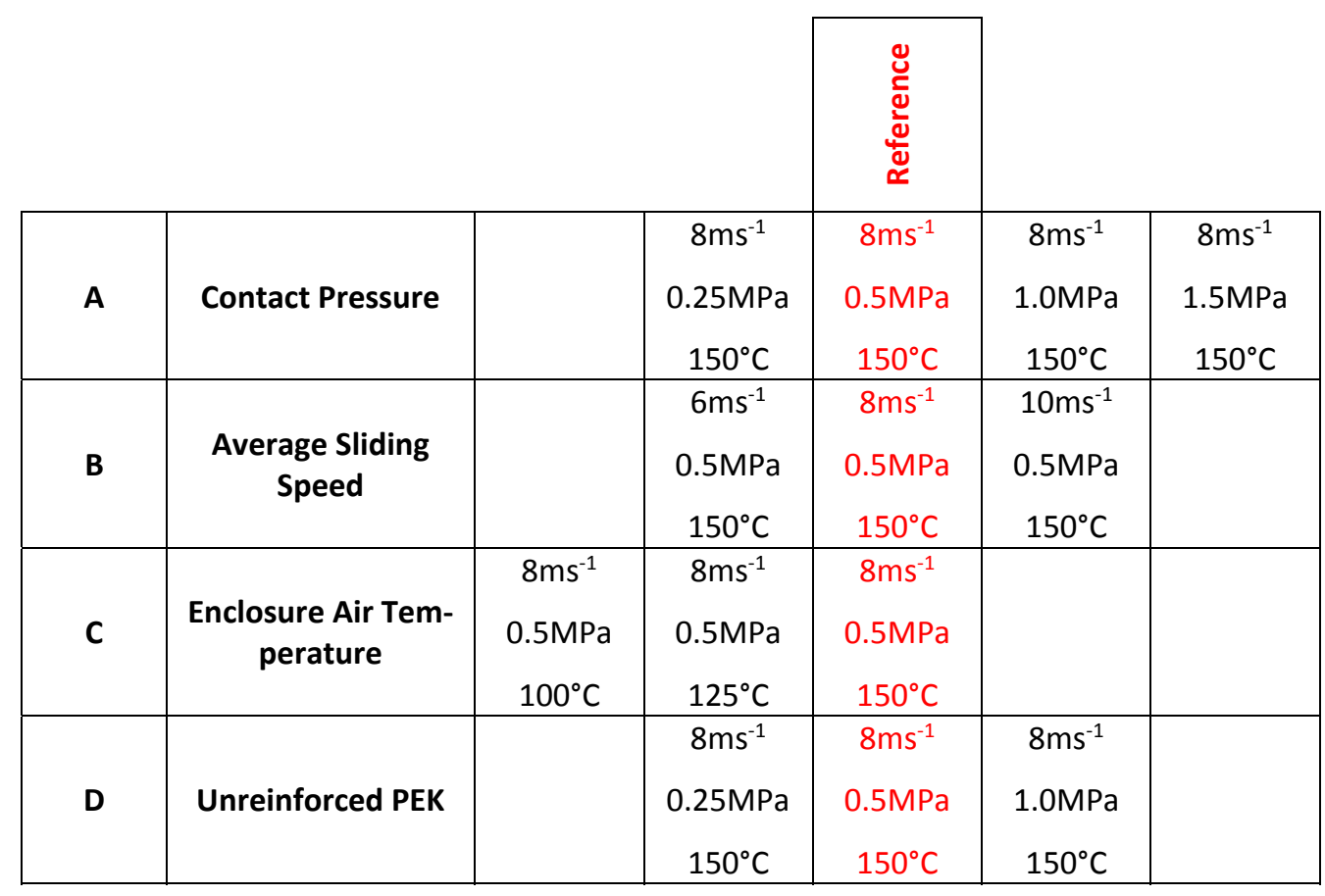


Table 4: Physical and Mechanical Properties of PEK Materials Studied [1]

\begin{tabular}{|c|c|c|}
\hline Property & PEK & $\begin{array}{c}\text { PEK + 30\%wt } \\
\text { Carbon Fibres }\end{array}$ \\
\hline${\text { Tensile Strength @ } 23^{\circ} \mathrm{C}, \mathrm{MPa}}^{\mathrm{T}}$ & 110 & 250 \\
\hline Tensile Strain at Break, $\%$ & $20 \%$ & $2.2 \%$ \\
\hline Tensile Modulus, $\mathrm{GPa}$ & 3.9 & 25 \\
\hline Thermal Expansion Coefficient, $<\mathrm{T}_{\mathrm{G}} \&>\mathrm{T}_{\mathrm{G}}\left(\mu \mathrm{m}^{\circ} \mathrm{C}^{-1}\right)$ & $45 / 75$ & $5 / 5$ \\
\hline Thermal Conductivity, $\mathrm{Wm}^{-1} \mathrm{~K}^{-1} @ 23^{\circ} \mathrm{C}$ & 0.29 & 0.95 \\
\hline
\end{tabular}

Table 5: Key Physical Properties of the Test Lubricants

\begin{tabular}{|c|c|c|}
\hline & $\begin{array}{c}\text { Trinonyl } \\
\text { Trimellitate } \\
\text { Ester }\end{array}$ & $\begin{array}{c}\text { Pentaerythritol } \\
\text { Ester }\end{array}$ \\
\hline Kinematic Viscosity @ $40^{\circ} \mathrm{C}, \mathrm{cSt}$ & 92 & 94 \\
\hline Kinematic Viscosity @ $100^{\circ} \mathrm{C}, \mathrm{cSt}$ & 10.2 & 10.2 \\
\hline Viscosity Index & 90 & 88 \\
\hline Density @ $20^{\circ} \mathrm{C}, \mathrm{g} / \mathrm{cm}^{3}$ & 0.983 & 0.955 \\
\hline TGA Onset of Oxidation @ $10^{\circ} \mathrm{C} / \mathrm{min},{ }^{\circ} \mathrm{C}$ & 258 & 275 \\
\hline
\end{tabular}

